This repart was prepored as an account of work sponsorect by the Uniled States Government. Neither the United States nor the Umiled Stotes Atomie Energy Commission. nor any of theif employees. not any of their contras. tors, subcontractors, or their employees, makes any waranty. express or imy. plied, or assumes any legat liability or responsibitity for the accufacy. com. pleteness or usetulncss of any information, apparatus. poduct or process elis. closed. or represents that its use wowlot not infringe privately owned pights

In the interest of prompt distribution, this LAMS ra. port was not edited by the Technical information statt.

Printed in the United States of America. Available from Netional Technical Intormation Service

U. S. Dupartment of Commerce 5295 tort Royal Road Springlield, Virginia 22151

Price: Printed Copy S4.00: Micratiche $\mathbf{5 0 . 9 5}$ 


\section{Polynomial Solutions of the Schrödinger Equation Applied to Photon Cross Sections in Atoms}

by

A. L. Marts

Watter Matusk: $\$$

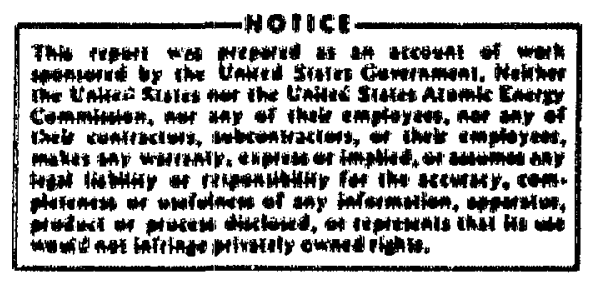




\title{
POLYNOMIAL SOLUTIONS OP THE SCHRÖDINGER EQUATION APPLIED TO PHOTON CROSS SECTIONS IN ATOMS
}

by

A. L. Metes and Walter Matuska, Jr.

\begin{abstract}
Solutions of the Schrötinget equation swith a realistic potencial ste carried out in detail. To theck aur methods, wre have calculated a few boundbound, bound-free, and free free cross sections and compared out waltes with existing calculations and experimental data. These comparisons, afong with a listing of the computer code in ite bound-free forti, are included.
\end{abstract}

\section{INTHODJCTION}

This repore intends to show how the CDC-7600 cote DEGA-A CDense Elestron Gas Approximation-Absopuion) computes the bound-frec, frectiec, and bound-

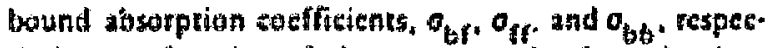
kitcty. as a futhcrion of photon enexy, hu, from the given potential function $V(r)$ and the electron otcupancy of the atom. Assuming $V(r)$ so be exses, the ende twill do its computation at any cesifed acsuracy, within the machine timits, because the Sthridinger equation is solved using exact poster-serics expansions, not difference equations.

As the code is now writren, any potential function can te used if it adheres to the three following requizemerves.

1. $\lim _{x \rightarrow 0} y(r) r^{2}=0$

2. After some finite value of $t_{1} R_{1}$, the porentiat must be $V(u)=-k$ tre

3. $V(r)$ must be a negative, manetoniealty, increasing function.

Although it is not necessary to the internat structure of the code, we would giso like $V(r)$ to be a function of ceriperature, density, and the acomic number of the atom.

Throughout this report, $\left|0, R_{1}\right|$ is called Region $I$ and $[R, \infty]$ Rezion 2.
The following $V(r)$ is the one most of ten used in the code.

Expericnec has shown that a parameterized potential works well and gives energy levels slose to those that Htorman and stillman" calculated using their Hartreefoek-siater method for isoluced neukral atoms.

The potential form for an isolated atom is

$$
v(r)=2(x)+a r)^{2} \text {. }
$$

where $a=0.6057 z^{3 / 3}$. Howeter, the form setually used in this report, which is also valted for a compressed atom, is

$V(r)=-\left(t^{*} e\right) / R_{1}\left(\frac{R_{1}}{r}+\frac{r^{2}}{2 k_{1}^{2}}-3 / 2\right)$

for $r_{a}<r<R_{1}$.

where

$2^{*}$ is the "effective number" of free electrons.

$R_{1}$ is the ratius of the sphere representing the spherical atomic volume.

$r_{0}$ is the value of the adial distance for which Eq. (2) is equal to the value given in Bq. (3) below, ant

$c$ is the clectzonie charge.

It the inner region, the patential is gisen by

$V(r)=-2 c / \pi(1+a r)^{2}-2 \cos \left(\frac{s^{2}}{2 \mathrm{~K}_{i}^{2}}-\mathrm{BO}_{0}\right)$

for $0<r<r_{0}$. 


$$
\begin{aligned}
& B_{0}=\left(\frac{Z}{Z^{*}}\right)\left(\frac{R_{1}}{r_{0}}\right) /\left(1+\alpha r_{0}\right)^{2}-\frac{R_{1}}{r_{0}}+3 / 2 . \\
& Z^{*}=Z /\left(1+\alpha r_{0}\right)^{2}\left[\left(\frac{2 \alpha r_{0}}{1+\alpha r_{0}}\right)+1\right] .
\end{aligned}
$$

After the form of the potential in the two regions is chosen, Egs. (4) and (5) follow from the potential's continuity and its relation to charge density through Poisson's equation. In the potential outlined above, the value of $\mathbf{R}_{\mathbf{l}}$ is derermined by the density of the material being considered. The value of $Z^{*}$ is chosen by an iterative procedure so that ar some finite cemperarure $T_{\text {, }}$ and for an atom occupying a spherical volume of radius $R_{1}$, we have

$Z=N\left(Z^{*}\right)=\int_{0}^{R_{1}}\left[\int_{0}^{\infty} n(r, T, P) d P\right] 4 \pi r^{2} d r$

where $\mathbf{n}$ is the Fermi-Dirac distribution function, representing the number of electrons at point $r$, having momentum between $P$ and $P+d P$. Using Eq. (5) we have also determined $r_{0}$.

We-must correct the above potential for self-interaction. This is done in the simplest possible fashion. We replace: $Z$ in Eqs. (2) through (5) with $(Z-1)$ and add the term $-1 / r$ to Eqs. (2) and (3). The potential for $r>R_{t}$ is defined as $-1 / r$. This then represents our potential function ured to calculate the one-electron energies and the one-electron orbitals from which we calculate the cross sections and f-values.

This potential can be shown to satisfy the thee previously stated conditions.

The hydrogenic potential $V(r)=-1 / r$ for $0 \leqslant r \leqslant \infty$ is often used to check parts of the code because analytic solutions for this potential are known. form

The code considers the Schrödinger equation in the

$$
\varphi^{\prime \prime}(r)+\left[\lambda-2 V(r)-\frac{l(R+1)}{r^{2}}\right] \varphi(r)=0,0 \leqslant r \leqslant \infty .
$$

where

$r \varphi(r)$ is the radial wave function (however, $\varphi(r)$ will be called the wave function throughout the rest of this repert).

$\lambda$ is the energy eigenvalue, and

$Q$ is the angular-mornentum quant um number.
Equation (7) has an infinite (in some cases finite, but large) number of discrete bound solutions (negative $\lambda$ ) commanly denoted by $15,2 s, 2 p, 3 s, 3 p, 3 d$, etc. Of this infinite sequence, we calculate only the solutions allowed by the electron occupancy. $o_{b b}$ can be evaluated only at discrete values of hv, because $h_{1}=\left|\lambda_{1}-\lambda_{2}\right|$ where $\lambda_{1}$ and $\lambda_{2}$ both represent bound solutions. By using a line profile, we then distribute each $\sigma_{b b}$ over a nancow range of $h v$. However, every positive $\lambda_{1}$ given $l_{2}$ is an cigenvalue for a frse state. This allows us to choose any Enite number of positive $\lambda$ 's. Therefore, wa can evaluate of at any energy hu above the threshold, and $\sigma_{f f}$ at any desired value of hv. Here $h v=\left|\lambda_{1}-\lambda_{2}\right|, \lambda_{1}$ represents either a bound oz a free solucion, and $\lambda_{2}$ represents a free solution.

\section{THE METHOD OF SOLUTION OF THE SCHRÖDINGER EQUATION}

\section{A. The Potential Approximation}

To solve Eq. (7) on the computer, we choose a finite $R>R_{1}$ to approximate $r=\infty$, and divide $[0, R]$ into a finite number of intervals. FCr each of these intervals, $r^{2}$ times the potential is approximated by a parabola to some specified degree of accuracy, $\xi$. This series of fits is started at $r=0$ with an interval of arbitrary length. In this first interval, we approximate the potential with

$$
V(r) \approx c_{1}+\frac{c_{2}}{r}+\frac{c_{3}}{r^{2}}
$$

Let $r_{1}$ be the left end point of this interval, $r_{3}$ the right end point. and $r_{2}$ the midpoint. To evaluate the $c$ 's, we solve the set of equations

$$
c_{1} r_{j}^{2}+c_{2} r_{j}+c_{3}=V\left(r_{j}\right) r_{j}^{2} \text { for } j=1,2,3
$$

These equations have $\mathrm{n} n$ difficulty at $\mathrm{r}=0$, and they fit the potential exactly ar $r_{1}, r_{2}$, and $r_{3}$. Because $V(r)$ is a smooth, monotonic function, we can check our fit by checking the validity of

$$
\left|c_{1}+\frac{c_{2}}{r}+\frac{c_{3}}{r^{2}}-V(r)\right|<|V(r)| \xi
$$

at several poines between $r_{1}$ and $r_{3}$. If this inequality is not satisfied for all points, we decreuse the length of the interval until inequality (Eq. (10)] is satisfied for all points checked. This process is continued until Region 1 is completc. Here $c_{1}, c_{2}$, and $c_{3}$ should actually be 
thought of as $c_{1, i}, c_{2, i}$ and $c_{3, i}$, where the subscript $i$ denotes the ith interval.

In Region 2, obviously, $c_{2}=-1$ and $c_{1}=c_{3}=0$. The lengths of the intervals in this region are governed only by an additional condition discussed later. This condition applies to all intervais.

As the code now exists, for a given set of conditions, all solutions to the Schrödinger equation are found by using the same set of intervals over Region 1; howevet, each solution has its own set of intervals in Region 2. The code could also be written so that each solution would have its own set of intervals over the entire range of $r$. Is would be impractical to requite all solutions to have the same set of intervals in Region 2 because the maximum interval lengths allowed for the various solutions in Region 2 are so different.

\section{B. The Expansion of the Radial Wave Function}

In the expansion of the wave function, we will aeed the condition $c_{3,1}=0$. This is satisfied if the first requirement on the potential is met.

We assume the wave function to have the form

$$
\varphi(r)=\sum_{j=1}^{-} a_{j i} i^{j-1} \text { for } i=1
$$

in the first interval. Dropping the subscript $i$, we substitute the powet series and its second derivative for p(r) and $\varphi^{\prime \prime}(r)$ and the approximation for $V(r)$ in Eq. $(8)$ into the Schrödinger equation to get

$$
\begin{aligned}
& \left\{-\left[2 c_{3}+Q(q+1)\right] d_{1}\right\} / t^{2} \\
& +\left\{-2 c_{2} a_{i}-\left[2 c_{3}+R(R+1)\right] a_{3}\right\} / x \\
& +\sum_{j=3}^{-}\left\{\left(x-2 c_{3}\right) z_{j-2}-2 c_{2} a_{j-1}\right. \\
& \left.+\left[(j-2)(j-1)-2 c_{3}-q(Q+1)\right] a_{j}\right\} r^{j \cdot 3}=0 .
\end{aligned}
$$

Here we assume that $c_{3}=0$ and $a_{j}=0$ for $1<j<R+Q$. Aso $a_{g+2}$ is arbitray because any constant times a solu. tion eigenfunetion $p(r)$ is stifl s solution. As each ecrm in Eq. (12) must be zeno for every $c$ in the interval, we now have the recursion telation

$$
a_{j}=\frac{2 c_{2}{ }_{j-1}-\left(\lambda-2 c_{i}\right) a_{j-2}}{(j-2)(j-1)-2(R+1)} \text { for } i>Q+2 .
$$

The power-series expansions in all other intervals are also expanded about one of the interval's end points. If expanding about the left end point, we make the substitution $d=r-\rho_{i}$ and require that $0 \leqslant d \leqslant \rho_{i+1}-\rho_{j}$ where the $\rho$ 's are the end points of the intervals. When it is necessary to expand about the right end point, the roles of $\rho_{i}$ and $\rho_{i+1}$ aze switched and $\rho_{i}-\rho_{i+1} \leqslant d \leqslant 0$. Again omisting the subscript $i$, the Schrödinger equation can now be written as

$$
\left(\rho^{2}+2 \rho d+d^{2}\right) \varphi^{\prime \prime}(d)+\left(B_{3}+B_{2} d+B_{3} d^{2}\right) \varphi(d)=0 ，
$$

where

$$
\begin{aligned}
& B_{1}=b_{1} \rho^{2}+b_{2} \rho+b_{3} \\
& B_{2}=2 b_{1} \rho+b_{2} \\
& B_{3}=b_{1} \\
& \text { and } \\
& b_{1}=\lambda-2 c_{1} \\
& b_{2}=-2 c_{2} \\
& b_{3}=-\left\{2 c_{3}+Q(\ell+1)\right] .
\end{aligned}
$$

Hete we assume the wave function to have the form

$$
f(d)=\sum_{j=1}^{-} a_{j j} d^{j-1} \text { for } i>1
$$

Substituting the power series and its second derivative for $o$ (d) and $f^{\prime \prime}(d)$, we get

$$
\begin{aligned}
& {\left[2 p^{2} a_{3}+B_{1} a_{1}\right]+\left[6 p^{2} a_{4}+4 p_{3}+B_{1} a_{3}+B_{2} a_{1}\right] d} \\
& +\sum_{j=5}^{\infty}\left[(j-2)(j-1) \rho^{2} x_{j}+(j-3)(j-2) 2 \rho a_{j-1}\right. \\
& +(j-4)(j-3) a_{j-2}+B_{1} a_{j-2} \\
& \left.+B, y_{j \cdot 3}+B_{3} 3_{j \cdot-4}\right] d^{j-3}=0
\end{aligned}
$$

with the subscript $i$ omitced. Again, because each term of Eq. (16) must be zero for all valucs of $d$, we have the recursion relutions 


$$
\begin{aligned}
a_{3} & =-B_{1} a_{1} / 2 \rho^{2} \\
a_{4} & =-\left[B_{2} a_{1}+B_{1} a_{2}+4 \rho a_{3}\right] / 6 \rho^{2} \\
a_{j} & =-\left\{B_{3} a_{j-4}+B_{2} a_{j-3}+\left[B_{1}+(j-4)(j-3)\right] a_{j-2}\right. \\
& \left.+2(j-3)(j-2) \rho a_{j-1}\right\} /(j-2)(j-1) \rho^{2} \\
& \text { for } j>4
\end{aligned}
$$

when $a_{1}$ and $a_{2}$ are known.

We can easily show that $a_{1}=\varphi(d)$ and $a_{2}=\varphi^{\prime}(d)$ at $d=0$. Therefore, $a_{1}$ and $a_{2}$ will always be known by the right-soundary condition or can be evaluated with the power-series expansion of the wave function in the previous interval.

In practice, we start with $a_{j}=0$ for $1 \leqslant j \leqslant \ell+1$ and $a_{+2}$ an arbitrary nonzero constant to start the powerseries expansion in the first interval. Then we evaluate this power-series and its first derivative at its right end point. This determines $a_{1}$ and $a_{2}$ for the second interval. This process is repeated until we reach some $\hat{\boldsymbol{r}}, 0<\hat{\mathrm{r}}<\boldsymbol{R}$, where we evaluate $\varphi_{f}(\hat{r})$ and $\varphi_{f}^{\prime}(\hat{l})$; the determination of $\hat{r}$ is dist-assed later. At the right boundary, $R, \varphi(R)$, and $\varphi^{\prime}(R)$ are given by the boundary condition. This enables us to start our successive power-series expansions at $R$ and work ollr way backward to $\hat{r}$ where we evaluate $\varphi_{b}(\hat{R})$ and $\varphi_{b}^{\prime}(r)$. We have a solution when $\varphi_{f}^{\prime}(\mathrm{r})=\varphi_{b}^{\prime}(\mathrm{P})$ for $\varphi_{g}(\mathrm{P})=\varphi_{b}(\mathrm{P}) . \varphi_{f}(\mathrm{P})$ is simply the value of the wave function at $\hat{\imath}$ found by forward expansions, and $\varphi_{b}(\hat{\imath})$ is the value of the same wave function ar $\hat{\imath}$ found by backward expansions.

\section{Determination of the Expansion Interval Length}

In real life, these power series can have only a finite number of terms. The maximum number of terms in the present code is 50. This leads to the other condition regulating the maximum length of a particular interval. Let us define

$$
\widetilde{v}(r)=\left[\lambda-2 V(r)-\frac{R(R+1)}{r^{2}}\right]
$$

Using this definition, we can write the Schrödinger oquztion as

$$
\varphi^{\prime \prime}(r) \pm h^{2} \varphi(r)=0, \text { where } h^{2}= \pm \widetilde{V}(r)
$$

choosing the sign so that $h^{2}>0$. If $h$ is assumed to be constant locally, the solution is either

$$
\varphi(r)=A e^{-h r}+B e^{h r}
$$

or

$$
\varphi(r)=A \sin h r+B \cos h r,
$$

depending upon the sign. Expanding the decreasing exponential solution in a Taylor series about an end point of the interval, we get

$$
\varphi(r)=A e^{-h \omega_{i}} \sum_{j=0}^{\infty}(-1)^{j} \frac{\left(h \Delta r j^{j}\right.}{j l}
$$

where $\Delta r=r-p_{i}$ is the maximum allowable interval length. With this series, we can estimate the largest value of $(h \Delta r)$ that allows the series to converge to a specified accuracy in the alloted number of terms. In Region 1, all solutions are considered in estimating the maximum interval length; however, in Region 2 only one solution at a time is considered. The code then plugs the largest encountered value of $h$ into

$$
\Delta \mathrm{r}=\frac{\mathrm{C}}{\mathrm{h}} .
$$

This $C$ is an input parameter, and for a 50-term expansion and 8-place accuracy 2 conservative value for $C$ is 6 .

The sinusoidal and increasing exponential solutions have a series similar to Eq. (22), and the interval lengti is also estimated by Eq. (23).

\section{Finding the Join Point $\widehat{\mathbf{r}}$ for Forward and Dackward Integration}

Let us consider the question of stability. Here again, Eqs. (20) and (21) can be thought of as local solutions to the Schrödinger equation. If an error is introduced in Eq. (20) during forward integration (increasing $r$ ) when the first term is the desired solution, this error will grow exponentially. However, any error introduced will diminish exponentially during backward integration. Likewise, when the second term is the desired solution, backward integration is unstable and forward integration causes any error to diminish exponentially. Equation (23) is considered stable for integration in either direction. Any error introduced into the integration will not grow exponentially; however, once an errer is introduced it cannot be diminished as was the case with Eq. (20). Figure 1 shows the regions of stable and unstable integration for the four possible combinations of given condicions. 


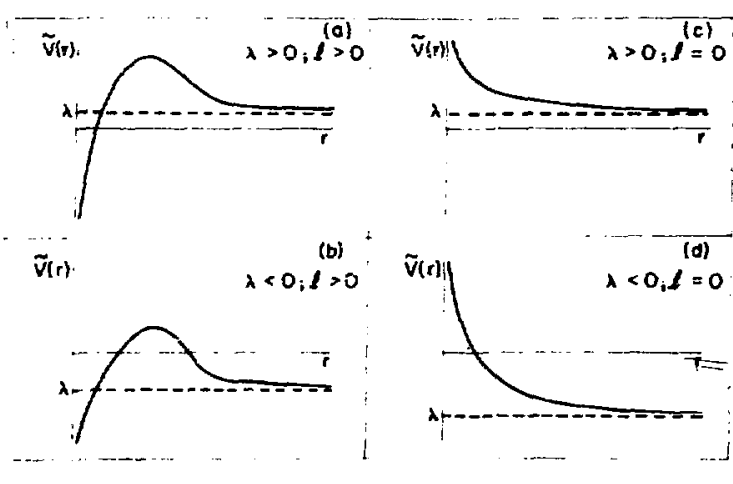

Fig. 1 .

Integration is stable in botb directions for $\widetilde{V}(r)>0_{\text {; }}$ integration is stable in only one direction for $\widetilde{V}(r)<0$. $\lambda$ indicates the asymtotic limit of $\widetilde{V}(r)$.

For the cases shown in Figs. $1 \mathrm{a}$ and $1 \mathrm{~b}, \hat{\mathbf{r}}$ is chosen such that $\widetilde{V}(\boldsymbol{r})$ is the maximum value of $\widetilde{V}(r)$. For the case shown in Fig. 1c, $\hat{\mathbf{r}}$ is the center of the rightmost interval, and for the case shown in Fig. 1d, $\hat{\mathbf{r}}$ is chosen such that $\widetilde{V}(\hat{r})=0$. For positive $\lambda$, the value of $\lambda$ is known and is used to find $\hat{r}_{\text {; }}$ however, for negative $\lambda$ one has only a maximum and minimum guess at its value at this stage, so the minimum guess is used in evaluating $\hat{\mathrm{r}}$.

\section{E. Boundary Condition at $\mathbf{R}$}

1. Bound States-Negative $\lambda$. The two right-boundary conditions used in the code are discussed below; however, this method of solving the Schrödinger equation is not limited to these two conditions. For the bound state, the Schrödinger equation becomes

$$
\varphi^{\prime \prime}(r)-|\lambda| \varphi(r)=0 \text { as } r \rightarrow \infty \text {. }
$$

Note that this is true only in Region 2. Because $\varphi(R)$ is arbitrary and

$$
\varphi(r)=A e^{-\sqrt{|\lambda|} r}
$$

is the desired solution to Eq. (24), we derive the boundary condition

$$
\varphi^{\prime}(R)=\sqrt{|\lambda|} \varphi(R) .
$$

Although we have no exact relation between $\mathbf{R}$ and the accuracy desired, we regulate $R$ by the following method. First, we find the largest root of $\widetilde{V}(r) . R$ is then taken as some constant (typically 25) times this root. Then, after the Schrödinger equation is solved using this $R$, we check the validity of

$$
|\varphi(r)|_{\max }<\gamma|\varphi(R)|
$$

$\left(10^{-15}\right.$ is a typical value for $\left.\gamma\right\rangle$. If this condition is not satisfied, we simpiy keep increasing $R$ until it is. A quick method for getting a value near $\mid \varphi(r) !_{\max }$ is to check $\varphi(r)$ at the end points of the intervals.

2. Free States-Positive $\lambda$. The sinusoidal condition given by Carson, Mayers, and Stibbs ${ }^{2}$ is used on the right boundary in the free case. This boundary condition also applies only in Region 2.

For large $r$, the solution may be written

$$
\varphi(r)=M(r) \cos [k r+\delta(r)]
$$

in which $k=\sqrt{\lambda}$,

$$
\lim _{r \rightarrow \infty} M(r)=M,
$$

and

$$
\lim _{r \rightarrow \infty} \frac{\delta(r)}{r}=0
$$

$M$ fixes the scale of the solution. We shall require the normalization $M=\sqrt{2 / \pi k}$.

In Region 2 where $V(r)=-c / r$ for $c>0$, we assume a solution of the form

$$
\varphi(r)=A(r) \cos \left(k r+\frac{c}{k} \ln r\right)+B(r) \sin \left(k r+\frac{c}{k} \ln r\right)
$$

Now substitute Eq. (30) into the Schrödinger equation. Then asymptotic expansions for $A(r)$ and $B(r)$ exist in the form

$$
A(r)=\sum a_{n} / r^{n}, B(r)=\sum b_{n} / r^{n}
$$

where

$$
\begin{aligned}
& a_{n+1}=\left\{\left[\ell(\ell+1)+\frac{c^{2}}{k^{2}}-n(n+1)\right] b_{n}\right. \\
& \left.-\frac{c}{k}(2 n+1) a_{n}\right\} / 2 k(n+1) \\
& b_{n+1}=\left\{\left[n(n+1)-\frac{c^{2}}{k^{2}}-\ell(\ell+1)\right] a_{n}\right. \\
& \left.-\frac{c}{k}(2 n+1) b_{n}\right\} / 2 k(n+1)
\end{aligned}
$$


and

$$
a_{0}=M, b_{0}=0
$$

The sums in Eq. (31) are only semiconvergent. Therefore $A(r)$ and $B(r)$ must be evaluated at an $r$ large enough that the sums converge to the desired accuracy.

Equation (30) can also be written as

$$
\varphi(r)=M(r) \cos \theta(r),
$$

where

$$
M(r)=\sqrt{A(r)^{2}+B(r)^{2}}
$$

and

$$
\theta(r)=k t+\frac{c}{k}+\ln r+\tan ^{-1}\left[\frac{A(r)}{B(r)}\right]
$$

The asymptotic series expansion for the solution of $\varphi(r)$ given by Eq. (34) is uniquely determined up to some constant phase $\alpha_{\ell}$; therefore, we can write

$$
\varphi(r)=M(r) \cos \left[\theta(r)+\alpha_{Q}\right] \text { : }
$$

instead of Eq. (34), and we also have

$$
\begin{gathered}
\varphi^{\prime}(r)=M^{\prime}(r) \cos \left[\theta(r)+\alpha_{Q}\right] \\
-M(r) \theta^{\prime}(r) \sin \left[\theta(r)+\alpha_{Q}\right] .
\end{gathered}
$$

For sufficiently large $R_{s} \varphi(R)$ and $\varphi^{\prime}(R)$ are the desired right-boundary conditions. The guesses at $R$ may have to be increased several times before Eq. (31) is satisfied.

The phase $\alpha_{R}$ is determined by an iteration process that is explained later.

\section{DETERMINATION OF THE EIGENVALUES AND PHASE FACTORS}

\section{A. The Eigenvalue}

As stated previously, for the bound state, $\lambda$ is varied until we find a $[\varphi(\lambda, r), \lambda]$ that solves the Schrödinger equation. We start with a minimum and a maximum guess at $\lambda$. This difference in $\lambda$ is divided into a specified number of logarithmically equal $\lambda$-intervals. We define

$$
F(\lambda)=\frac{\varphi_{b}(\lambda, \widehat{r})}{\varphi_{f}(\lambda, \widehat{r})} \varphi_{f}^{\prime}(\lambda, \widehat{r})-\varphi_{b}^{\prime}(\lambda, \widehat{r})
$$

at the end points of these $\lambda$-intervals and look for a sign change in $F(\lambda)$ in each. If we detect a sign change in an interval, we use the Regula $\mathrm{Falsa}^{3}$ method to find the root of $F(\lambda)$ in that interval. As $F(\lambda)$ also changes sign through poles, we check to reject these intervals.

When we find a $[\varphi(\lambda, r), \lambda]$ solution, we must determine whether it is the desired one for specified quantum numbers $n$ and $\ell$, where $\ell \leqslant n-1$. We have the desired solution when

$$
1=\mathbf{n}-\ell-1 \text {, }
$$

where $I$ is the number of roots in $\varphi(r)$. I is found using a Sturm Sequence. ${ }^{3}$ If Eq. (39) is not satisfied, we reject this solution and continue our search. The value of $\lambda$ so obtained is called the eigenvalue.

\section{B. Phase Determination}

In the free state, $\lambda$ is specified and the phase $\alpha_{Q}$ at the right boundary is varied over the range $0 \leqslant \alpha_{Q} \leqslant \pi$ until we find a $\left[\varphi\left(\alpha_{\ell}, r\right), \alpha_{Q}\right]$ that solves the Schrödinger equation. To find this solution, we again use the Regula Falsa method to find the root of $F\left(\alpha_{\ell}\right)$ where

$$
F\left(\alpha_{\ell}\right)=\frac{\varphi_{b}\left(\alpha_{\ell}, \widehat{r}\right)}{\varphi_{f}\left(\alpha_{\ell}, \widehat{r}\right)} \varphi_{f}^{\prime}\left(\alpha_{\ell}, \widehat{r}\right)-\varphi_{b}^{\prime}\left(\alpha_{\ell}, \widehat{r}\right)
$$

Here, we need not check for poles or unwanted solutions as was necessary for the bound states.

\section{Normalization}

Even though the wave functions need not be normalized to be solutions to the Schrodinger equation, they must be normalized to produce correct absorption coefficients. We define $\varphi(r)$ as normalized when, for bound states:

$$
\int_{0}^{\infty} \varphi(r) \varphi(r) d r=1,
$$

and, for free states:

$$
\int_{0}^{\infty} \varphi_{\lambda} \varphi_{\lambda}^{\prime} \mathrm{dr}=\delta\left(\lambda-\lambda^{\prime}\right)
$$


The free states have this normality built into the rightboundary condition. However, for each bound state, we evaluate

$$
\int_{0}^{\infty} \varphi(r) \varphi(r) d r=\beta^{2},
$$

and the normalized wave function is then $\varphi(r) / \beta$. Equation (43) is evaluated by polynomial multiplication and integration over each interval of $r$.

\section{EVALUATION OF MATRIX ELEMENTS}

Now that we have found all of the necessary solutions to the Schrödinger equation, we compute the matrix elements, $\mathbf{H}_{m n}$, used in evaluating the absorption coefficients. The matrix elements are found by

$$
H_{m n}=2 \int_{0}^{\infty} \varphi_{m}(r) \frac{\partial v(r)}{\partial r} \varphi_{n}(r) d r
$$

where $m$ and $n$ refer to eigen solutions of the Schrödinger equation. If one wave function is bound and the other is free, $\mathbf{h}_{\mathrm{mn}}$ is used in evaluating $\sigma_{\mathrm{bf}}$. Likewise, if both are bound, the result is $\sigma_{b b}$, and if both are free, the result is $\sigma_{\text {ff. }}$.

Equation (44) is evaluated by summing the integrals calculated in each expansion interval. Because $\partial \mathrm{V}(\mathrm{r}) / \partial \mathrm{r}$ decreases as $r^{-2}$ and $\varphi(r)$ decreases exponentially for bound states, this integral converges rapidly to a specified accuracy at some finite value of $r$, provided at least one $\varphi(r)$ represents a bound state. However, if both wave functions represent free states, the convergence is much slower, because each bound wave function ssymptotically approaches a constant amplitude. Here, convergence is achieved only through the $r^{-2}$ decrease in $\partial V(r) / \partial r$.

In the first interval we have

$$
\frac{\partial V(r)}{\partial r}=-c_{2,1} r^{-2}
$$

multiplied by the polynomial representations of $\varphi_{\mathrm{m}}$ (r) and $\varphi_{n}(r)$ that can be integrated easily. In the rest of the intervals, we have

$$
\frac{\partial V(d)}{\partial d}=-\frac{c_{2, i}\left(\rho_{i}+d\right)+2 c_{3, i}}{\left(\rho_{i}+d\right)^{3}}
$$

which, by continued long division, can be written as a converging power series in $\mathrm{d}$ when $\left|\mathrm{d} / \rho_{\mathrm{j}}\right|<1$. Now, multiplying these three polynomials, we get a polynomial that can be integrated easily.

\section{EXAMPLES}

\section{A. Bound-Free Absorptions}

In the code, $\lambda, r, V(r)$, and $H_{m n}$ are dimensionless parameters. Both $\lambda$ and $V(r)$, when multiplied by one Rydberg, are energies expressed in Rydbergs, and $r$, when multiplied by one Bohr radius, is a length expressed in Bohr radii.

The bound-free absorption coefficient is given by

$$
\sigma_{b f}(h v)=10.756 \times 10^{6} \sum \frac{\ell_{\max } H_{m n}^{2} \eta}{\left|\lambda_{m}-\lambda_{n}\right|^{3} g},
$$

where

$\ell_{\max }$ is the maximum of $\ell_{m}$ and $\ell_{n}$.

$\eta$ is the number of electrons in the bound state that can make this transition.

$g$ is the maximum possible degeneracy given by $2(2 \ell+1)$ for the $\ell$ of the bound state.

Here $\lambda_{m}, \lambda_{n}$, and $H_{m n}$ are dimensionless numbers and $\sigma_{b f}$ is expressed in barns per arom. Also when $h v=13.605\left|\lambda_{m}-\lambda_{n}\right|, h v$ is expressed in electron volts. The sum in Eq. (47) is over all possible bound-free transitions at the given $h v$.

Figures 2 through 7 show examples of bound-free absorptions for cold, normal-density beryllium, carbon, aluminum, iron, copper, and lead as computed by DEGA-A. In these figures, the continuous line was computed by DEGA- $A$ and the $X$ 's are experimental data given by Storm and 1srael. ${ }^{4}$ In Fig. 5 , the three experimental points at the $m$ edge for iron were given by Carter and Givens. ${ }^{5}$ In Fig. 4, DEGA-A was compared with calculations by Barfield, Koontz, and Huebner ${ }^{6}$ for aluminum at low photon energies.

Even though the bound-free cross sections have been computed down to the lowest edge in these examples, we make no claims about the accuracy of the copper and lead cross sections at these low photon energies.

None of the cross sections in this report include elecron spin or relativistic effect. 


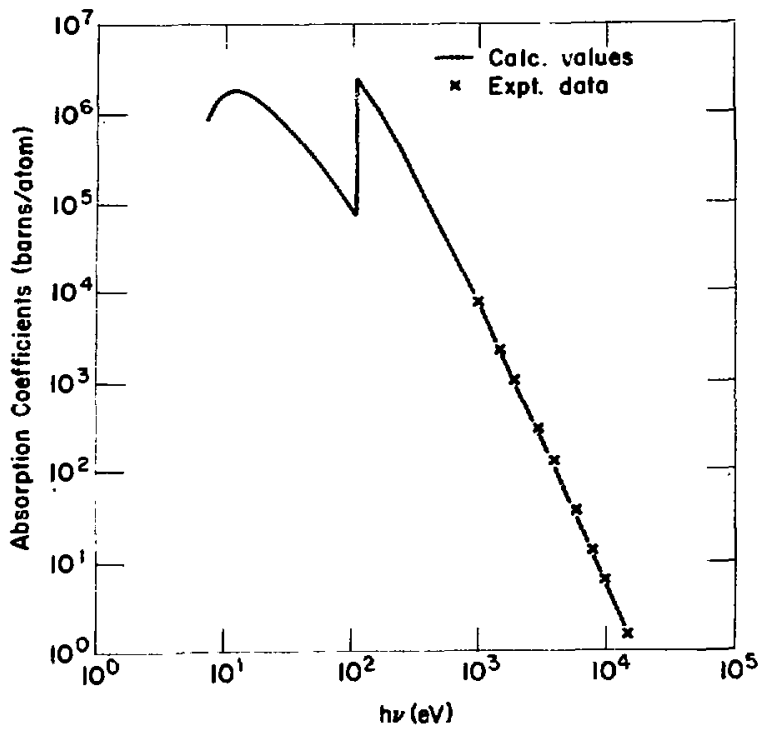

Fig. 2.

Bound-free absorption coefficients for cold, normal density $\left(1.845 \mathrm{~g} / \mathrm{cm}^{3}\right)$ Be. $\quad\left(Z=4, r_{0}=1.406\right.$, $R_{1}=2.355$ )

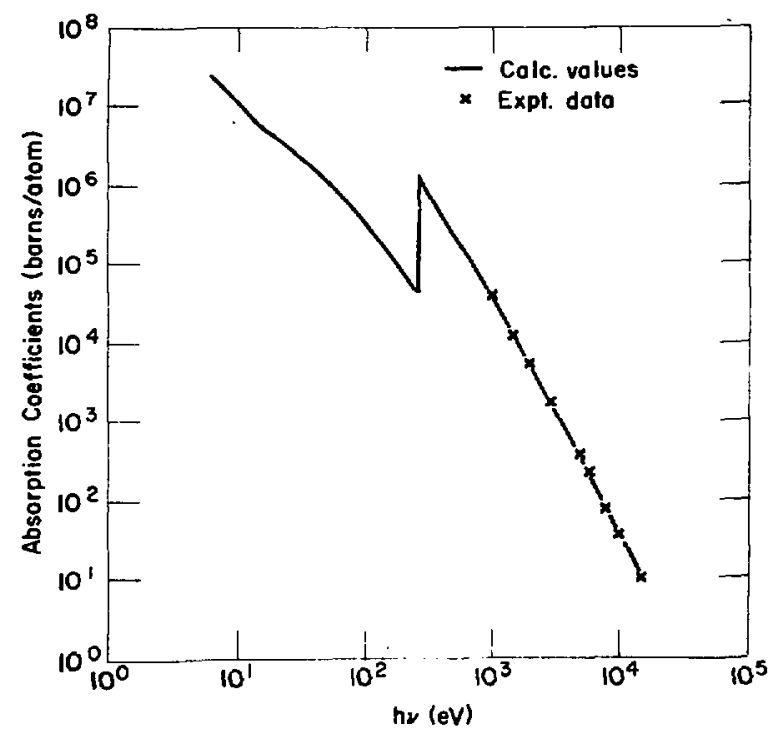

Fig. 3.

Bound-free absorption coefficients for cold, normal density $\left(2.25 \mathrm{~g} / \mathrm{cm}^{3}\right) \quad C . \quad\left(Z=6, r_{0}=1.442\right.$, $R_{1}=2.426$ )

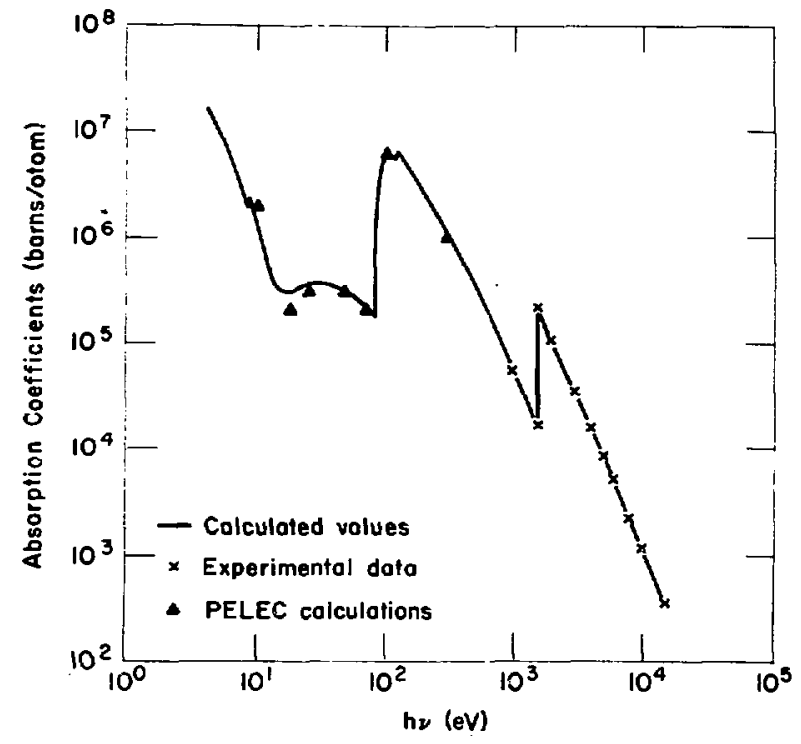

Fig. 4.

Bound-free absurption coefficients for cold, normal density $\left(2.699 \mathrm{~g} / \mathrm{cm}^{3}\right) \mathrm{Al} . \quad\left(Z=13, r_{0}=1.699\right.$, $R_{1}=2.990$ )

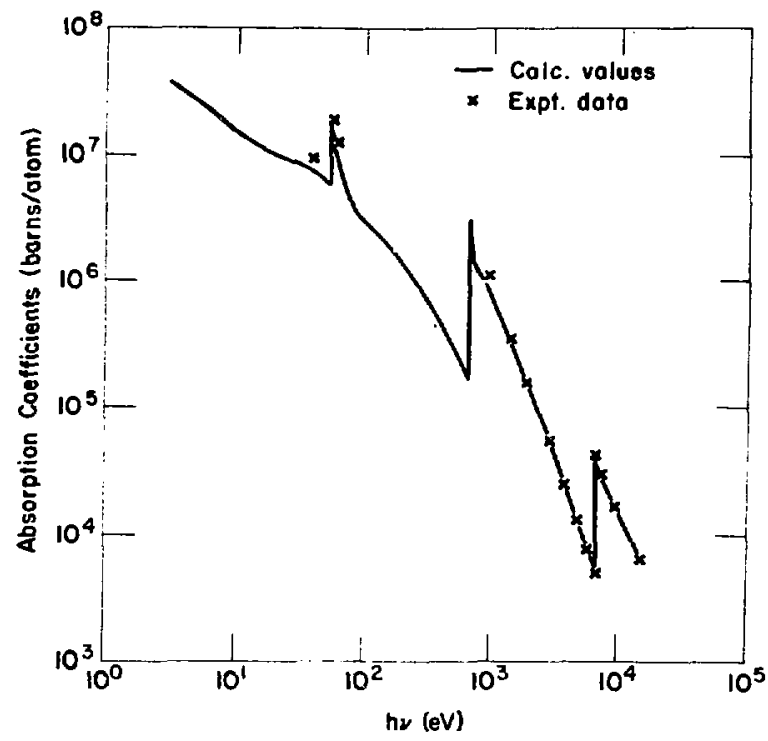

Fig. 5.

Bound-free absorption coefficients for cold, normal density $\left(7.85 \mathrm{~g} / \mathrm{cm}^{3}\right)$ Fe. $\left(Z=26, r_{0}=1.512\right.$, $R_{1}=2.670$ ) 


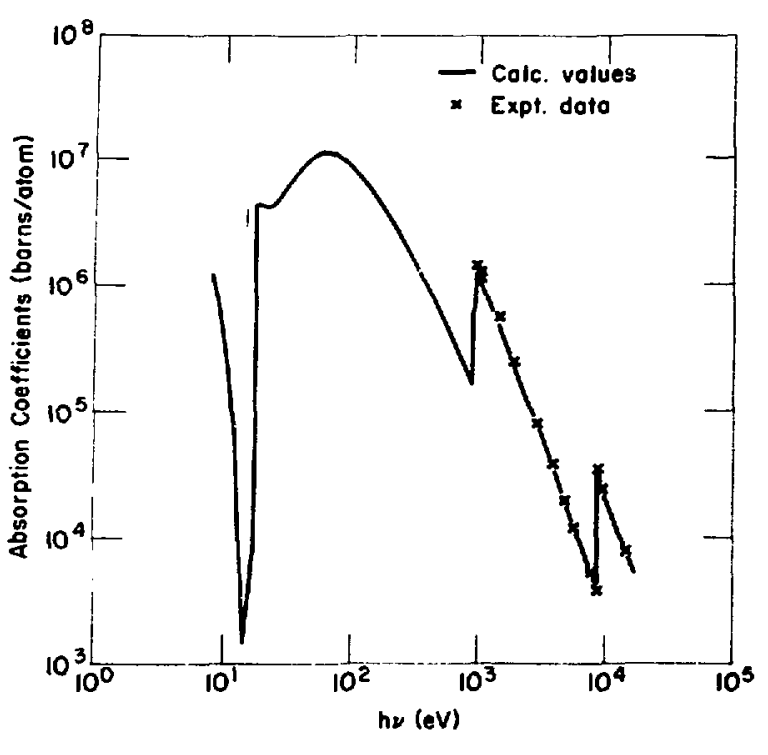

Fig. 6.

Bound-free absorption coefficients for cold, normal density $\left(8.89 \mathrm{~g} / \mathrm{cm}^{3}\right) C u$. $\left(Z=29, r_{0}=1.517\right.$, $\left.R_{1}=2.674\right)$

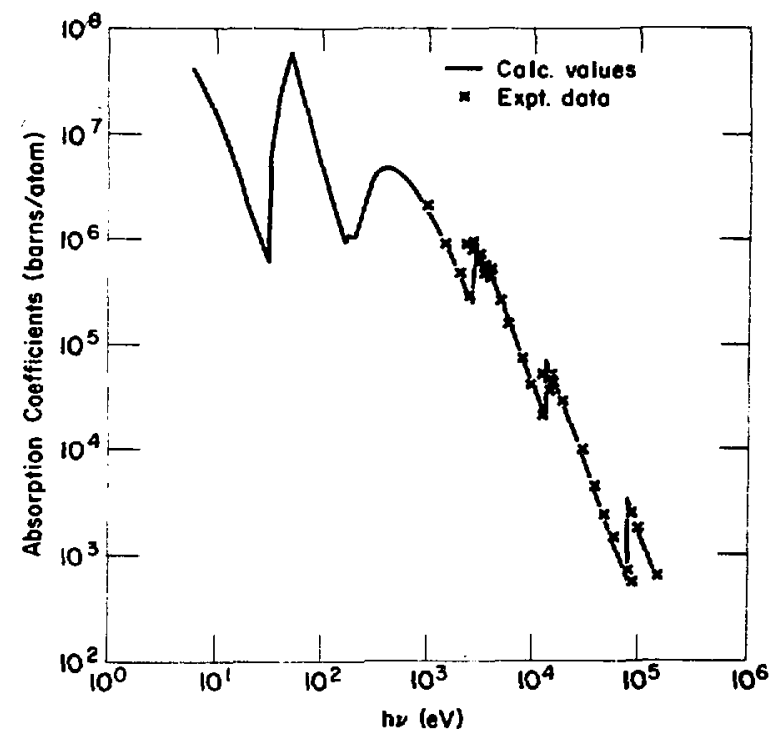

Fig. 7.

Bound-free absorption coefficients for cold, normal density $\left(11.34 \mathrm{~g} / \mathrm{cm}^{3}\right) \mathrm{Pb} . \quad\left(Z=82, r_{0}=2.003\right.$, $R_{1}=3.656$ )

\section{B. Bound-Bound Absorptions}

In checking the bound-bound case, we consider hydrogen, lithium, beryllium, sodium, potassium, and strontium. A formula similar to Eg. (47) can be derived for $\sigma_{b b}(h v)^{2}$ However, because the data found in the lizerature? appeared in a different form, we used the formula

$$
\tau=\frac{4 H_{\operatorname{mn}}^{2}}{\left|\lambda_{m}-\lambda_{n}\right|^{4}\left(4 Q_{\max }^{2}-1\right)}
$$

to make our numbers directly comparable. See Table $\mathbf{I}$.

Squares of dipole moments for hydrogen were computed by

$$
M^{2}=\frac{4 H_{1 m n}^{2}}{\left|\lambda_{m}-\lambda_{n}\right|^{4}} .
$$

These results checked with the values of the squares of dipole moments ${ }^{*}$ given by Bethe and Salpeter. ${ }^{8}$ Note that Eq. (49) is not defined by the method presented in this report when $\lambda_{m}=\lambda_{n}$.

To check the code to more digits than given by Bethe and Salpeter (the CDC 7600 is a 14-digit machine), $H_{15,2 p}$ was computed to the maximum possible accuracy using the hydrogenic potential and was compared with its analytic solution. We know that for hydrogen

$$
\varphi_{1 \mathrm{~s}}=2 \mathrm{re}^{-\mathrm{r}}
$$

and

$$
\varphi_{2 \mathrm{p}}=\frac{1}{2 \sqrt{6}} \mathrm{r}^{2} \mathrm{e}^{-\mathrm{r} / 2}
$$

When these analytic expressions for $\varphi$ are used in Eq. (44) along with $V(r)=-1 / r$, we obtain

$$
H_{1 \mathrm{~s} 2 \mathrm{p}}=\frac{8}{9 \sqrt{6}}=0.36288736930121
$$

and DEGA-A computed

$$
H_{1 s, 2 p}=0.36288736930118 \text {. }
$$

'Compare with Table 13, page 264, Bethe and Salpeter. 8 
TABLE

\section{TRANSITION INTEGRAL T FOR COLD, NORMAL DENSITY ELEMENTS}

\begin{tabular}{|c|c|c|c|c|c|}
\hline \multirow[b]{2}{*}{ Efement } & \multirow[b]{2}{*}{ Transition } & \multicolumn{4}{|c|}{ Transition lncegral $r$} \\
\hline & & $\begin{array}{l}\text { Serecned- } \\
\text { Hydrogenie }\end{array}$ & $\begin{array}{l}\text { Coutornb } \\
\text { Approx }\end{array}$ & $\begin{array}{l}\text { Self-Cons } \\
\text { Ficitu }\end{array}$ & DEGA-A \\
\hline \multirow[t]{8}{*}{$\operatorname{LiI}^{*}$} & $2 p \cdot 2 s$ & 5.96 & 5.42 & $5.5 \cdot 5.6$ & $4.2 B$ \\
\hline & $3 p-2 s$ & 0.011 & 0.016 & $0.011 \cdot .020$ & 0.071 \\
\hline & $3 s-2 p$ & 1.72 & 2.39 & & 1.75 \\
\hline & $4 s-2 p$ & 0.105 & 0.177 & & 0.548 \\
\hline & $5 s-2 p$ & 0.029 & 0.056 & & $0.04 \%$ \\
\hline & $6 s-2 p$ & 0.013 & 0.025 & & 0.020 \\
\hline & $3 d-2 p$ & 1.28 & 1.14 & & 0.748 \\
\hline & $4 d-2 p$ & 0.19 & 0.18 & & 0.148 \\
\hline $\mathrm{Be} \mathrm{I}^{\mathrm{b}}$ & $2 s 2 p-2 s^{2}$ & 2.27 & 2.03 & 1.86 & 3.29 \\
\hline \multirow[t]{3}{*}{$\mathrm{Nal} l^{\mathrm{e}}$} & $3 p-3 s$ & 3.41 & 6.0 & 6.7 & 3.63 \\
\hline & $4 p \cdot 3 s$ & 0.211 & $0.0 \% 7$ & 0.051 & 0.026 \\
\hline & $4 s-3 p$ & 2.06 & 6.09 & 6.2 & 3.60 \\
\hline$K l^{d}$ & $4 p-45$ & 4.61 & 8.05 & 9.05 & 7.72 \\
\hline Sr $t^{e}$ & $5 d-5 p$ & 0.483 & 0.42 & & 1.39 \\
\hline \multicolumn{6}{|c|}{$2=3, x_{0}=1.928$, and $R_{1}=3.263$} \\
\hline
\end{tabular}

\section{Free-Free Absarptions}

1. Discussion of Gaunt Factors. A formula similar to Eq. (47) ${ }^{2}$ can be derived for $\sigma_{\text {ff }}$ (hu) in terms of Gaunt factors $G_{f f}$, however, here we only compute Gaunt factors for hydrogen and sodium and compare some of these results with Karzas and Latter. ' Gaunt factors can be evaluated with

$$
\begin{aligned}
& g_{f f}\left(\lambda_{a}, h v\right)=\frac{\pi \sqrt{3}}{8\left(Z^{e f f}\right)^{2}} \\
& \sum_{Q=0}^{L^{\prime}}\left[(\ell \cdot !) H_{Q+1, \ell^{2}}\left(\lambda_{a}, h u\right)^{2}+\ell H_{Q-1, Q}\left(\lambda_{2}, h v\right)^{2}\right]
\end{aligned}
$$

when the sum converges rapidly enough to be practical. Here $\lambda_{2}$ is the initjal energy of the electron, $h v$ is the photon energy, $z$ eff is the effective number of free elec- trons in the atom under consideration, and $L^{\prime}$ is a finite integer approximation to infinity. The matrix elements are still defined by Eq. (44), but we rewrite the equation 25

$H_{m n}\left(\lambda_{1}, h u\right)=2 \int_{0} \varphi_{m}\left(\lambda_{a}, r\right) \frac{\partial V(r)}{\partial r} \varphi_{n}\left(\lambda_{2}+l u, r\right) d r$

to define the association between energy levels and quantum numbers.

The som in Eq. (S1) is not always converging rapidly. Results for other than a coulomb potential can often be obtained in these cases by making use of the formula 10

$$
\begin{aligned}
& g_{f f}\left(\lambda_{a}, h v\right)=g_{f f}^{c}\left(\lambda_{a}, h w\right) \\
& +\frac{\pi \sqrt{3}}{g} \sum_{Q=0}^{L}\left\{(R+1)\left[H_{t+1, Q}\left(\lambda_{a}, h u\right)^{2}-H_{Q+1, Q}\left(\lambda_{2}, l u\right)^{2}\right]\right. \\
& \left.+\ell\left[H_{Q-1, Q}\left(\lambda_{a}, h v\right)^{2}-H_{Q-1, Q}^{c}\left(\lambda_{2}, h u\right)^{2}\right]\right\} \text {. }
\end{aligned}
$$


where $g_{\text {fif }}$ is the coulombic Gaunt factor for the initiat enety and photon energy under consideration, $t_{\text {tr }}^{5}$ is a coulombic matrix element defined by Eq. (s2) utsing $V(r)=-1 / r$, and $L$ is an integer suffieiently large so that the sum has converged to a prederetmined accuracy. A graph of $g_{f f}(\lambda, h u)$ is given by karzas and Lattet who citcurnvented the slow convergense problem in Eq. (51) by using hergeometric funations. Applisarions of this procedure are limited to the coutomb potential.

The method for obuining a noncoutombic of $(h v)$, as described in this report, nevet tequires the evaluation of a

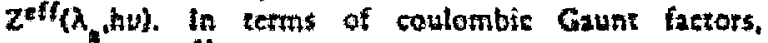

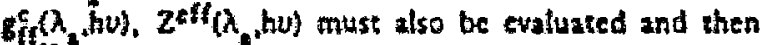
$Z^{\text {th }}\left(\lambda_{,}, h v\right) g_{f}^{c}\left(\lambda_{n}, h u\right)$ must be used as the desired Gaunt factor. However, Eqs. (51) and (53) give the desired noncoulombie $g_{f}\left(\lambda\right.$, hv) for $2^{\text {eft }}=1$ when the matrix elements are computed by DEGA-A using a realistic porenrial.

2. Onecks an Methad. For the first check on the code, we computed serat Gaunt factors with Eq. (51) using the coulomb porential, $V(r)=-1 / t$, and compared these tesults with the Karzas and Latzet graph. Hete comparisons were made up to, at most, three significant figutes, which is the maximam atruraty for rading the graph. Table II shows that for several cases we were able to reprodtuce the Karzas and Lattet values. In the remaining eases, Eq. (51) had not ernvetged for $2=34$, the maximum value of $Q$ used in these calculations.

Cold, notmal-density sodium $\left(z=11, t_{0}=2.264\right.$ $\left.R_{t}=3.986\right)$ was arbitrarily used in the next check (Fig. g). Here, for tost phoron energies and low initial cnergies, the Gaun: factors tusing the sodium potential and $2^{\text {cff }}=1$ should approuch the coulombic Gaunt factors. Aso, for large photon energies and large initial enengies, the Gaunt factors using the sodium potentiat and $\mathbf{Z}^{\text {eff }}=11$ should approach the coulombic Gaunt factors. In both cases, the sodium Gaunt factor for $\left(A_{3}, h v\right)$ is compared with the coulombie Gaunt fastor for $\left.\left\langle\lambda_{2} /\left(z^{\mathrm{aff}}\right)^{2} \text {. hu/(zelf }\right)^{2}\right\rangle$.

3. Diteussion of Screening. The general sercening effects are noted for the small clectron kinetic energy and the small photon energy shown in Fig. 8 . As the photon energy is held fixed ard the eicctron energy is increased. the calculated Gaunt factor increases faster than would the expected from the coulombic case. The qualieative reason for this follows. As the electron energy is increased, the electron wave funetion sumples in greater and greater detail the structure of the atom (the shielting), and as a result the effective change $Z^{\text {cff }}$ increases with increasing energy. The result is that, relative to a coulomb posentiall, the cross section is raised. However, as the energy of the clectron and the photon increase, we cventually arrive at a

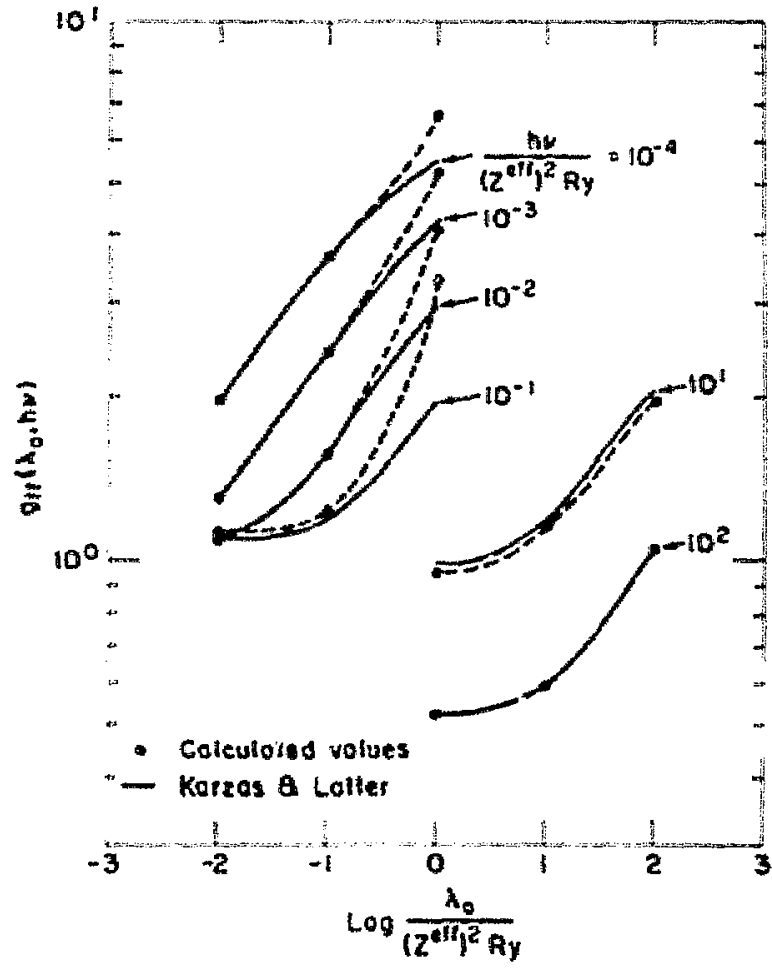

Fig. \&

4 comparison of conlombic and sbielded potential (Nol) Gaunt fuctors.

point where the wave function of the electron oscitlates sufficiently rapidly that it is essentially seeing the coulomb ficld of the nucleus. The effective charge is then the nuclear change and we have agreement with the coulomb field results. This corresponds to the lower righr-hand curves of Fig. 8.

4. Numarical Results. The purpese of Table II is to illustrate \pm trend in the convergence rate for each of Eqs. (51) and (S3) as a function of $(\lambda, h v)$. An integer in parentheses indicares the value of $Q$ for which the series was terminated. For example, where $\left(\lambda_{2}, h u\right)=(1.0,0.01)$, Eq. (51) has summed to 3.07 by 34 terms, whereas Eq. (53) hes summed to within $2 \%$ of the expected (converged) value of 4.10 by' three terms. Here convergence means no change in the sum to the accuracy given in Tabie H. Also, for the coulombic case at this energy pair, Eq. (51) has not converged for $l=34$. For the $(1.0,10)$ entry, both Egs. (51) and (53) have converged by $Q=3$ for the sodium ease, and Eq. (51) has converged by $Q=3$ in the coulombic ease.

Table II also shows that neither Eq. (51) nor (53) has converged for the entries labeled with footnote $b$. The use 


\section{TABLE $\mathrm{I}$}

\section{CALCULATIONS OF COLD, NORMAL DENSITY SODIUM} AND COULOMBIC GAUNT FACTORS"

\begin{tabular}{|c|c|c|c|c|c|c|c|}
\hline \multirow{2}{*}{$\frac{\lambda_{\mathrm{e}}(\mathrm{Ry})}{0.01}$} & \multirow{3}{*}{$\frac{h e(R y)}{0.0001}$} & \multirow{2}{*}{ 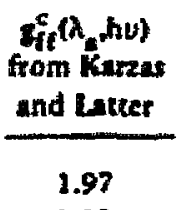 } & \multirow{2}{*}{ 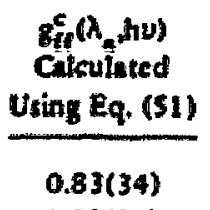 } & \multirow{2}{*}{$\frac{\begin{array}{c}B_{t e}^{\left(A_{\alpha}(h u)\right.} \\
\text { for Na Cleulnted } \\
\text { Using Eq. (51) }\end{array}}{0.83(34)}$} & \multicolumn{3}{|c|}{ 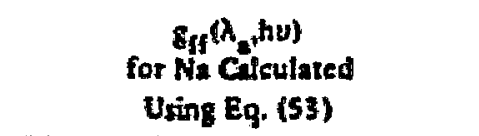 } \\
\hline & & & & & $1.97(3)$ & $1.97(34)$ & \\
\hline & & 1.32 & $1.20(34)$ & $1.30(34)$ & $1.32(3)$ & $1.32(34)$ & \\
\hline & 0.01 & 1.11 & $1.11(29)$ & $1.09(29)$ & $1.09(3)$ & $1.09(29)$ & \\
\hline & 0.1 & 1.08 & $1.08(14)$ & $1.11(14)$ & $1.11(3)$ & $1.11(14)$ & \\
\hline & 1.0 & 1.10 & $1.10(3)$ & $1.51(3)$ & $1.51(3)$ & $1.5 \mathbb{E}(9)$ & \\
\hline \multirow[t]{5}{*}{0.1} & 0.0901 & 3.65 & $1.34(34)$ & $1.34(34)$ & $3.64(3)$ & $3.65(34)$ & \\
\hline & 0.001 & 2.46 & $1.41(34)$ & $1.40(34)$ & $2.45(3)$ & $2.45(34)$ & \\
\hline & 0.01 & 1.58 & $1.53(34)$ & $1.53(34)$ & $2.58(3)$ & $1.58(34)$ & \\
\hline & 0.1 & 1.21 & $1.21(24)$ & $1.24(24)$ & $1.24(3)$ & $1.24(24)$ & \\
\hline & 1.0 & 1.13 & $1.13(3)$ & $1.99(3)$ & $1.99(3)$ & $1.99(11)$ & \\
\hline \multirow[t]{6}{*}{1.0} & 0.0201 & 5.5 & $1.92(34)$ & $3.01(34)$ & $6.50(3)$ & $6.59(25)$ & $6.59(34)$ \\
\hline & 0.001 & 4.2 & $1.92(34)$ & $3.01(34)$ & $5.20(3)$ & $5.29(25)$ & $5.29(34)$ \\
\hline & 0.01 & 3.0 & $1.97(34)$ & $3.07(34)$ & $4.02(3)$ & $4.10(25)$ & $4.10(34)$ \\
\hline & 0.1 & 1.95 & $1.89(34)$ & $3.23(34)$ & $3.22(3)$ & $3.29(25)$ & $3.29(34)$ \\
\hline & 1.0 & 1.31 & $1.31(15)$ & $5.50(15)$ & $5.44(3)$ & $5.50(15)$ & $5.50(22)$ \\
\hline & 10. & 0.97 & $0.97(3)$ & $37.4(3)$ & $37.4(3)$ & $37.4(7)$ & \\
\hline \multirow[t]{5}{*}{10.0} & 0.01 & 4.55 & $2.23(34)$ & $27.5(34)$ & $26.7(3)$ & $29.8(25)$ & $29.8(34)$ \\
\hline & 0.1 & 3.25 & $2.19(34)$ & $27.6(34)$ & $25.5(3)$ & $28.6(25)$ & $28.7(34)$ \\
\hline & 1.0 & 2.09 & $2.06(34)$ & $29.6(34)$ & $26.6(3)$ & $29.6(25)$ & $29.6(34)$ \\
\hline & 10. & 1.20 & $1.20(10)$ & $50.6(10)$ & $49.4(3)$ & $50.6(10)$ & $50.6(16)$ \\
\hline & 100. & 0.59 & $0.59(3)$ & $106.7(3)$ & $206.7(3)$ & $106.7(7)$ & \\
\hline \multirow[t]{5}{*}{100.0} & 0.1 & 4.55 & $2.28(34)$ & $102.2(34)$ & $82.6(3)$ & $104.3(25)$ & $104.5(34)$ \\
\hline & 1. & 3.30 & $2.31(34)$ & $102.4(34)$ & $81.7(3)$ & $103.2(25)$ & $103.4(34)$ \\
\hline & 10. & 2.08 & $2.05(34)$ & $106.1(34)$ & $85.8(3)$ & $106.0(25)$ & $106.2(34)$ \\
\hline & 100 & 1.06 & $1.06(10)$ & $125.4(10)$ & $121.0(3)$ & $125.4(10)$ & $125.4(15)$ \\
\hline & 1000 & 0.42 & $0.42(3)$ & $117.7(3)$ & $117.7(3)$ & $117.7(7)$ & \\
\hline \multirow[t]{4}{*}{1000.0} & $10.0^{b}$ & 3.30 & $2.31(34)$ & $187.3(34)$ & $122.4(3)$ & $185.7(25)$ & $188.3(34)$ \\
\hline & $100 .^{b}$ & 2.07 & $1.89(17)$ & $187.7(34)$ & $129.0(3)$ & $172.8(10)$ & $183.1(17)$ \\
\hline & 1000 & 0.99 & $0.99(10)$ & $141.3(10)$ & $135.2(3)$ & $141.3(10)$ & $141.3(15)$ \\
\hline & 10,000 & 0.36 & $0.36(3)$ & $74.1(3)$ & $74.1(3)$ & $74.1(7)$ & \\
\hline \multirow[t]{4}{*}{$10,000.0$} & $100.0^{b}$ & 3.30 & $2.31(34)$ & $244.8(34)$ & $132.1(3)$ & $235.4(25)$ & $245.8(34)$ \\
\hline & $1000 .^{b}$ & 2.06 & $2.03(34)$ & $232.2(34)$ & $139.5(3)$ & $228.1(25)$ & $232.2(34)$ \\
\hline & 10,000 & 0.98 & $0.98(10)$ & $128.1(10)$ & $122.4(3)$ & $128.1(10)$ & 128.1(15) \\
\hline & 100,000 & 0.35 & $0.35(3)$ & $51.8(3)$ & $51.8(3)$ & $51.8(7)$ & \\
\hline
\end{tabular}

\footnotetext{
Alt values in this table, with the exception of the Karzes and Latter entries, were computed with the DEGA-A code. An integer in parentheses is the value of $R$ for which either Eq. (51) o: (53) was terminated to obtain the Gaunt factor. These integers illustrate the speed of convergence of Eqs. (51) and (53).
}

Beither Eq. (\$1) nor (53) has converged. 
of a geometric sum enables the extrapolation of Eg. (51) to results that should represent a lower bound to the infinite sum. Numerical checks indicate that this extragolation is good to $10 \%$ ar better. To derive this extrapolation formula, iez us simplify Eq. (51) by setting

$$
Y_{Q}^{\prime}=(2+1) H_{Q+1,2}\left(\lambda_{2}, h u\right)^{2}
$$

and

$$
Y_{Q}^{2}=2 H_{1-1,2}\left(\lambda_{2}, h u\right)^{2} .
$$

From calculations, we note that both $\left(\log Y_{Q}^{\prime}, R\right)$ and $\left(\log Y^{2}, \ell\right)$ approximate straight lines for large values of $\ell$. (The $\left(\log Y_{q}, R\right)$ pair is noz to be confused with the $\left(\lambda_{2}, h v\right)$ pair.) Figure 9 illustrates this point for $(1000,100)$. The straight line for $Y_{Q}^{\prime}$ is written as

$$
\log Y_{Q}^{\prime}=s\left(Q-\ell^{\prime}\right)+q
$$

and two known points, (log $\left.Y_{Q}^{\prime}, l^{\prime}\right)$ and $\left(\log Y_{q^{*}+1}^{\prime}, Q^{\prime}+1\right)$, are chosen to evaluate $s$ and $q$. Equztion (55) can also be written as

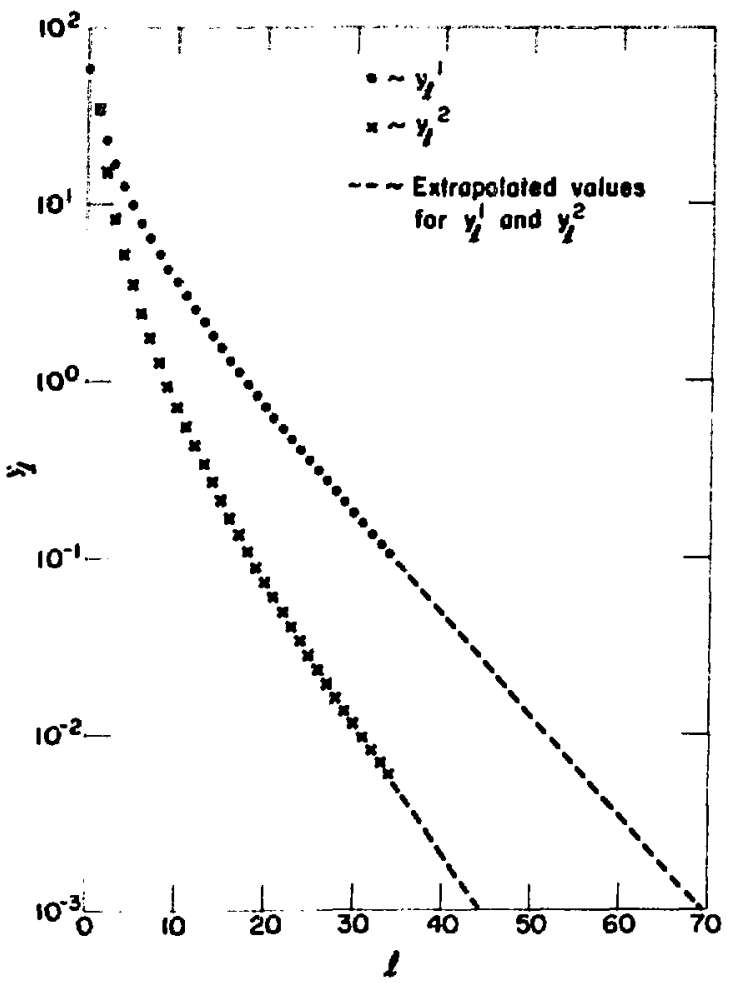

Fig. 9.

A graphic representation of the terms in Eq. (51) and the extrapolation indicated in Eq. (56).

$$
Y_{Q}^{\prime}=e^{q}\left(e^{5}\right)^{Q-R^{\prime}} .
$$

Now using Eq. (56) to take the infinite sum for all $\ell \geqslant \ell^{\prime}$, we have the extrapolation formula

$$
\sum_{Q=\ell^{\prime}}^{\infty} Y_{Q}^{\prime}=e^{9} /\left(1-e^{5}\right) .
$$

The above procedure is repeated using $Y_{Q}^{2}$. These two extrapoiated values are added to the number obtained by summing Eg. (51) to $\ell=\ell^{\prime}-1$. The results obtained by

\begin{tabular}{|c|c|c|c|c|}
\hline \multirow{2}{*}{$\frac{\lambda}{1000.0}$} & \multirow{2}{*}{$\begin{array}{c}\text { hv } \\
10.0 \\
100 .\end{array}$} & \multirow{2}{*}{ 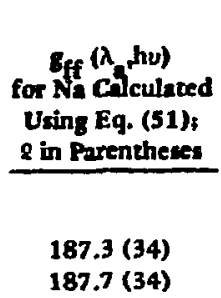 } & \multicolumn{2}{|c|}{$\begin{array}{l}8_{f f}\left(\lambda, \lambda_{1} \text {,hv) }\right. \\
\text { for Na Calculated } \\
\text { Using Extrapolated } \\
\text { Form of Eq. (51); } \\
\ell^{\prime} \text { in Parencheses }\end{array}$} \\
\hline & & & $\begin{array}{l}189.5(27) \\
188.3(27)\end{array}$ & $\begin{array}{l}189.9(34) \\
188.3(34)\end{array}$ \\
\hline $10,000.0$ & $\begin{array}{l}100.0 \\
1000 .\end{array}$ & $\begin{array}{l}244.8(34) \\
232.2(34)\end{array}$ & $\begin{array}{l}259.0(27) \\
234.2(27)\end{array}$ & $\begin{array}{l}261.7(34) \\
234.3(34)\end{array}$ \\
\hline
\end{tabular}
using this extrapolation formula are given in Table III.

TABLE II

\section{EXTRAPOLATED VALUES OF GAUNT FACTORS}

\section{REFERENCES}

1. P. Herman and S. Skilman, Atomic Structure Calculations (Prentice-Hall Inc., Englewood Cliffs, New Jersey, 1963).

2. T. R. Carson, D. F. Mayers, and D. W. N. Stibbs, "The Calculation of Stellar Radiative Opacity," Mon. Not. R. Aetr. Soc. 140,483 (1968).

3. A. S. Householder, Principles of Numerical Analysis (McGraw-Hill Book Company Inc., New York, 1953).

4. E. Storm and H. 1. Isreel, "Photo Cross Sections from 0.001 to $100 \mathrm{MeV}$ for Elements 1 through 100," Los Alamos Scientific Laboratory report LA-3753 (November 15, 1967).

5. D. E. Carter and M. P. Givens "Soft X-Ray Absorption of Thin Films of Iron and Iron Oxide," Phys. Rev. 101, 1469 (1956).

6. W. D. Barfield, G. D. Koontz, and W. F. Huebner, "Fits to New Calculations of Photoionization Cross Sections for Low Z-Elements," J. Quant. Spectrose. Radiat. Transfer 12, 1409 (1972). 
7. A. M. Naqui, "Calsulations and Applications of Streened Hydrogenic Wave Funetions," J. Quant. Spectrose. Radiet. Transfer 4, 597 (1964).

6. H. A. Hethe and E. E. Salpeter, Quantam Mfchanics of One. and Two-Electron Aloms (Academic Press Inc., New York, 1957).
9. W. J. Karas and R. Latrct, "Electron Radiarive Transitions in 2 Coulomb Field," Apl. J., Suppl. 6, 167 (1961). Alea set "Freefree Gaunt Factars," The Rand Comoration, Santa Monica. California, report RM-2010-AEC (November 8 , 1957).

10. R. R. Jolunston, "Frec-Fre Radiative Transitions-A Surucy of Theoretical Results," J. Quant. Spectrose. Radiat. Transfer 7,835 (1967). 


\section{APPENDIX}

DEGA-n

DHGA-A in its present form is a resezech and nat a production code. The expsion, whose listing follows, anly calculates bound-free absorptituts. The codt lists these atrorption coefficirnts and makes plots as sen in the previous sectinn. With slight modifications in the coding. bound-batud and freefrec absorptions can be calculated.

There are sereral fee parameters that redutite flat aceuracy of the codte. Most of these patameters are set at the beginning of the cade: however. a few are found throughtout the code. The values in the listing will gine at least four-place accuracy. The usef sheuld feel free to vary these parameters as he picases and at his own risk.

Data are tead into the bound-frec version of DECiA-A with the following FORTRAN statements.

2 [OORMAT (8F 10.3)

7 FORMAT (1615)

133 FOLMAI' (F15.5.215)

READ $2, Z, R R 2, R R$

IF (Z.LT.0.0) end job

EEAD 7, ISSMAX

READ 7, (NSUBSHL (ISS), ISS = 1, ISSMAX)

READ 7, KWKB

DO $132 \mathrm{~K}=1$, KWKB

332 READ 133, XLAMLVKB(K), LWKB(K), NWKB(K)

READ 7, IHNUMAX

READ 2, (IINUVEC(IINU), ACOFVEC(HINU), IINU $=1$, IHINUMAX)

$\mathbf{z}$

is the atomic number of the element under consideration.

RR2

is the same as $r_{o}$ on page 1.

RR is the same as $R_{1}$ on page 1. Units for RR2 and RR are number of Bohr Radii.

ISSMAX

is the number of subshelis under consideration.

NSUBSHL(ISS) is an array that contains the number of electrons in each subshell. The entries are read into this array in the order $1 \mathrm{~s}$, 2s, 2p, 3s, 3p, 3d, etc., up to the last occupied subshell. If any previous subshell is vacant, it must be assigned the value zero.
KukB

is tife number of bound wate functions to be computed. The necessan free atate functions are generated internally by tlac code.

StAMWkB(f) is th artay that contains guestes at the eigenvalues of the bound stazes. Urits are number of Rydbetgs.

EWKB(K) is an artay that contains the quantum numbers $Q$. $Q=0$ for $\$-s t a t c s, Q=1$ for $p \cdot$ states, $Q=2$ for $d$ - states, etc.

NWKB(K) is an array that contains the quantum numbers $n . n=1$ for the 15 state, $n=2$ for the $2 s$ and $2 p$ states, $n=3$ for the $3 s, 3 p$, and 3d stares, etc.

For each K, XLANWKB(K), LWKB(K), and NWKB(K) should be consisent with Eq. (39). These guesses at bound eigenvalues can be read in any order. NSUBSHL(ISS) should be defired for each of these guesses at a bound eigenvaluc.

IHNUMAX

is the number of $\left(h v, o_{b f}(h v)\right)$ pairs from a separate source that one wants to conpare with the results of DEGA-A. This option is illustraced by the $X$ 's in Figs. 2 through 7. If IHNUMAX equals zero, no $\left(h v, o_{b f}(h v)\right)$ pairs will be read.

HNUVEC'IHNU) is the array that contains the hu's given in electron-volts.

ACOFVEC(IHNU) is the array that contains the obf(hv)'s given in barns/atom.

Data decks may be stacked one behind the other. The job terminates normally when it encounters a negative $Z$. 


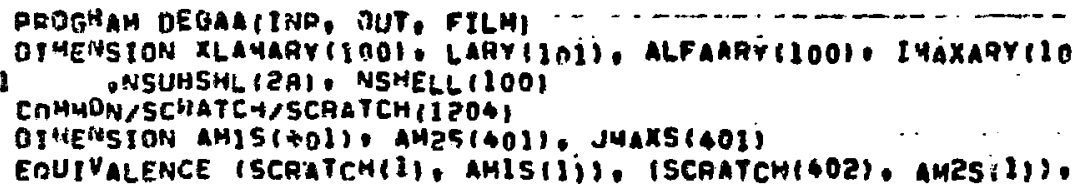

1

D) HENSTON AROOT(Z)

D) HEISION PDUMIZ1

CกU40N/CA3, 2, TH1, RRE, QR, Aó

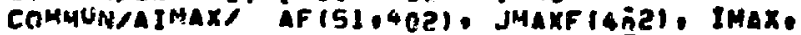

1 THAXF. IMAXFPl, lMAXB. IHAXBDi. Ci3,4001.

2 CF $(3, \$ 02), A T B P(\$ 0)$, ATOPF 1402$)$

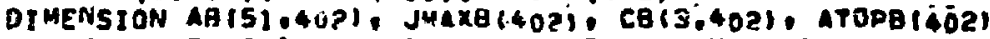

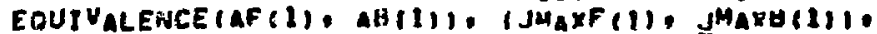

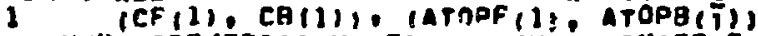

DTMENSION AXLAMB(100)

DTHEHSTON RLAMWKBI100). LWKB(101). NWKä1100)

COMUUNMI/PI. TWOSPI

COMMON/CRI/ MVUVEC(500). ACOFVEC(5nOO). NOPTS, IMNUHAX. MM(100).

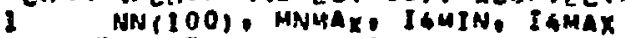

COMMUN/UE THODSIMETHOD. TEMPLAM. CAJF, CAPFP. THETA. THETAP.

P) $=3.1415926535 \mathrm{Bg}$ S TWOSPI $=2.0 / P !$

MAKITER $=100$

MAXOLIM $=200$

EOSCONV $\approx 1.0 E-5$

FAHAX $=1.0 E 200$

EMI6 $=1.0 E-8$

EMATELE $=1.0 E-5$

EMDY

AMAXT $A C=25.0$

EPHI $=1.0 E-15$

DQMIN $=1.0 E-8$

DVMAX $=1.0 E-6$

ATOPF $A C=.5$

OHNU $I^{i}=.1$

ZZZFAC $=10.0$

NODIVNG $=70$

XLAutel $=3,0$

XLAMFC? $=.2$

MAKE XLAMFCL .GT. 1.0 ANO XLAMFCE .LT. 1.0

CALL ADV (25)

1 FORMATIEZ4.14, 215 )

2 FOAMAT (aF 10,3).

3 FORMAT (5E25. It)

7 FNAMAT (1615)

9 FOAMAT (AF 10.3)

997 CONTINIE

MFAC $=1$

NOPTS 500

KDHIMAX $=0$

IFRROR $=0$

RMTN $=0.0$

REAN 2. Z, RAZ, RR

IF $(Z$ LT. 0.0$)$ GO TO 998

RMAX = RR

PRINT 3, Z, RRZ, RR

$241=2-1.0$

$A O=.6057 * z * .333333$

RFAD 7. ISSMAX

PRINT 7. ISSMAX

$\begin{array}{ll}\text { DEGA } & 00002 \\ \text { DEGA } & 00003 \\ \text { DEGA } & 00004 \\ \text { DEGA } & 00005 \\ \text { OEGA } & 00006 \\ \text { DEGA } & 00007 \\ \text { DEGA } & 00008 \\ \text { DEGA } & 00009 \\ \text { DEGA } & 00010 \\ \text { DEGA } & 00011 \\ \text { DEGA } & 00012 \\ \text { DEGA } & 00013 \\ \text { DEGA } & 00014 \\ \text { DEGA } & 00015 \\ \text { DEGA } & 00016 \\ \text { OEGA } & 00017 \\ \text { DEGA } & 00018 \\ \text { DEGA } & 00019 \\ \text { DEGA } & 00020 \\ \text { DEGA } & 00021 \\ \text { DEGA } & 00022 \\ \text { DEGA } & 00023 \\ \text { DEGA } & 00024 \\ \text { DEGA } & 00025 \\ \text { DEGA } & 00026 \\ \text { DEGA } & 00027 \\ \text { DEGA } & 00028 \\ \text { DEGA } & 00029 \\ \text { DEGA } & 00030 \\ \text { DEGA } & 00031 \\ \text { DEGA } & 00032 \\ \text { DEGA } & 00033 \\ \text { DEGA } & 00034 \\ \text { DEGA } & 00035 \\ \text { DEGA } & 00035 \\ \text { DEGA } & 00037 \\ \text { DEGA } & 00038 \\ \text { DEGA } & 00039 \\ \text { DEGA } & 00040 \\ \text { DEGA } & 00041 \\ \text { DEGA } & 00042 \\ \text { DEGA } & 00043 \\ \text { DEGA } & 00059 \\ \text { DEGA } & 00053 \\ \text { DEGA } & 00054 \\ \text { DEGA } & 00055 \\ \text { DEGA } & 00056 \\ \text { DEGA } & 00057 \\ \text { DEGA } & 00058 \\ \text { DEGA } & 00059 \\ \text { DEGA } & 00045 \\ \text { DEGA } & 00048 \\ \text { DEGA } & 00047 \\ \text { DEGA } & 00048 \\ \text { DEGA } & 00061 \\ & 00062 \\ & 00063\end{array}$




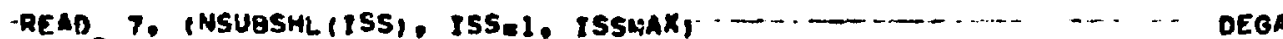
PRIN! 7. INSUGSHLIISSI: ISSEI: ISSHARI DEGA READ 7, RAKB

PAINT 7. RHKB

133 FORMATIF 15.5 , 2 ISI

on 132 Kal. KWKa

AE AD 133, XLAWLKB $(K), L W K B(K)$, NWKA $(K)$

PRINT I: XLAYWKB(K): LWKB (K): NWKB $(K)$

XLAMARY $(K)=$ XLAMHKB $(K)$

$L_{A B}(K)=L_{H} K B(K)$

132 NSHELL $(K)=$ NHKB(K)

LARY (KWKB - 1) =-1

IF (AHZ, GE. 0.0) SCRATCH(1) VI (RABZ)

CALL YYYPRMIN.RMAX,DRMIN, OVMAX,ATOPFAC,IZ IERROR.

1. XLAHHKE, LWKB, KWKA, ZZZFACI

IFITERROR. NE. O) GO TO 99

$I 3 P_{1}=12: 1$

ISKIP = JMMAXOIM •

IECS $=1-I$ ISIP

Dn $118 \quad 1=1.12$

IFCS $=$ IECS - ISKIP

CALL ECHR (ATOP(I•I), IECS, 1, IE)

118 CALL ECWR (CII,I). IECS*1.3. IE)

PRINT 7. IMAX - iC

$I \operatorname{MAX}^{P} I=I \operatorname{MAX} \bullet I$

If $\{$ MAXP\}. GT. 400$\}$ GO TO 109

DO $108 I=I M A X D I, \$ 00$

$C(1.1)=0.0$

$C(2,1)=-100$

$108(3.1)=0.0$

109 ATOP(1) $=0.0$ DO $10 I=1$ * I YAX

10 PRINT3, C(1,I), C(2,I), C(3,I), AT́P(I+1) Co 7049

135 CONPINUE

CALL ZZZ (XLAMARY. LARY. NSHELL. KPHIMAX, HNUVEC. NOP̈TS.

1 IHNUMAX, DHNUI, ZZZFACI

136 FORMAT $(1 / 1)$

PRINT 136

DO 137 KPHI 1 1 KPHIMAX

137 PRINT 133. XIAMARY (KPHI) LARY (KPHI) NSHELL(KPHI) -

PRINI 136

PRINT 3. (HNUVEC(IHNU), IHNU=1: IHNUHAX)

PRINT 136

DO 1 IS IHNU $=1$, IHNUMAX

138 ACOFVEC(IHNU) $=0 . \overline{1}$

$K W K_{B} M_{A X}=0$

DO $139 \mathrm{KPHI}=1$. KPHIMAX

KWKGMAX = KWKBMAX $\bullet 1$

NWKB (KWKBMAX) = NSHELL (KPHI)

LWKR (KWKBMAX) = 1000 (LARY (KPHİ) + 1$)$ - LARY(KPHI)

XLAMWKA $(K W K B H A X)=$ XLAMAPY (KPHY)

IF (LARY (XPHI) ELO. O) GO TO 139

$K_{W} K_{B M} M_{A X}=K_{W K A M A X}+1$

NWKA $(K W K B M A X)=$ NSHELL (KOHI)

LWKR (KWKBMAX) = 1000 (LARY (KPHi) - 1) - LARY(KPHI)

XLAHWKA (KWKBHAX) $=$ XLAMARY (KPHI)

139 CONTINUE

$K W K B=0$

$14 M I N=1$

$140 K_{W K}=K_{W K O} \cdot 1$

XLAMARY (I) $=$ XLAMWKB (KWKB)

DEGA

DEGA

DEGA

OEGA

DEGA

DEGA

DEGA

DEGA

DEGA

DEGA

DEGA

DEGA

DEGA

DEGA.

DEGA

DEga

DEGA

DEGA

DEGA

DEGA

DEGA

DEGA

DEGA

DEGA

DEGA

DEGA

DEGA

DEGA

DEGA

DEGA

DEGA

DEGA

DEGA

DEGA

DEgA

DEGA

DEGA

DEGA

DEGA

DEgA

DEGA

DEGA

DEGA

DEGA

DEGA

DEGA

DEGA

DEGA

DEGA

DEGA

DEGA

DEGA

DEGA

DEGA

DEGA

DEGA

DEGA

DEGA

DEGA

00189

00090

00091

00092

00093

00094

00095

00096

00097

00098

00099

00100

00101

00102

00103

00104

00105

00106

00107

00108

00109

00110

00111

00112

00113

00114

00115

00116

00117

00118

00119

00120

00121

00122

00123

00124

00125 
HSHELL $(1)=$ NAKB $\{K H K B\}$

DEGA

LPOS * LWKE (KAKB)/1000

DEGA

LAPY $(1)=$ LWKB $(K W K B)-\angle 0051000$

141 IF $(1.0000001$ ABS (XLAMARY II) . LT. HNUVFC (IAMIN) GO TO 142

DEGA

I4MIN $=$ I4MIN *I

Gก TO 141

142 I MAX IHNUMAX

MNMAX $=0$

DO $143 \quad I 4=I 4 M Y N, I 4 M A X$

MNHAX $=$ MNMAX +1

MNMAXPL = MNHAX * i

MM(MNMAX) $=1$

NN(M(NMAX) $=$ MVMAXP1

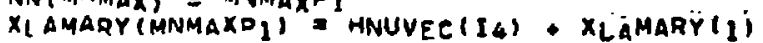

LARY (MNMAXPI) = LPOS

143 NSHELL, YNMAXP1) $=0$

LARY (MNYAXP1 $: 11=-2$

KPHIMAX $=0$

49 CONTINUE

KPHIMPI = KPHIMAX - 1

$L \approx$ LAPY (KPHI YPI)

IFIL.$E O$. - I) GO TO 135

IF $1 L . E Q .-2\}$ GO TO 99

METHUD $=2$

IF :XLAMARY (KPHIMPII LT

$X L=L$

$x L L P 1=L *(L \bullet 1)$

$X L L 4]=X L *(X L-1,0)$

TWOXL $=2,0 * \times L$

$L M 2=L-2$

$L M !=L-1$

$L P 1=L * 1$

$X P_{1}=L P L$

IF (METHOO :EQ. 1 ) GO TO 107

XLAMEDA $=$ XLAYARY (KPHIMP 1$)$

SMALLK = SORT (XLAMAOA)

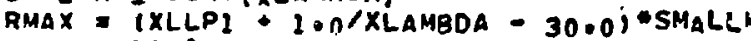

RTMD $=10.0 / X$ LAMBOA

IF (RTMP .GT. TMAX) AMAX = KTMP

IF (ATOP $(I 2+1)$, GT. RMAX) RMAX $=1$. I5*ATOP $(12+1)$

IF (RMAX IT. 1.01) RMAX $=1.01$

60 to 122

146 AMAX $=1$. 2*RMAX

IERROR $=0$

Gก To 110

$107 \triangle A R O D T(1)=0.0$

$\triangle R O O !(?)=0.0$

$\ln _{4} A=12+1$

aTOP $(\operatorname{IMAX}+1)=1000 \cdot 0$

CALL ROOTUIVIXLAMARY KKPHIMPI), XLLD̈, aRONT, ICNTR, ICNTD, ICASE.

1 IERROR, II

PRINI 3. KLAHARY (KPHIMP 1 , AROOT $j$, AROOT(Z)

IF IIERROR. EO. O) GO TO 151

PRINT 152. JEFROR

152 FORMATII5: RMAX SET TO 1.1 ATOP $(12 * 1) * 1$.

IERROR $=0$

$R M \Delta X=1.1 * A T O P(12+1)$

Go TO 122

151 RMAX = ARODT 2 (2)

IF (AROOT (d) - GT. RMAX) RHAX = AROOT (I)

QMAX = RMAXFAC RMAX

IF (RMAX .LT. 1.91*ATOP(I2+1) RMAX $=1 . n 1 * A T O P\{I 2+1\}$

DEGA

DEGA

DEGA

DEGA

DEGA

DEGA

DEGA

DEGA

DEGA

DEGA

DEGA

DEGA

DEGA

DEGA

DEGA

DEGA

DEGA

DEGA

DEGA

DEGA

DEGA

DEGA

DEGA

DEGA

DEGA

DEGA

DEGA

DEGA

DEGA

DEGA

DEGA

DEGA

DEGA

DEGA

DEGA

DEGA

DEGA

DEGA

DEGA

DEGA

OEGA

DEGA

OEGA

DEGA

OEGA

DEGA

DEGA

DEGA

DEGA

DEGA

DEGA

DEGA

DEGA

OEGA

DEGA

DEGA

DEGA

DEGA 
PRINT 153. RMAX

153 FRRMATIO RMAX = E E20.10)

122 IMAX $=I 2$

$110 D Q=A T O P F A C * A T O P(I M A X+1)$

RTMDE $\triangle T O P(I 4 A X$ * I)

SMALLK = SURTIABS (XLAMARY (KPHIMPI) + (200-XLLPI/ZTMPI/RTMP))

RTMP = ATOP (I YAX+1)* $5 *(A T O P(I M A X+2)=\triangle T O P(I M A X) I=$

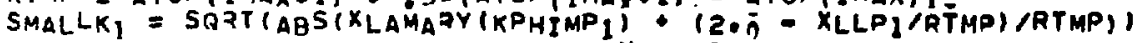

IF (SMALLKI -GT. SMALLK) SMALLK = SMALLKI

DRMAX $=6.28 /$ SHALLK

IF (OR GT: DRMAXI OR = DRMAX

$I H \Delta X=I \operatorname{MAX} \cdot 1$

ATOP $(I M A X+1)=A T O P(I M A X)$ - OR

IFIIMAX EQ. 400 I 124,123

124 PRINT 125

125 FORMATIO Go ró 999

400 INTERVALS WILL NOT SPAN iORAMAX) is

123 If $\triangle$ TOP $(I M A X+1) . G E \cdot$ RMAX) 111: 110

111 ATOP $($ IMAX+1) = RMAX

$C A P R=$ RMAX

ATOPTHP I ATOD(IMAX * I)

$A T O D(1 M A X+1)=$ CAPR

GO TU $(6 B, 69)$. METHOD

$6 B$ NODIV = NODIVVG

NONIVPI $=$ NODIV +1

$A \times L A M B(1)=X L A M F C 1$ OXLAMAPY IXPHIMP1)

AXLAMB (VODIVEI) = XLAMFC? XLAMARY (KPHIMPI)

DAXLAMB = ABS (ALOG (ABS (AXLAMB (1) I))

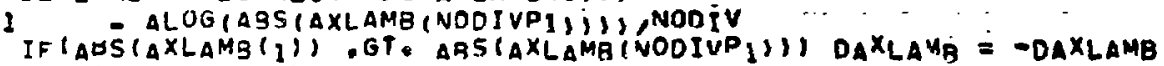
DO $60 \mathrm{O} I \pm 2, N O 2 I V$

$\left.60 A_{X L A M B} I\right)=-E_{X}$ (ALOG (ABS (AXLAMA $\left.(1.1)\right)$ + DAXLAMB)

$X L A M B O A=A X L A M B(1)$

Gก $70 \quad 70$

69 TEMDLAM $=$ XLAYBDA

NODIV $=4$ S NOOIVP $=$ NOOIV $+i$

AXLAMBIII $=0.0$ S OXLAM $=$ PI 140

DO $71 \quad l=1$, NODIV

$71 \triangle X L A^{M} B(I+\mid)=A X L A M B(I)$ DXLAM

CALL CARSONIXLAMRDAO C $(2$.IMAX). MFAC, CAPR, XLLPI.

1 CAPF, CAOFP, THETA, THETAP, IERROR)

IF(IERROR .EQ. I2) GO TO 146

70 CONT INUE

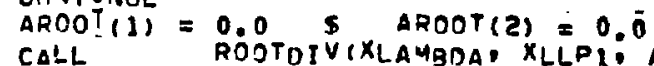

CALL

1 IERROR, 0 )

PRIN! 3. XLAMBDA, AROOT (1), AROOT (5)

JZSSET $=1$

80 JPSFST $=1$

J2SMIN $=$ JZSSET

JPSMAX = NOOIVPI

GO TO 90

81 Jว5FST $=2$

JP5YIN $=$ NOOIVPI +1

JP5MAX = NODIVPI 20

D25 = (XLAMST $-X L A M S T T) / 19,0$

$A X L A M B(J 25 M I V)=X L A M S T T$

$A X L A M B(J 25 M A X)=X L A M S T P$

$I 794 I N=J 254 I N+1$

$179 M 4 X=J 254 A X-1$

DO 74 I I

79 AXLAMB I I9) = AXLAMB I I - 1). D25

AROOT. ICNTR. ICNT̃D. ICASE. 
90 Do $25 \mathrm{~J}=\mathrm{J} 25 \mathrm{YIN}, \mathrm{J} 25 \mathrm{MAX} \ldots \ldots \ldots \ldots$

XLAMSTP = AXLAMB (J) DEGA

CALL TAYLORF (XL, XLAMSTD. IERROR̈, AFO JMAXF, IMAXF, CF, ATOPF) DEGA

IQKW $=$ IMAXFPI +1

CALL TAYLORB(XL, XLAMSTD, IERROR, AB(I: IAKW).

1 JHAXH(IBKW), IMAXBQ CB(I.IBKW): ATOPA (IBKW)

CALL ROUNDRY IFCONV, FBSTP,

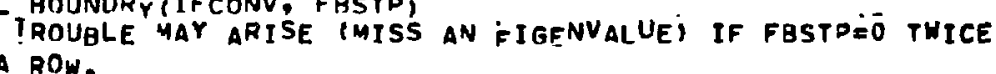

DEGA

DEGA

DEGA

DEGA

DEGA

IN A ROW.

IF (IFCONV EQ. 1) 73,74

73 CAPLAMA = XLAMSTP

Go to 75

74 IF (J,EA. J25MIN) 26,27

27 IF IFHSTT OFBSTP. LE, $0.0128,26$

28 XLAMMIO $=.5 \%$ IXLAMSTP XLAMSTF';

CALL YAYLOAFIXL, XLAMMIO, IERROR, AF, JMAXF, IMAXF, CF, ATOPF,

IAKW = IMAXFPI + 1

CALL TAYLORB(XL, XLAMMID. IERROŔ, AB (1:IBKW).

1 JMAX 1 (IBKW). IMAXB,CB(1,IBKW;, AFOPB(IBKW),

CALL BOUNUAYIIFCONV, FBMID)

IF (FHSTT ET. FBSTP) 29,30

29 FATOP $=$ FBSTT 5 FBAOT $=$ FBSTP S 60 TO 31

3O FBTOP = FBSTP S FBBOT = FBSTT

3 IF (FBTOF - GT. FBMID) -AND. (FBMIO .GT. FRBOTI) 32.57

DEGA

DEGA

DEGA

DEGA

DEGA

DEGA

DEGA

DEGA

DEGA

DEGA

DEGA

DEGA

DEGA

DEGA

DEGA

DEGA

DEGA

OEGA

DEGA

PRINT 58

PRINT $\mathbf{5 9}$

PRINT 58

PRIN! 58

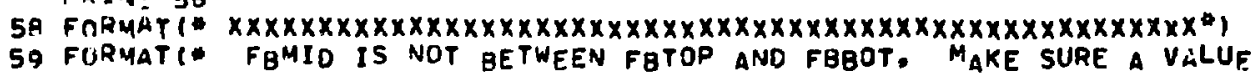

1 OF LAMBDA WAS NOT MISSED.*I

60 TO 87

$32 X_{L A M H O}=X_{L A Y S T T}$ S XLAMBI $=X_{L A M S T \dot{P}}$

FRO = FRSTT S FBI = FBSTP

DEGA

DEgA

DEGA

DEGA

DEGA

DEGA

DEGA

DEGA

DEGA

DEGA REGULA DDES NOTT CHECK STARILITY CONOTTIONS.

CALL REGULA (XLAMBO,XLAMBI FBO FRI CAPLAMR,MAXITER,XL̈, IERROR)

DEGA

DEGA

DEGA

DEGA

IF (IERROR. NE. O) GO TO A7

IF (XLAMSTT OLT. XLAMSTP) GO TO 105

XLAYBO = XLAMSTP

DEGA

DEGA

$X$ LAMB $_{1}=$ XLAMST T

DEGA

60 TO 104

$105 \times$ X AMBO $=$ XLAMSTT

$X_{L A M B I}=$ XLAYSTP

104 IF (XLAMBO .LE. CAPLAMB.AND. CAPLAMB.LE. XLAMBI) 75; 86

BG PAINT 58

PRINIT 58

ORINT 88

88 FORMATI CAPLAMB IS NOT BETHEEN XI'AMSTTt aND XLAMSTË. XlaMSTT. Ca

IPL AMU. AND XLAMSTP ARE OI

PRINT 3. XLAMSTT, CAPLAMB, XLAMSTP

PRINT 58

PRINT 58

87 IF IJZJFFST EQ. $11 \mathrm{BZ}, \mathrm{BH}$

$82 \mathrm{JPSSET}=\mathrm{J}$

PAINI 83

B3 FORMATI DIVIDE THIS INTERVAL INTO 19 ERUAL INTERVALS AND TRY AGA

$1 I N \cdot * 1$

PRINI $5 B$

DEGA

DEGA

DEGA

DEGA

DEGA

DEGA

DEGA

00250

00251

00252

00253

00254

00255

00256

00257

00258

00559

00260

00261

00262

00263

00264

00265

00266

00267

00268

00369

00270

00271

00272

$00>73$

00274

00275

00276

00277

00278

00279

00280

00281

00282

00253

00284

00285

00286

00287

$0 \cap 288$

00299

$00>90$

00291

00292

00 ? 93

00294

00295

00296

00297

00298

00299

00300

00301

00302

DEGA

00303

00304

00305

00306

00307

OOJOA

00309

00310

DEGA

00311 
PRINT $58 \ldots \ldots \quad \ldots \ldots+\ldots \ldots$

GO TO BI
DEGA

00322

B4 PRINT 25

85 FRRMĀTIO THIS INTERVAL FAILED FOR THE SECOND TIME. FORGET IT AND

1 GO TO THE NEXT INTERVAL. I)

PRINT 58

PRINT 58

GO TO 80

75 GO TO $(65,66)$, METHOD

66 ALPHA $=$ CAPLAMB S CAPLAMB $=X L{ }_{A} M B$

PRINT 67. ALPHA, CAPLAMB

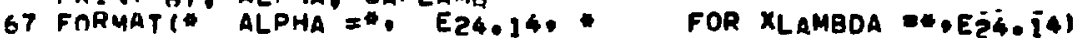

DEGA

00313

00314

00315

00316

00317

00318

DEGA

DEGA

DEGA

DEGA

00319

00320

00321 $\begin{array}{llll}G O & \text { TO } & 127\end{array}$

65 CONTINUE

IVI $=0$

$D=A T O P F(Z)$

DLP1 1 DE LP $_{1}$

JMAXHOT $=$ JMAXF $(1)=1$

PDUM $(1)=A F(1,2) / O L P I$

DEGA

DEGA

DEGA

DEGA

OEGA

DEGA

DEGA

DEGA

DEGA

$\operatorname{PDUM}(2)=\mid A F(2,2)-X L P 1 \in A F(1,2, / D) / D L P\}$

CALL STURMSOIAF(2+j). JMAXBOT, PDUM, D. IVZP IERROR)

DEGA

DEGA

IVI $=$ IVI + IVZ

IFIIMAXF,EQ, 1$) 60$ TO 98

DO QI IF $=2$, I YAXF

$D=A T O D F(I F+1)-\triangle T O P F(I F)$

CALL STURMSQ (AF (1,IF), JMAXF (IF), AF (1;IF+1), D, IVZ: IERROR)

91 IVI $=$ IVI + IV2

98 CNNTINUE

DO $95 I A=1$, I HAXB

IBKW = IMAXFPI $*$ IB

$D=A T O P B$ (IBKN + I) - ATOPB (IBKW)

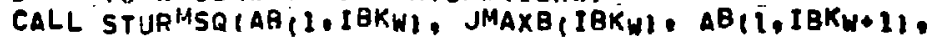

DEGA

DEGA

DEGA

DEGA

DEGA

DEGA

DEGA

DEGA

DEGA

DEGA

1 D, IVZ, IERRORI

DEGA

DEGA

DEGA

DEGA

PRINI IS8, IVI

128 FORMATI THIS WAVE FUNCTION HAS* I5. "CROSSINGS."I

I2T IBKW = TMAXFPI - IMAXBPI

$F A C=A 5(1, I B K W) / A F(1,14 A X F P L)$

DO $33 \quad I=1$, I HAXF

JJJ $=\operatorname{JMAXF}(\mathrm{T})$

DO $33 \mathrm{JF}=1$, JJJ

DEGA

DEGA

DEGA

DEGA

DEGA

DEGA

DEGA

DEGA

DEGA

IF (CAPLAMB .LT. O.0) CALL NORMDHI (CAPLAMB, L)

PRINT 3. CAPLAMB

KDHIMAX = KPHIMAX + 1

GO TO $(129,130)$. METHOD

129 IVILI $=$ IVI $\bullet$ L 1

IF (NSHELL(KPHIMAX) .EQ. PVILI) GO TO 154

IVI $=$ NSHELL $($ XPHIMAX) $-i=1$

KPHIMAX $=$ KPHIMAX -1

PRINT 134, IVI

136 FOHMATIG THE PREVIOUS WAVE FUNCTION SHOULO HAVE HAD", IS.

1 CROSSINGS. $\%$ FORGET THE LAST EIGENUALUE AND TRY SOMEMORE. Go TO 26

154 IRKW $=$ IMAXFPI 1

PHIMIN9 = ABS (AU $(1, I B K H))$

PHIMAX9 = PHIMING

IF (TMAXB EQE. II GO TO 155

Do 156 IB=2, IMAXB

$I B K H=I M A X F D_{1}+I B$

PHIQ $=A B S(A B(1, I B K W))$

If (DHIQ.GT. PH!MAX9) PHIMAX9 I PHIT

DEGA

DEGA

DEGA

DEGA

DEGA

DEGA

DEGA

DEGA

DEGA

DEGA

DEGA

DEGA

DEGA

DEGA

DEGA

DEGA

DEGA

DEGA

00322

00323

00324

00325

00326

00327

00328

00329

00330

00331

00332

00333

00334

00335

00336

00337

00338

00339

00340

00341

00342

00343

00344

00345

00.346

00347

0034 A

00349

00350

00351

00352

00353

00354

00355

00356

00357

00358

00359

00360

00361

00362

00364

00365

00366

0036 ?

00368

00369

00370

00371

DEGA

00373 
ISG CONTINUE

155 DO 157 IF=1. IMAXF

PHIQ $=$ ABSIAF (1, If) )

IF (PHIQ -GT. PHIMAX9) PHIMAX9: PHI9

157 CONTINUE

\section{PRINT 158, PHIMAX9. PHIMIN9}

15. FORMATI PHI MAX AND MIN ARE: ZE20.10) IF (PHIMINO LT. PHYYAX9GEPHI) GO TO IJT PRINT 159

159 FORMATI RMAX IS NOT BIG ENOUGH'; KDHIMAX = KPHIMAX - I GO TO 146

130 NSHELL (KHPIMAX) $=$ D

131 IMAXARY (KPHIMAX) = IMAX

XLAMARY (KPHIMAX) = CAPLAMB LARY (KPHIMAX) $=L$ IF(CAPLAMH .LT. 0.0) 112, 113

112 ALFAARY (KPHI YAX) $=0.0$ GO TO 114

113 ALFAARY (KPHIMAX) = ALPHA

124 CONTINIJE JMAXS(1) = J4AXF(1)

DO $115 I=1$, IMAXF

$A M I S(I)=A F(I, I)$

1 I5 AMZS I $)=A F(2, I)$

$I C=I M A X B P I$

$I D=I$ MAXF

On $116 \quad I=1$. IMAXE

$I C=I C-I$

In $=I D+1$

$I B K_{W}=I M A X F P I+I C$

$A M I S(I D)=A B(I . I B K W)$

$\triangle M Z S(I D)=\triangle B(2, I B K W)$

OEGA

00375

DEGA 0C377

DEgA 0037E

DEGA 00379

DEGA $003 \mathrm{AO}$

DEGA 0038 I

DEGA 00382

DEGA $003 B 3$

DEGA OOJAG

DEGA 00385

DEGA $003 B 6$

DEGA 00387

DEGA 00388

DEGA 00380

DEGA 00390

DEGA 00391

DEGA 00392

DEGA 00393

DEGA 00394

DEGA 00395

DEGA 00396

DEGA DO 0397

DEGA 00398

DEGA 00399

DEGA 00400

DEGA 004BI

DEGA OO\$DZ

DEGA $00_{43}$

DEGA 00404

DEGA 00405

DEGA 00406

$116 J M A_{X} S(I 0)=J A_{X} B\left(I B K_{W}\right)$ DO $117 I=2$, IMAXFPI

$217 \operatorname{JMAXS}(I)=0$

IMAXBF $=$ IMAXB +IMAXF

IFCS = KPHIMAX * 4

$\left.I E C_{5}\right\rfloor=I E C S * M_{A} \times D I M$

IECSL = IECSI + MAXOIM

CALL ECWR (JMAXSII), IECS, 1, IE)

CALL ECWR (AMISII), IECSI. I, IE)

CALL ECWR (AMZS(1), IECS2, 1, IE)

DO $121 \mathrm{I}=3$, I2PI

IFCS = IECS $\bullet$ ISKIP

IECSI = IECS MAXDIM

IECS2 = IECS1 - MAXDIM

CALL ECWR (JMAXSPI). IECS. 1. IE)

CALL ECWR (AMISII), IECSI, 1, IE)

121 CALL ECWR (AMZS(I), IECS?, I. IE)

IF (IMAX $E Q$. I I) GD TO 126

IECS $=401400-I 21$

$I E C S=I E C S *(K P H I M A X-1) \cdot 1$

IFCS = IECS $+I Z$ ISKIP

I JUMP $=400-12$

INUM $=$ IMAX $-I 2$

$I>P 2=I 2+2$

CALL ECWR IATOP,IZP2), IECS, INIM, IE)

IECS = IECS + IJUMP

CALL ECWR (JMAXS IIZPZ), IECS, INIJM, IEI

DEGA

DEGA

DEGA

DEGA

DEGA

DEGA

DEGA

DEGA

DEGA

DEGA

DEGA

DEGA

DEGA

DEGA

DEGA

DEGA

DEGA

DEGA

DEGA

DEGA

DEGA

DEGA

DEGA

DEGA

DEGA

DEGA

DEGA

00407

00408

$00 \$ 09$

00410

00411

00413

00413

00414

00415

00416

00417

0041 a

00419

00420

00421

00422

00423

00424

00425

00426

00427

IECS = IECS * I JUMP

CALL E.CWR (AMIS(IZPZ), IECS, INUM, IE)

DEGA

DEGA 


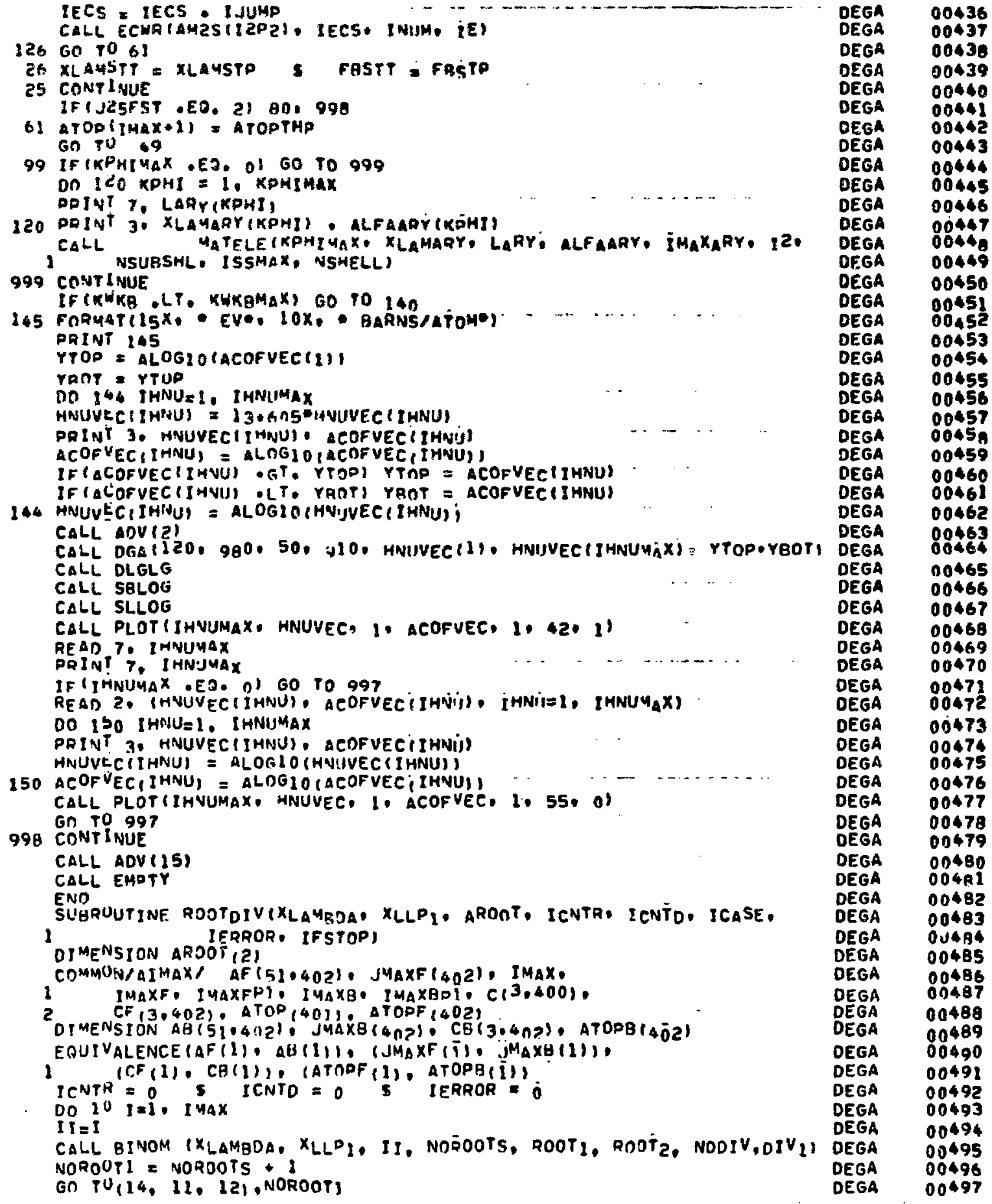




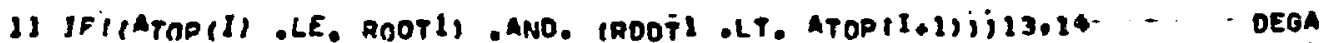

13 ICNTR = ICNTR - I AROOI (TCNTA) = ROOTI

IF ICNTR.EO. 2) 15, It

I2 IFIRUOTl ILT. ROOT2I 2 B, 27

27 TEMP = ROUTI S ROOTI ROOT2 S RONT2 = TEMO

ZQ IFI(ATOPII) -LE. ROOTI) -AND.IROOTI -LT. ATOPII*IIIIIG.IT

is ICNTK = ICNTZ AROOT (ICNTR) E ROOTI

IFIICNTA EO. 2IIS. 17

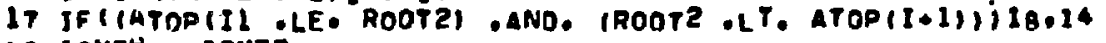

IA ICNTH = ICNTR AROOTIICNTAI = AOOTZ IF IICNTR EQ, 2,15, 14

DEGA

OEGA

OEGA

DEGA

DEGA

DEGA

DEGA

DEGA

DEGA

15 IF IISNTD. EO, 1,19.20

DEGA

20 IF (NUDIV EO. 1121, 19

DEGA

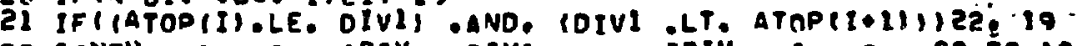

$22 I C N T U=15 \triangle D I V=$ OIVI $\$$ IOIV $=1$ S GJ TO 19

14 IFIICNTD OEO. 1110.23

23 JFINUOUIV EEQ 1/24, 10

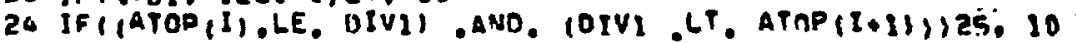

25 ICNTU $=1$ S ADIV = DIVI 5 IOIV $=1$

10 CoNTINUE

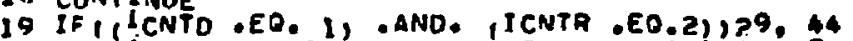

Q IF (IICNTD - EJ.1) . AND. (ICNTR -EO. OS) 45 . 26

45 ICASE $=5$ S 60 TO 31

29 ICASE $=6$

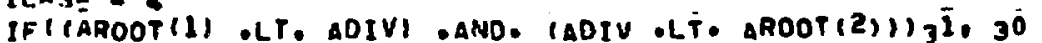

30 IERAOR $=2$ DAINT

?. FRAMATI- IERROR=Z, ICASE*4. MAX IS NOT BETHEEN THE TOW ROOTS, 1 RETURN

26 IF ( ICNTD,EQ, O).AND, ICNTA,EQ, 01,34, 35

34 ICASE $=1$ \& IOIV = IMAX

ADIV $=(A T O P(I M A X)$ ATOS(IMAX+2); 2.0 GO TO 31

35 IF (IICNTD .EO. O). AND. IICNTR .EQ. 1)I37.40

DEGA

DEGA

DEGA

DEGA

DEGA

DEGA

DEGA

DEGA

DEGA

DEGA

OEGA

DEGA

DE.GA

DEGA

OEGA

DEGA

DEGA

DEGA

DEGA

DEGA

DEGA

DEGA

DEGA

IF (XLLP I .LT. .25) 47.46

47 IMAXPI $=$ IMAX 1

on $4 \mathrm{Y} I=2$, IMAXPI

IF (AROOTII) LT. ATOPII) 49,48

49 InIV $=1-1$

ADIV = AROOT(I)

GO TO 31

$4 B$ CONTINUE

IDIV = IMAX

GO TO 38

$4610 I_{V}=I M A X$

IF (AROOTII) ILT. ATOP $(I M A X)) 38,39$

3E AOIV = (ATOP (IMAX) - ATOO(IMAX+1) $1,2.0$ Gก TO 31

39 ADIV $=($ AHOOT $(1)+\operatorname{ATOP}(I M A X+1) i / 2.0$

Go TO 31

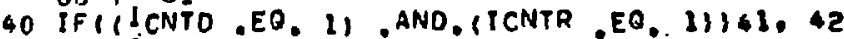

42 IFRROR $=1$

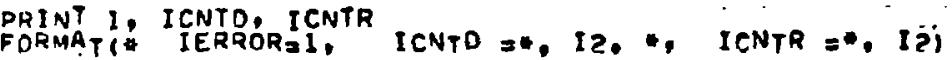
RETUKN

41 I CASE $=3$ IF(AKONTII) .LT. ADIV) 3I. 43

43 IEPROR $=3$

DEGA

DEGA

DEGA

DEGA

DEGA

DEGA

DEGA

DEGA

DEGA

DEGA

DEGA

DEGA

DEGA

OEGA

DEGA

OEGA

OEGA

DEGA

DEGA

OEGA

DEGA

DEGA

00519

00520

00521

00522

00523

005 है

00525

00526

00527

00528

00529

00530

00531

00532

06533

00536

00535

00536

00537

00538

00539

00540

00541

00542

00543

00544

00545

00546

00547

00548

00549

00550

00551

00552

00553

00554

00555

00556

00557

00558

00559 
PRINT 3. AROOT(I) ADIV

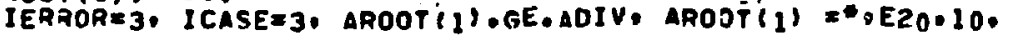
RETUAN

- ADIV $=*$ E20,101

31 IF I IF STOP.EQ. II RETURN

IMAXF = IDIV S IMAXFOI = IMAXF + I

IMAX I IMAX - I - IOIV S IMAXRPI $\doteq$ IMAXB

DO $32 I=1$ : IMAXF

ATOPF $(I)=A T O P(I)$

$C F(1, I)=C(1, I)$ S $C F(2, I)=C(2, I)$

$32 \mathrm{CF}(3.1)=C(3.1)$

ATODF (IMAXFPI) = ADIV

II $=$ IMAX $* 1$ S III $=I$ MAX $\bullet 2$

$003^{3} I=1$ * $I 4 A \times B$

III $=1 I I-1$

$I_{A K}=I$ IMAXFPl +1

ATOPH (IEKW) = ATOP(III)

$I I=I I-I$

$C P(1 \cdot I B K H)=C(I, I I) \quad$ \& $C B(2, I B K H)=C(2, I I)$

$33 \mathrm{CB}(3 \cdot I R K W)=C(3, I I)$

IAKW = IMAXFDI + \{HAXBPI

$\triangle T O P B(I B K W)=A D I V$

RETUHN

END

SUBROUTINE BI VOMIXLAMBDA, XLLPI, I. NOROOTS, RDOTI, ROOTZ,

1 NODIY, DIVI)

COMMON/AIMAX, AF (51,4C2), JMAXF (4R̈2), IMAX.

1 IMAXF. I YAXFPI. IMAXA. IMAXAPI: C(3.400).

2 CF $(3,402)$. ATOD $(401)$. $\triangle T O P F(4 R 2)$

DIMEINSION AB (51,402), J4AXB(40), CB(3,402), ATOPB (40̈2)

EQUIVALENCE (AFI), $A B(1)$ : $\left(J M_{A} \times F(F), j M_{A} \times B(1)\right)$.

1 (CF (1), CB(1)), (ATOPF (1), ATOPB(1))

$B_{1}=-(2,0 * C(3,1) * X L L P 1)$

$B 2=-2 \cdot 0 * C(\varepsilon, I)$

B3 $=$ XLAMBDA $-2.00 \mathrm{C}(1.5)$

ARSAL $=A B S(91)$

IF (AUSA

2 IF IABSBI $: L T$.
1 ROOTI

NOROOTS $=1$

NODIV $=0$

60 YO

3 RAD $=B 2 * 12-4.0 * B 1 * 83$

TWnQL $=2.0 * \mathrm{~B} 1$

NODIV $=1$

DI $V_{1}=-T W O_{B 1} / B 2$

IFIRAD .LT. 0.014.5

4 NOROOTS $=0$

60 TO 6

5 NOROOTS $=2$

$R A D=$ SPRT (RAD)

$T 1=\triangle A S(T H O B)$

$T 2=A B S(B 2 \cdot$ RAD

IFIT2. LT. TI*1.OE-20I 7,

9 FORMATI I5, 3520.10. XXXX:日)

$711=1$

PDINI 90 II, THOBI, B2, RAD

ROOTI $=1.0$ E 100

Gn TO 10

8 CONTINIIE

ROOT $1=-T W O B 1 /(B Z$ - RAD)

$10 \mathrm{Tl}=$ ABS (THOSI)

00562

00563

00564

DEGA

DEGA

DEGA

00565

00566

00567

DEGA

DEGA

00568

00569

DEGA

DEGA

DEGA

90570

00571

00572

00573

00574

DEGA

DEGA

DEGA

00575

00576

DEGA 00577

DEGA

00578

DEGA

DEGA

DEGA

00579

005BO

DEGA

00581

00582

DEGA

DEGA

DEGA

DEGA

DEGA

DEGA

DEGA

DEGA

DEGA

DEGA

DEGA

DEGA

DEGA

DEGA

DEGA

DEGA

DEGA

DEGA

DEGA

DEGA

DEGA

DEGA

DEGA

DEGA

DEGA

DEGA

DEGA

DEGA

DEGA

DEGA

DEGA

DEGA

DEGA

DEGA

DEGA

DEGA

DEGA

00583

00584

00585

00586

00587

00588

00589

00590

00591

00592

00593

00594

00595

00596

00597

00598

00599

00600

00601

0060 ?

00603

00604

00605

00606

00607

00608

00609

00610

00611

00612

00613

00614

00615

006l6

00617

00618

00619

DEGA

00620

DEGA

00621 
$T_{2}=A B S(-B Z+R A D)$

IF (T⿱ $\left.T^{2} \cdot L T, T I * I, D E-20\right) 11.12$

DEGA

DEGA

DEGA

PRINTT $T^{2}, I_{1}$, TWOBI, B2, RAD

DEGA

ROOT2 $=1.0 E 100$

go to 6

12 CONTINUE

ROOTZ = TWOB $1 /(-B Z+$ RAD $)$

6 RETURN

END

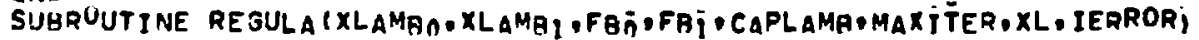
COMYON/AIMAX/ AF (51,402), JHAXF (402), IHAX.

1 IMAXF, I YAXFPI, IMAXB, IMAXBPI, $(3,3,600)$.

2 CF $(3.402), \triangle T O P(40) 1$. ATOPF (402)

DIMENSION $A B(51,402)$. JMAXB(40?), CB(3,40?). ATOPB (40̈)

EDUIVALENCE (AF $(1)$, AB $(1)),(J M A X F(i)$, JMAXB(1)),

1 (CF (1), CB(1)), (ATOPF (1), ATOPB(1)

COMMON/EPS/ EDSLONV. FBMAX

1 FORMAT (2E24.14, 4E20.10)

IERQOR $=0$

DO 14 ITER $=1$. MAXITER

IF (FHI EO, FAO) 20,21

20 IRKW $=$ IMAXFP 1 IMAXBP,

$A F A C=A A(I, I 3 K W) / A F\left(1, I H_{A} \times F P I\right) * A F(2, I M A X F P I)$

DEGA

DEGA

DEGA

DEGA

DEGA

DEGA

DEGA

DEGA

DEGA

DEGA

DEGA

DEGA

DEGA

DEGA

DEGA

DEGA

DEGA

DEGA

DEGA

FPOUNOC = FBOJND/ABS (AFAC)

CAPLAMA $\left.=.5 *\left(X L_{\triangle M} M^{*}\right)+X L_{A M B O}\right)$

PRINT 22

PRINT 22

PRINT 23. FBOUNDC, EPSCONY

PAINT 24, CAPLAMB, XLAMBI, XLAMBO

PRINT 22

PRI VI 25

RET UAN

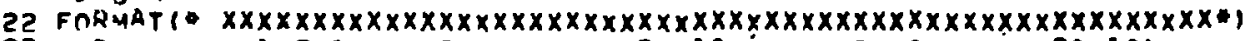

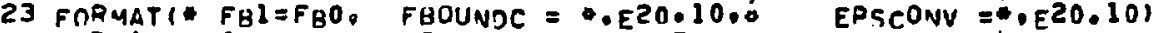

24 FOAMAT 10 CAPLAMB $=0 . E 24,14,4 \mathrm{H}=\left(. E 24.14,2^{H}, . E 24.14,4 \mathrm{H}, 1 / 2\right)$

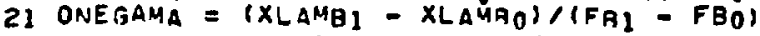

$X L A M B 2=X L A M B 1-$ ONEGAMA FBI

. IF (XLAMBZ.EO. XLAMB 1. OQ.XLAMBZ,FO,XIAMBÖ) 90 TO 15

CALL PAYLORF IXL, XLAMBZ, IERROR, AF, JMAXF, IMAXF, CF, ATOPFI

IF IIERROR - NE. O) RETUAN

IRK $=$ IMAXFDI +1

CALL TAYLORB IXL, XLAMBZ, IERROA, AB (I.IBKW).

1 JMAXH(IBKW), IMAXB, CB(1,IBKW). ATOPA (IBKW)

IFIIERROR - NE O OI RETURN

COLL BOUNDRY (IFCONV. FROUND)

IFIIFCONV EO. I) 15,16

15 CAPLAMB = XLAYB? S RETURN

16 IF(ABS(FBOUND) GT. FBMAX) 17, 19

17 IFRROR $=7$

PRINT 7

7 FORMATT IE IERQOR $=7$ FROUND \&GT. FBMAX*)

RETUHN

$19 X_{L A M B O}=X_{L A M B I}$ \& $X X_{L A M B I}=X L A M B Z$

$F R O=F B I$

$14 F R I=F B O U N D$

IFARUR $=B$

PRINT B: MAXITER

O FORMAT ( DROBLEM DOES NOT CONVERGE WITHIN* I5O ITERATIONSE)

RETUKN

END

SUGROUTINE TAYLORF IXL, ALPHLAM: IER̈ROR, A, JMAX, IYAX, C, ATOPI

DEGA

DEGA

DEGA

DEGA

DEGA

DEGA

DEGA

DEGA

DEGA

DEGA

DEGA

DEGA

DEGA

DEGA

DEGA

DEGA

DEGA

DEGA

DEGA

$D E_{G A}$

DEGA

DEGA

DEGA

DEGA

DEGA

DEGA

DEGA

DEGA

DEGA

DEGA

DEGA

DF.GA

DEGA

DEGA

DEGA

DEGA

DEGA

00622

00623

00624

00625

00626

00627

0068B

00629

00630

00631

00632

00633

00634

00635

00636

00637

00638

00639

00640

00641

00642

00643

00644

00645

00646

00647

00648

00649

00650

00651

00652

00653

00654

00655

00656

00657

00658

00659

00660

00661

00662

00663

00664

00665

00566

00667

00668

00669

00670

00671

00672

00673

00674

00675

00676

00677

00678

00679

00680

00681

00682

00683 


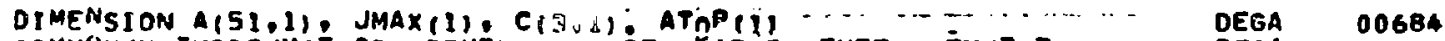
COMUONAMETHOOS/METHOD. TEMPLAM, CAPF, FAPFP. THETA. THETAP DO DEG CAMMUN/EPS/EPSCONV, FBMAX, EMLG DEGA OOGAG Gก TO (60, 61), METHOD $\quad$ DEGA OOGB7

60 XLAMBDA = ALPHLAM GO TO 62

61 ALPHA $=$ ALPHLAM

XLAMB̂OA = TEMDLAM

62 CONTINUE $0030 I=1$. IMAX

30 JMAX $|I|=0$ IFRQOR $=0$ $D=A T O D(2)$

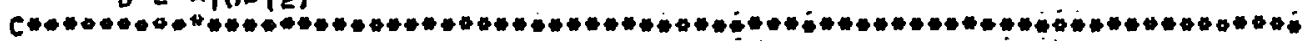

C PHI $(0)=0$ HHEZE PHI (R) IS THE EIGENFUNCT INN.

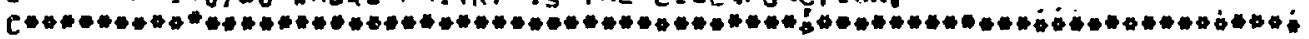
$A, 1,1,=0,0$

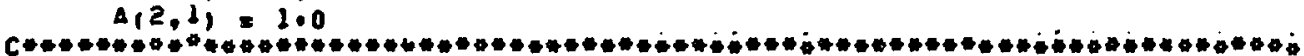

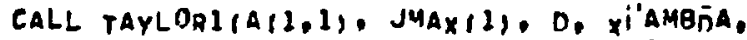

$1 X L, C(2,1),(12,1), E M 16$, IERROR IF (IERROR . EO. 9) RETURN $R D=A T O P(2)$

CALL POLYOP(A $(1,1)$. JMAXI1), RR. Di $A(1,2)=P \& R * X L$

CALL POLYIP(A(1,1), JMAX (1), RR, DFRIVṔ)

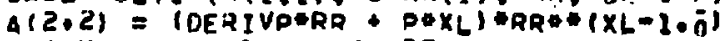

IFIIMAX.EQ. II GO TO 37

IBOT $=2$

go TO 50

ENTAY TAYLORB

De $54 t=1$. I HAX

54 JMAXII) $=0$

Gn TO $(65,65)$, METHOD

$65 \times L A 4 B D A=A L P H L A M$

Gก TO 67

66 ALPHA = ALPHLAM

XLAYUDA = TEMPLAM

67 CONT INUE

IFRROR $=0$

IFOT $=1$

DEGA OOGBB

DEGA 00689

DEGA 00690

DEGA 00691

DEGA 00692

DEGA 00693

DEGA 00694

DEGA 00695

DEGA 00696

DEGA 00697

DEGA OOG98

DEGA 00699

DEgA 00700

DEGA 00701

OEGA 00702

00702
00703

$\begin{array}{ll}\text { DEGA } & 00704 \\ \text { DEGA } & 00705\end{array}$

DEgA DOTnE

DEGA 00707

DEGA 00708

DEGA 00709

DEGA 00710

DEGA 00711

DEGA 00712

DEGA 00713

DEGA 00714

DEGA 0O715

DEGA 00716

DEGA 00717

DEGA - 00718

DEGA 00719

DEGA 00720

DEGA 00721

DEGA OOF̈22

DEGA 00723

DEGA 00724

DEGA 00725

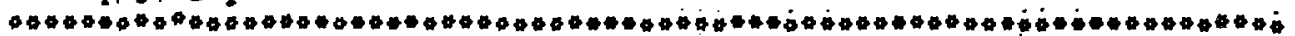
RIGHT BOUNDARY R.B. CONOITIONS. HERE A $(1,1)$ IS AN

AR ITRARY COVSTANT, THE MAGNITUNE OF OHI (R.B.). A(2.1) IS

DEGA

0.0726

00727

THE DERIVATIVE OF PHI, $, B, 1)$ NORMILIZED Tn A(1,1). DEGA

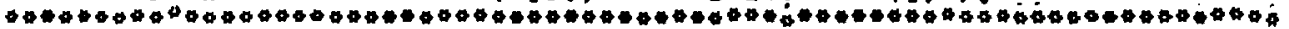

GO TO (63, 64): METHOD

$007^{2}$

00729

00730

00731

00732

A (1.) $=1.0 E-140$

$A(2, i)=$-SQRT(ABS $(X$ LAMADA ) $\triangle A(1,1)$

DEGA

DEGA

DEGA

00733

GO TO 58

64 THETAl = THETA : ALPHA

COSTHEI = COS (THETAI)

$A(1.1)=$ CAPF COSTHE 1

$A(2.1)=$ CAPFDOCOSTHEl - CAPF THETAPHSIN(THETAI)

DEGA

DEGA

DEGA

DEGA

DEGA

DEGA

00734

00735

00736

00737

00738

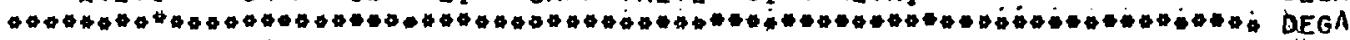

5E $X_{L L}=X_{L} *(X L+1 * 0)$

DO $2^{S} I=I B O T$ IMAX

DATGA

00739

00740

$0=\operatorname{ATOP}(I+1) \cdot A T O P(I)$

CALL PAYLORS(AII,I). JMAXII), APOP(I), D, XLAMBDA.

DEGA

00741

00742

DEGA

00743

1 XLL. $C(1,1), C(2, I) \cdot C(3, I)$ EMI6; IERROR)

DEGA

DEGA

00745 


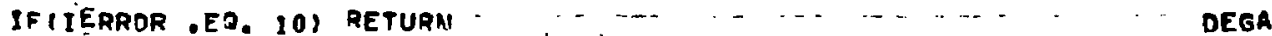

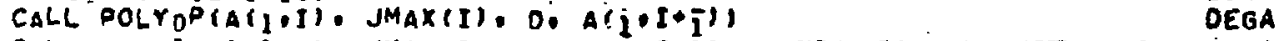

CALL POLYIP(AII,I), JMAX(I), D, A(I,I+I) $\cdots \ldots \ldots$ DEGA

25 CONTINUE

37 RETURN

END

SUGROUTINE BOUNDRY (IFCONV. FBOINND)

COMMUN/AIMAX/ AF(5I,40Z). JMAXF(4ח̈Z). IMAX,

DEGA

DEGA

DEGA

DEGA

1 IMAXF. IMAXFPI, IMAXB, IMAXBPI, C (3,400).

DEGA

2 CF (3,402), ATOP(401), ATOPF (402)

DIMENSION $A B(51,402)$. JMAXB $(402)$, CB $(3,402)$, ATOPB (40̃)

DEGA

DEGA

EOUIVALENCE (AF (1), $A B(1)$, JMAXF (i) JMAXB(1) :

1 (CF(I), CB(i), (ATOPF (1). ATOPB(i))

DEGA

DEGA

DEGA YOU ARE LIVING DANGEROUSLŸ IF YOU LET IMAXF =1. THIS MAY RESU DEGA IN AN UNDETECTED DIVISION BY ZERO OR AN UNDETECTED LOSS OF ACCURAC DEGA IF (IMAXF.EQ. I) 1 , 2

2 IF (ABS(AF $(1, I$ YAXFPI),$L T$. ABS $(A F(T, I M A X F))+1,0 E-4) 3,1$

DEGA

1 IAKW $=$ IMAXFPI IMAXB

$I B K W P 1=I B K W+1$

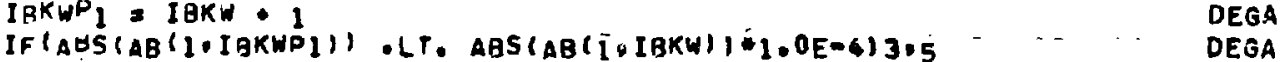

3 PRINT 4 FOAMAT

1AACY: क

5 IBKW $=$ IMAXFPI IMAXBPI

$F_{A C}=A B(1, I B K W) / A F\left(1, I M_{A} \times F P_{1}\right)$

$\triangle F A C=F A C$ AF $(2, I M A X F P I)$

FRO,IND = $\triangle F A C-A B(2, I B K W)$

EPSC = ABS (AFAC) $\triangle E P S C O N V$

IF(AUS(FBOUND) ILT, EPSCS $\& 7$

6 IFCONV $=1$ \& GO TO

7 IFCONY $=0$

Q RETURN

END

SUSROUTINE STURMSQ(AI, JMAXI. A2, D, IVZ, IERRORI

DEGA

DEGA

DEGA

DIMENSION AI (2), AP(Z), CPII 5I). CPIPI 51 )

COMUUUN/SCRATCH/SCRATCH (604)

EOUIVALENCE (SCRATCHII)! CPI (I)i. (SCRATCHIS2). CPIPIij)

IERAUR $=0$

JMAXI $=\operatorname{JMAXI}$

IF(D.LT. 0.0) 21.12

11 ISIGN $=-1$

GO TO 13

12 ISIGN $=1$

$13 I V Z=0$

J) $=J M A \times I+1$

OO $14 \mathrm{~J}=1$, JMAXI

$\mathrm{Jl}=\mathrm{Jl}-1$

$\operatorname{CPI}(J)=41(J 1)$

$14 \operatorname{CPIPI}(j)=(J]-1) * \operatorname{CPI}(J)$

$J M A X I P I=J M A X I-1$

$P_{0}=$ CPI (JMAXI)

$P D=A 2(1)$

$P I O=$ CPIPI JMAXIPI)

$P_{1} O=A 2(2)$

IFIPIO EO, 0.01 GO TO 15

IFIFUOPIO .LT. 0.0) 15, is

15 IVZ $=$ IVZ * 1

is IF(DID.EO. 0.0$)$ GO TO 17

IF IDUAPID .LT. 0,0$) 17,18$

17 IV2 $=$ IVZ - I

$18 F A C=\operatorname{CPI}(1) / C P I P I(1)$

DEGA

DEGA

DEGA

00793

DEGA

DEGA

00794

DEGA

OEGA

00795
00796

00796
00797

DEGA

00798

DEGA

00799

DEGA

DEGA

DEGA

DEGA

DEGA

DEGA 


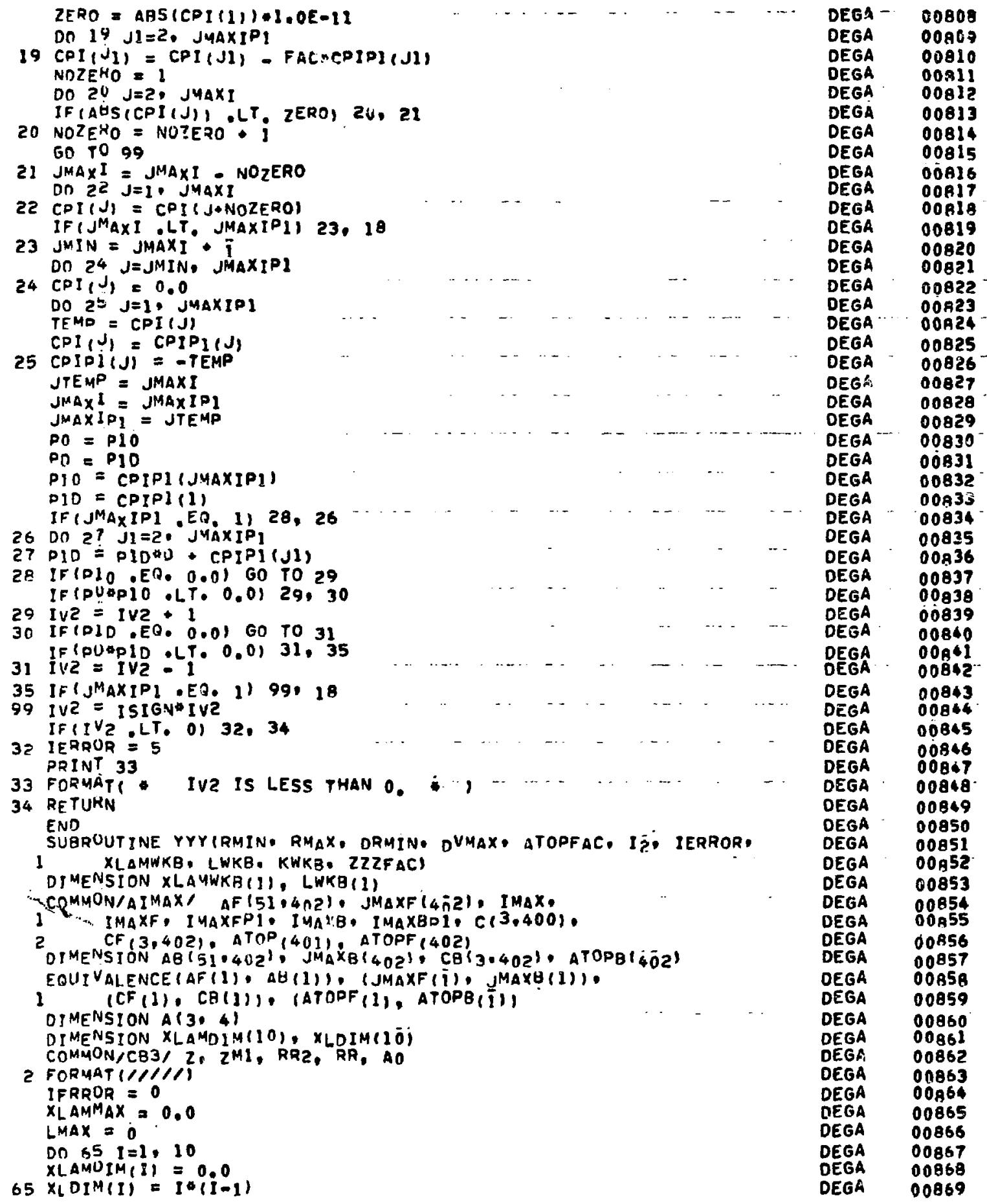




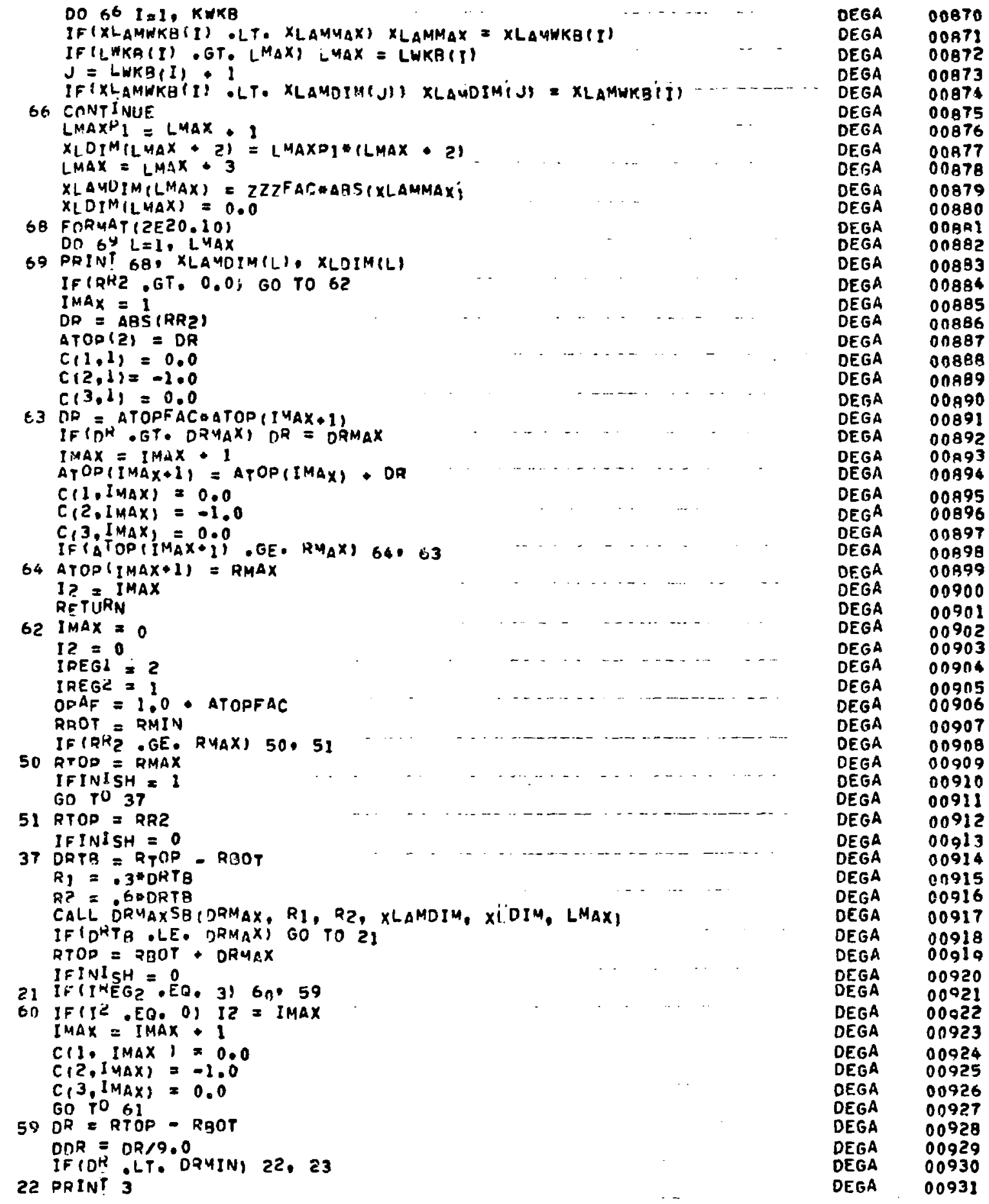


3 FRRMATI AN INTERVAL ALONG THE R-AXIS GOT TOO SMALLi. PRIVT 4. DR, DRMIN DEGA

4 FORMATIODR = $\triangle, E 20,10, *, 10 \times, 10 R M I N=\$, E 20,10)$ IFRZOR $=21$

6 FORMAT I० IEZROR $=\oplus$. I5I PRIVT 6. IERROR PRINT 2 GO TO 99

$23 R_{1}=$ RAOT $S$ R3 $=R T O P$ S R2 $=(R 1+R 3 \mid / 2.0$ IF $\{$ Q L LT. 1. OE-200\}, 33, 34

$33 A(3,4)=0.0$ s $G 0$ TO 35

$34 A(3.4)=R_{1} \oplus R_{1} \odot V\left(R_{1}\right)$

$35 A(2,4)=R 2 \otimes R 2 \otimes V(R 2)$

$A(1,4)=R 3 * R 3 * V(R 3)$

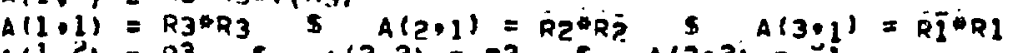
$A(1,2)=R^{3} s \quad A(2.2)=R 2$ s $A(3.2)=$ LI $A(1.3)=1.0$ s $A(2.3)=1.0 \cdot 5 \quad \Delta(3.3)=1.0$ CALL MATPAC (-1, A. 3, 1. DET, 0.0. IF SING) CHATI = A(1.4) S CHAT2 $=A(2,4)$ S CHAT3 $=13(3,4)$

DEGA

DEGA

OEGA

DEGA

DEGA

DEGA

DEGA

DEGA

DEGA

DEGA

DEGA

DEGA

DEGA

DEGA

DEGA

DEGA

DEGA

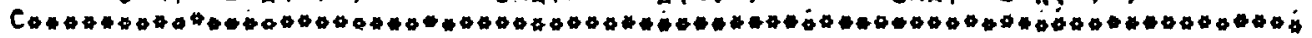

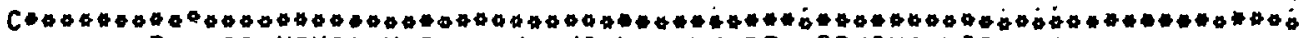
C R=U IS NEVE? USEN. WE WILL ONLY BE WORKING WITH VS

DEGA

DEGA

C WHEZE V(R). VE. O FOR R.NE. OE $R=K_{B O T}$

DEGA

DO $24 \mathrm{~J}=1,8$

$R=k+D D R$

$V R=V(R)$

$P=$ CHATI + CHAT2/R + CHAT3/RTÉ)

$x J=J$

c 1 FORÜAT (4E20.10)

C PRINI 1.XJ, R, VR, P

If: $\triangle A_{S}\left(V^{R} \cdot\right.$ DI/VR) $L T$, DVMAX) $24^{\circ} 25$

24 CONTINUE

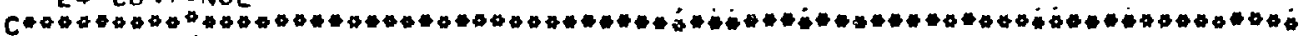
IQEG ${ }^{2}=$ IHEGI

$\operatorname{IMAX}=\operatorname{IMAX}+1$

$C\left(1, I_{M A X}=C_{A A T}\right.$ s $C\left(2, I M_{A X}\right)=C H_{A} T_{2}$ s $C\left(3\right.$, IMAX $_{A}=\mathrm{CHAT}_{3}$

DEGA

DEGA

DEGA

DEGA

DEGA

DEGA

DEGA

DEGA

DEGA

DEGA

DEGA

DEGA

DEgA

DEGA

61 ATOD (IMAX 1 II = RTOP

IF IIFINISH. EQ. II 99,31

DEGA

DEGA

DEGA

DEGA

32 PRINT' 7 FORMAT' THE MAXIMUM NUMBER OF ENTERVALS WILL NOT SD̈AN (RMIN, RMAX

11.01

IFRROR $=22$

DRINT 6. IERROR

PRINT 5

GO TO 99

28 RQOT $=$ ATOP

IF IIREGI.EQ, 3) 58,57

58 DRTOP = ATOPFAC QRTOP

$R I=R T O P$

$R ?=$ RTOP *.5०(ATOP - ATOP (IMAX)i)

CALL ORMAXSBIDRMAX, Ri, R2, XLAMOIM, XLDIM, LMAX)

IF (IRTOP.GT. DRMAX) DRTOP = ORMAX

RTOP = RTOP + DRTOP GO TO 52

DEGA

DEGA

DEGA

DEGA

DEGA

DEGA

DEGA

DEGA

DEGA

DEGA

DEGA

DEGA

DEGA

DEGA

DEGA

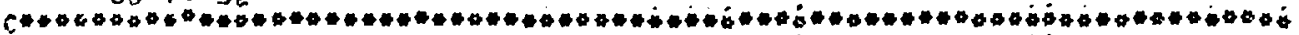

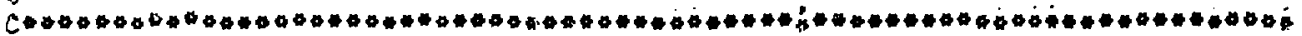
C THIS CARD DETERMINES MAXIMUM INTFRVAL LENGTH.

DEGA

DEGA

DEGA

5 IF (INAX:EQ. I) 40,4$)$

DEgA

DEGA

00932

00933

00034

00935

00936

00937

00938

00939

00940

00941

00942

00943

00944

00945

00946

00947

00948

00949

00950

00951

00952

00953

00954

00955

00956

00957

00958

00959

00960

00961

00962

00963

00964

00965

00966

00967

00968

00969

00970

00971

00972

00973

00974

00975

00976

00977

00978

00979

00980

00981

00982

00983

00984

00985

00986

00987

00988

00989

00990

00991

00992

00993 
ORI $=O R$

$D R 2=D R$

$D R 3=D R$

$D D_{4}=D R$

DRTMP $=D R$

GO TO. 42

41 DR5 = DR4

DR4 = DR3

$D R 3=D R 2$

$D R 2=D R_{1}$

$D D 1=D R$

DRTMP $=$ QDR1 + DR2 + OR3 + DR4 + DRE $51 / 5.0$

DEGA

DEGA

DEGA

DEGA

DEGA

DEGA

DEGA

DEGA

DEGA

OEGA

DEGA

DEGA

42 IF (2:0 DRTMP .LT, $\triangle$ TOPFAC

46 RTDD = RTDP $+2.0^{\circ}$ DRTMP

GO TO 48

47 RTOP = OPAF RTOP

4 RI = RAOT

$R Z=R B O T+.5 *(R B C T-A T O P(I M A X) I$

CALL DRMAXSB (DRMAX, RI, QZ, XLAMDIM, $X\left(D I M, L M_{A} X\right)$

IFIRIGP - RBOT GT. DRMAXI RTOP = RBOT. DRMAX

GO TO $\{54,53)$, IREG

54 IF $\{R$ IOP . GE, RR2) 55,52

55 RTOP $=$ RRZ

IREGL $=2$

GO 50

53 IF IRTOP. GE. QRI $56 \cdot 52$

56 RTOP $=$ RR

IREGI $=3$

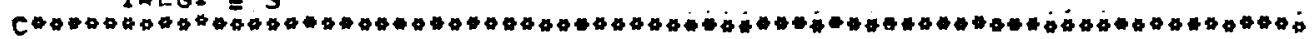

52 IF (RMAX LLE. RTOP) 29. 26

29 RTOP $=$ RMAX $\$$ IFINISH $=1$

GO TO 21

DEGA

DEGA

DEGA

DEGA

DEGA

DEGA

DEGA

DEGA

DEGA

DEGA

CEGA

DEGA

DEGA

DEGA

DEGA

DEGA

DEGA

DEGA

DEGA

DEGA

25 IREGI = IREG2

IFIIMAX.EQ. O) 43.44

44 IFI DR. LT. .5\$DRTMP) 43.45

43 RTOP $=\mathrm{R2}$

Gn TO 28

45 RTOO = RBOT *.75HDR

26 IFINISH $=0$

G TO 51

99 IFII $, E O, 0) I 2=I M A X$

RETURN

END

SIJBRUUTINE DRHAXSBIDRMAX, RI, R2, XLAMDIM, XLDIH, LMAXXI

DIMEINSION XLAMDIM(1), XLDIM(1)

SMALLK $=0.0$

$R 1 Z=1.0 / R 1 * R^{2}$

$R T 2=1.0 / 72 * 42$

TVR $1=2,0 * V(R 1)$

TVR2 $=2.00 V(R 2)$

Dก 7 U L=I, LMAX

$S K=A R S$ (XLAMOIM,L) - TVAI - XLDIM,L) ORI2,

IF (SK. GT. SYALLK) SMALLK $=S K$

$S K=. A B 5\left(X_{L A M D I M}(L)-T V R 2-X_{L D I M}(L){ }_{R Z 2}\right)$

IF $S K$. GT. SMALLK) SHALLK $=S K$

70 CONTINUE

DRMAX $=6.28 /$ SQRT (SMALLK)

RF TURN

END

FUNCTION $V_{2}$ (R)

COMMON/CB $3, Z, Z M I, R R Z, R R, A O$

DEGA

DEGA

DEGA

DEGA

DEGA

DEGA

DEGA

DEGA

DEGA

DEGA

DEGA

DEGA

DEGA

DEGA

DEGA

DEGA

DEGA

DEGA

DEGA

DEGA

DEGA

DEGA

DEGA

DEGA

DEGA

DEGA

DEGA

DEGA

FNZZ $=1.0 / 11.0+\triangle 0$ QRRZ)

DEGA

$D E G A$

01002

01003

01004

01005

01006

01007

01008

01009

01010

01012

01012

01013

01014

01015

01016

01517

01018

01 1ก 19

01020

01021

01022

01023

01024

01025

01026

0 ¡ 027

$01 n ̃ 28$

01029

01030

01031

01032

01033

01034

01035

01036

01037

0103 A

01039

0) 040

01041

01042

01043

01044

01045

01046

02047

01048

01049

01 กิ50

01051

01052

01053

01054

01055 


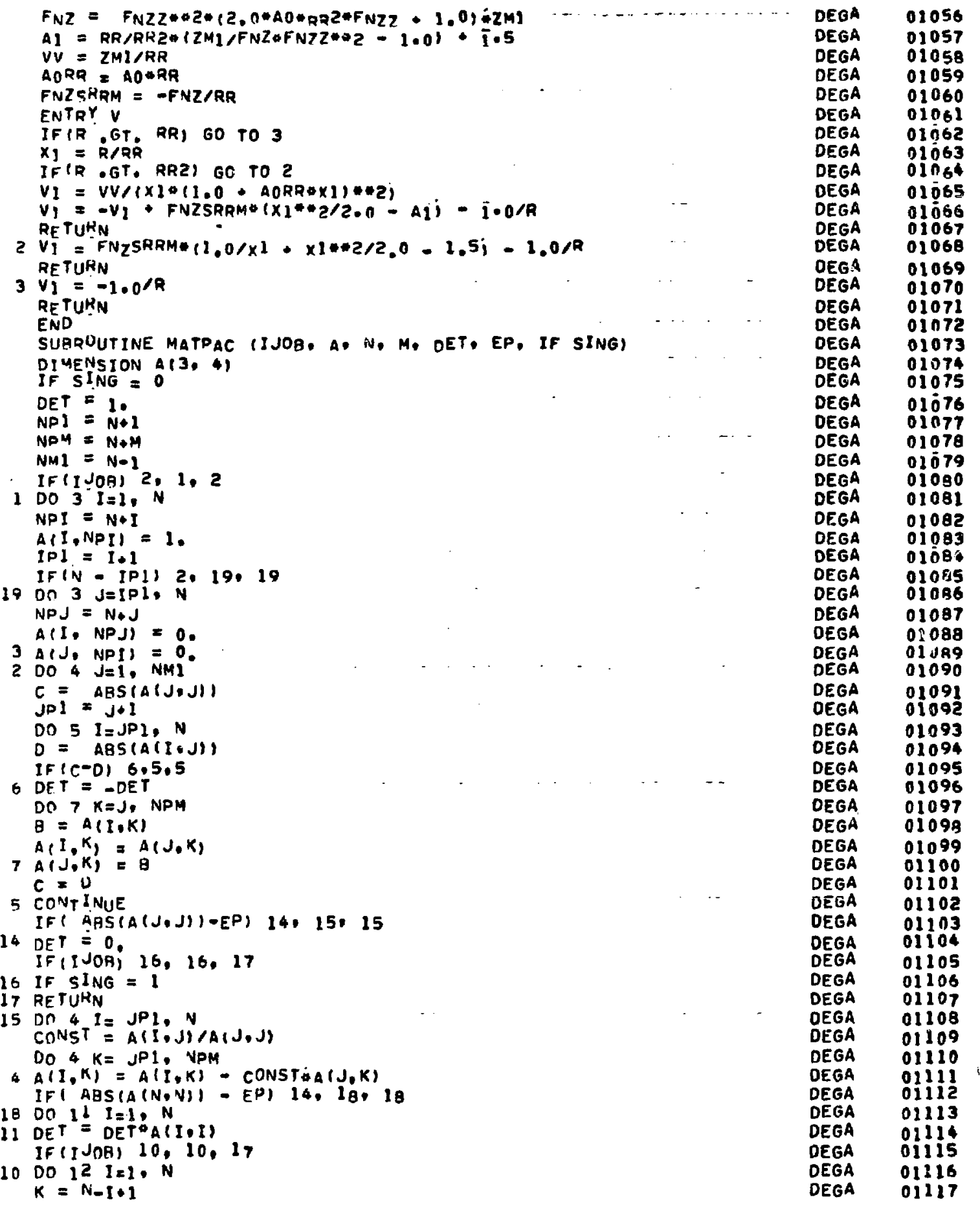




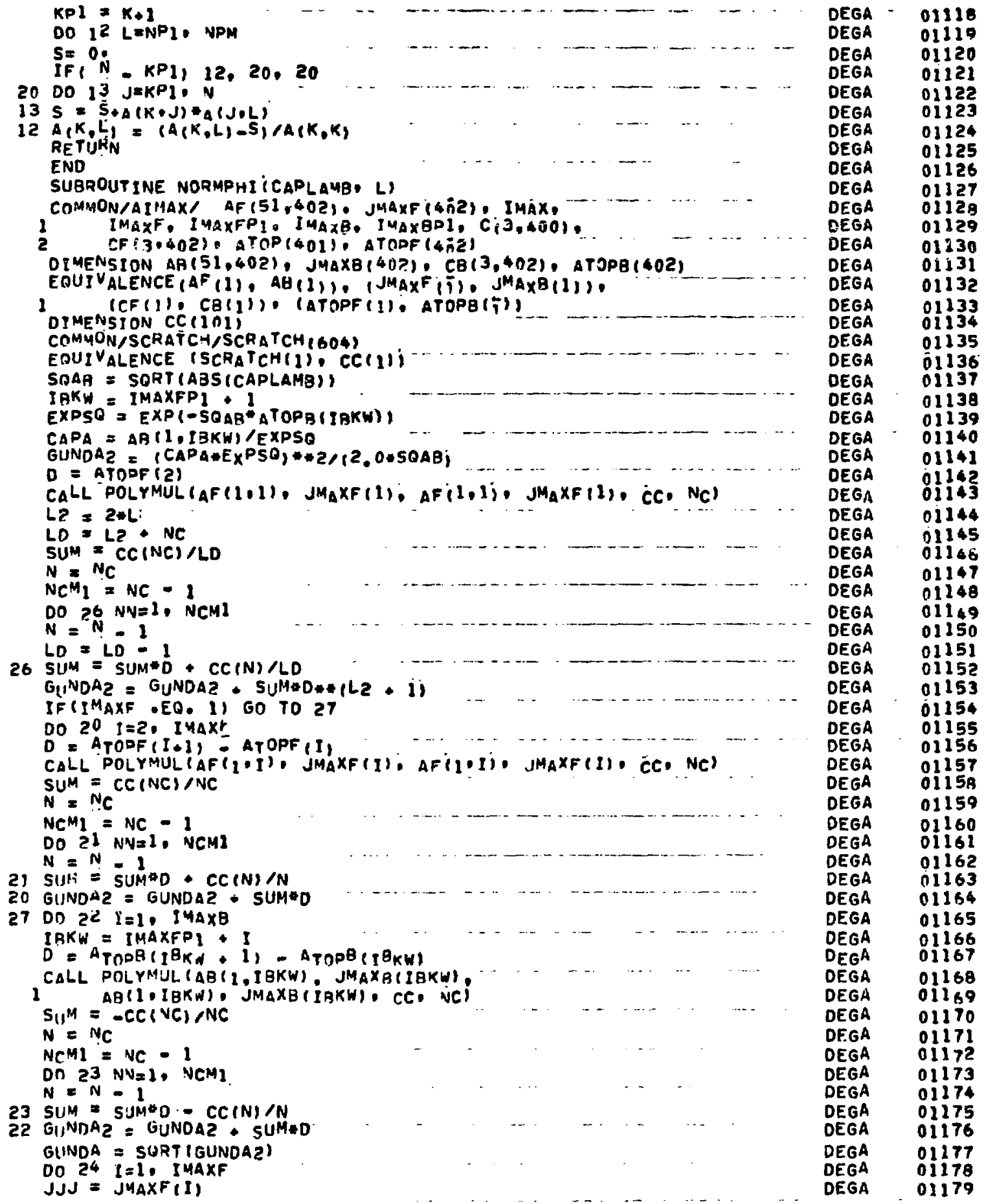


De 54. $5=1, \pi J$

24 AF (J:I) = AF (J,I)/GUNDA

DO $2^{5} I=1$. I YAXB

$I R K W=I M_{i} X F P I+I$

JJJ = JMAX日(IBKH)

DO $5 S J=1, J J J$

$25 A R(J \cdot I B K H)=A B(J \cdot I B K W) / G U N D A$

RF TURN

END

SUAROUTINE POLYMUL IA, LH, B, LN, $\bar{C}_{1}$ LLí)

DIMENSION A(1), B(1),C(1)

$L L=L M \cdot L N \cdot 1$

MMIN $=1$

DO $1 L=1, L L$

IF (L .GT.LM) 3. 2

2 MMAX $=L$

3 IF (L.GT. LN) $5 \cdot 4$

4 NMAXP1 $=L * 1$

GO TO 6

5 MMIN $=$ MHIN +1

$6 C(L)=0.0$

$N=$ NMAXP1

DO 1 M= MMIN . MMAX

$N=N-1$

$1 C(L)=C(L)+A(M) * B(N)$

RFTURN

END

SUBROUT INE YATELE (KPHIUAX, XLAMARY, LARY, ALFAARY, IMAXARY, I20

1 NSUBSHL, IS5MAX, NSHELL)

DJMENSION JMAX $(400)$. AMIS(400), AYวS (4D̃O)

EOHIVALENCE (SCRATCH(1): ATOPID, : (SCRATCHI2): $C_{1}$ ): :

1 (SCRATCH(3), C2)! (SCRATCH(4):C3), (SCRATCH(5), JMAX(1)),

2 (SCRATCH(W05), AM1S(1), (SCRATCH(R05), AH2S (1) ).

DIMENSION XLAMIRY $(1)$, LAPY $(1)$ : ALFAARY $(1)$ : IMAXARY (

1 NSUHSHL $(1)$. NSHELL 11$)$

COMMUN AIMAX, A(51,100), CAPO(100), IFSTOP(100),

1 XLLPI 1100$), S_{1}(300)$. S2 (300). DVPOLY (70). SCRATCH(1204)

$2, A 1 M(400), A 2 M(400), A M T(5) ; A M S(5 i)$

$3, \triangle 1 N(400), \triangle 2 N(400), A N T(51), A N S(5 i)$

4 ATOPPIM(400). ATOPPIN 400$)$ JMAXM(400). JMAXN 400$)$

COMMON/CBI/ HVUVEC (500). ACOFVEC 5000$)$. NOPTS. IHNUMAX, MH(100).

1 NN(100), MNMAX, I $4 M I N$, I 4 MAX

COMMUN/EPS/EPSCONV, FBMAX, EM160 EMATELE. EMDVDD. MAXOIM-

1 FORMAT (16I5)

2 FORMAT (25I5)

3 FORMAT (5E25.14)

4 FORMAT (2E25.14. I5)

5 FORMAT ( $)$

6 FIRMAT (4E25:14: 2I5)

PRINTI. MPUAAX

PRINI 1, (MM(YN), NN (MN), MN=1; MNMAX)

$\mathrm{KPHIM}_{4}=\mathrm{KPHIMAX}+4$

$M A X_{D I M 4}=$ MAXDIM 4

ISKIP = 3\$MAXDIM * 4

$I E C S=1$

IECS $1 \Rightarrow$ IECS + MAXOIM4

IFCS2 = IECSI+ MAXOIM

CALL ECRD (SCAATCHII), IECS. KPHIMA' IE)

CALL ECRO (SCRATCH(405). IECSI, KPHIMAX, IE)

CALL ECRD,SCRATCH(B05), IECS2, KPHIMAX, IE,

DO $31 \mathrm{KPHI}=1$, KPHIMAX

$A(1, K P H I)=A M 1 S$ (KPHI)

$\begin{array}{ll}\text { DEGA } & 01180 \\ \text { DEGA } & 01181 \\ \text { DEGA } & 01182 \\ \text { DEGA } & 01183 \\ \text { DEGA } & 01184 \\ \text { DEGA } & 01185 \\ \text { DEGA } & 01186 \\ \text { DEGA } & 01187 \\ \text { DEGA } & 01188 \\ \text { DEGA } & 01189 \\ \text { OEGA } & 01190 \\ \text { OEGA } & 01191 \\ \text { DEGA } & 01192 \\ \text { DEGA } & 01193 \\ \text { DEGA } & 01194 \\ \text { DEGA } & 01195 \\ \text { DEGA } & 01196 \\ \text { DEGA } & 01197 \\ \text { DEGA } & 01198 \\ \text { DEGA } & 01199 \\ \text { OEGA } & 01200 \\ \text { DEGA } & 01201 \\ \text { DEGA } & 01202 \\ \text { DEGA } & 01203 \\ \text { DEGA } & 01204 \\ \text { DEGA } & 01205 \\ \text { DEGA } & 01206 \\ \text { DEGA } & 01207 \\ \text { DEGA } & 01209 \\ \text { DEGA } & 01209 \\ \text { DEGA } & 01210 \\ \text { DEGA } & 01211 \\ \text { DEGA } & 01212 \\ \text { DEGA } & 01213 \\ \text { DEGA } & 01214 \\ \text { DEGA } & 01215 \\ \text { DEGA } & 01216 \\ \text { DEGA } & 01217 \\ \text { DEGA } & 01218 \\ \text { DEGGA } & 01229 \\ \text { DEGA } & 01230 \\ \text { DEGA } & 01231 \\ \text { DEGA } & 01232 \\ \text { DEGA } & 01219 \\ \text { DEGA } & 01221 \\ \text { DEGA } & 01222 \\ \text { DEGA } & 01233 \\ \text { DEGA } & 01234 \\ \text { DEGA } & 01235 \\ \text { DEGA } & 01236 \\ \text { DEGA } & 01237 \\ \text { DEGA } & 01238 \\ \text { DEGA } & 01223 \\ \text { DEGA } & 01224 \\ \text { DEGA } & 01225 \\ & 01249 \\ \text { DEGA } & 01227 \\ & 01241\end{array}$


31 A $(2, K P H I)=-A Y 2 S(K P H I) \cdot$

DEGA

DO 21 KDHI $=1$, KPHIMAX

$X L=$ LARY (KPHI)

IERROR $=0$

CALL TAYLORI IAIIPKPHI), JMAX (KPHII, ATUPYPL.

1 XLAMARY (KPHI), XL, C1. C2. EMI6, IERROR, JMAXKP $=$ JMAX (KPHI)

2] $X L L P 1(K P H I)=X L *(X L * 1.0)$

DO 20 MN $=1$. MNMAX

$M=\dot{M}_{M}\left(M_{N}\right)$

$N=N N(4 N)$

LNLMI $=\operatorname{LARY}(V) * \operatorname{LARY}(M)+1$

DEOM $=$ LNLMI -1

CALL POLYMUL IA

DO $30 \quad J=1$, IS2

DEOM = OEOM $\bullet 1.0$

$302>(7)=25(7) / D E O M$

CALL FOLYOP (S2, ISZ, ATOPIPI, P)

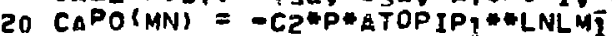

DN 36 MN=1. MNMAX

36 -IFSTOP $(4 N)=0$

Dn $24 \quad I=2,12$

ATOPI ATOPIPI

IFCS = IECS + ISKIP

IECSI $=$ IECS $*$ MAXOIM4

IFCSL $=$ IECSI + MAXDIM

CALL ECPD (SCRATCHII), TECS, KPHIM

CALL ECRD (SCRATCH 4 D5). IECSI.KPHIMAX. IE)

CALL ECPD,SCRATCH(B05), IECS2, KPHIMAX: IE;

DO 25 KPHI $=1$. KPHIMAX

A(l. KPHI) $=\triangle M I S(K P H I)$

$25 A(2, K P H I)=A M_{2} S(K P H I)$

$D=A T O P I=A T O P I P I$

DO 2 I KPHI $=1$, KPHIMAX

IERROR $=0$

27 CALL TAYLORS(AIIOKPHI), JMAX(KPHI): ATOPIPI.

1 D. XLAMARY (KPHI), XLLPI (KPHI): Cl, CZ, C3, EMI6, IERRORI CALL DVDDIATOPIPI, D, C2, C3, DVPOLY, IOVDD, EMDVDD;

MI.AST $=0$

OO $2 \bar{B}$ MN=1. MNMAX

IF (IFSTOP (MN) EQ. 5 ) 60 TO 28

$M=M M(M V)$

$N=N N$ IMNI

IFIM. EQ. MLASTI GO TO 33

MLAST $=M$

CALL POLYMUL $(A, 2, M), J M_{A} \times(M)$, OVPOIY, IDVNO. S1, ISIj

33 CALL POLYM,JL $(A, 1, N), J M A X(N), S_{1}, S_{1}, S_{2}$, I52)

CALL POLYINT (SZ, ISZ, D. P)

$C A P O(M N)=C A P O(M N)-P$

IF $(A B S, D)$. LT ABS, CAPO, MN, \#EMATELE, 34, 35

36 IFSTOP (MN) = IFSTOP(MN) I GO TO 28

$35^{\circ}$ IFSTOP (MN) $=0$

2B CANTINUE

24 CONTINUE

ATOPI $=$ ATOPIPI

ISKIP $=3 * M A X D I M+4$

IJUMP $=400-12$

MLAST $=0$

NLAST $=0$

DO 40 MN=1. MNMAX

IF (IFSTOP (MN) DEQ. 5 ) 60 TO 40
DEGA

DEGA

DEGA

DEGA

DEGA

DEGA

DEGA

DEGA

DEGA

DEGA

DEga

DEGA

DEGA

DEGA

DEGA

DEGA

DEGA

DEGA

DEGA

DEGA

DEGA

DEGA

DEGA

DEGA

DEGA

DEGA

DEGA

DEGA

DEGA

DEGA

DEGA

DEGA

DEGA

DEGA

DEGA

DEGA

DEGA

DEGA

DEGA

DEGA

DEGA

DEGA

DEGA

DEGA

DEGA

DEGA

DEGA

DEGA

DEGA

DEGA

DEGA

DEGA

DEGA

DEGA

DEGA

DEGA

DEGA

DEGA

DEGA

DEGA

DEGA
01242

01243

01244

01245

01246

01247

01248

01249

01250

01251

01252

01253

oi 254

01255

01256

01257

01258

01259

01260

01261

01262

01263

01264

01265

01266

01267

01268

01269

01270

01271

01272

01273

01274

01275

01276

01277

01278

01279

01280

$01>81$

01282

01283

01284

01285

01 B 6

01587

01288

01289

01290

01291

B1292

01293

01294

01295

01296

01297

01298

01299

01300

01301

01302

01303 


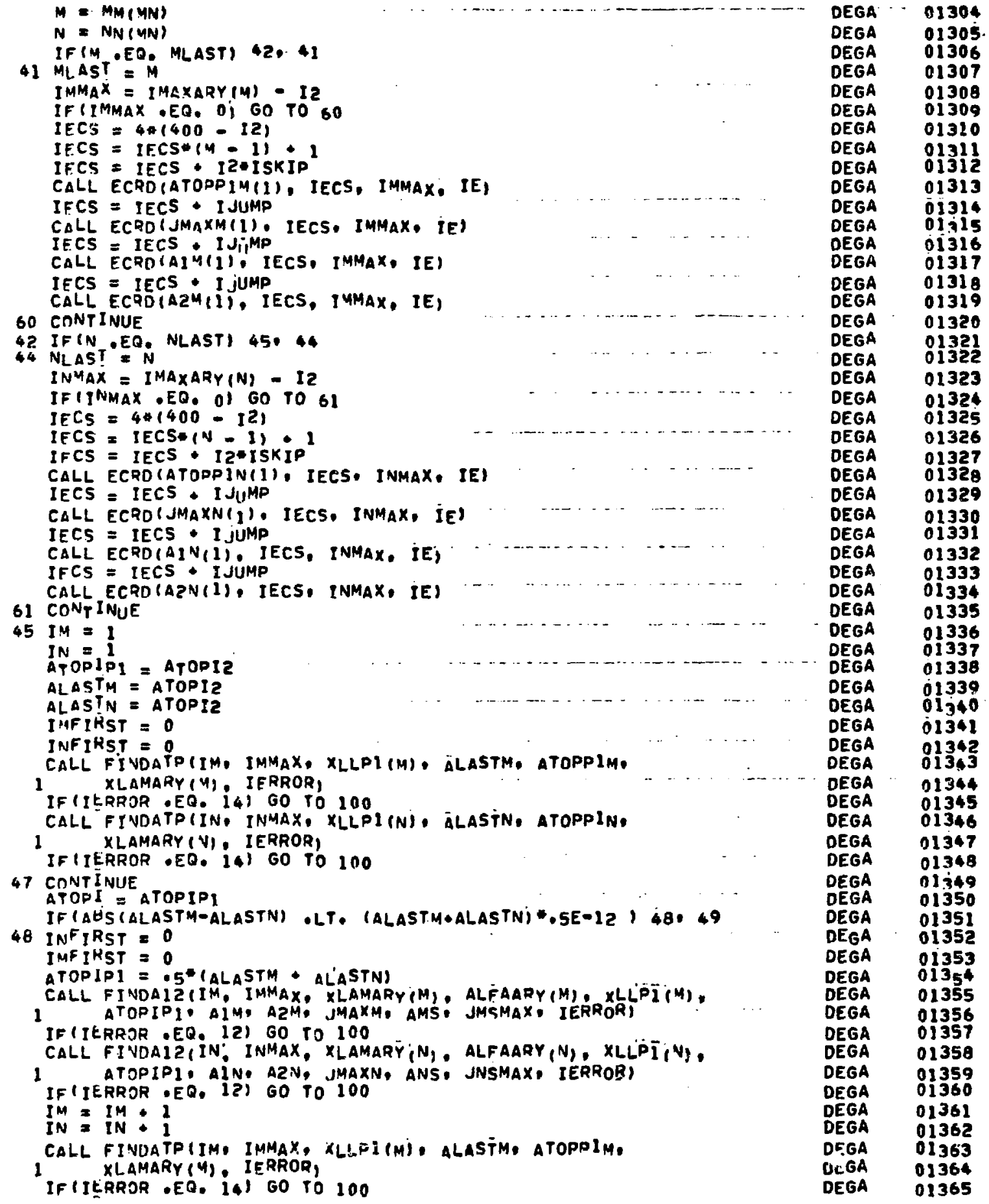


CALL FINOATP,IN, INMAX, XLLPI IN). BLASTN, ATOPPIN, ............ DECA

1 XLAMARY (VI: IERROR)

IFIIERROR -EQ, 14) 100, 50

49 IF IALASTM GT. ALASTNI 51, 52

51 INFIRST $=0$

IMFIRST $=$ IMFIAST + I

ATOPIPI = ALASTN

OM = ATOPIPI - ALASTM

IF (IMFIRST.EO. I) 53, 54

53 CALL FINDAIZIIM, IMMAX, XLAMAQY (H): ALFAARY (H)

1 XLLPI (M). ALASTM, AIM, A2M, JMAXM: AMT, JMTMAX: IERROR\}

IF (JERROR -EQ. 12) GO TO 100

IERROR $=0$

CaLL TAYLORS (AMT. JMTMAX. ALASTM. DM. XLAMARY (M).

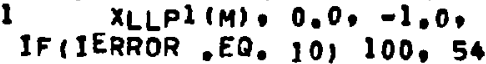

54 CALL POLYOP (AYT, JMTMAX, OM. AMSTii)

CALL POLYIP(AYT, JMTHAX, DH, AMS(E)).

JMSMAX $=0$

CALL FIÑOAIZ (IN, INMAX, XLAMARY (N): ALFAARY (N), XLLPİ (N). ATOPIPI: AIN, AZN, JMAXN. ANS*.JNSMAX, IERRORI

IF (IERROR EQ. I2) GO TO 100

$I N=I N+1$

CALL FINDATP! IHO INMAX, XLLPI IN), ALASTN, ATOPPIN,

2 XLAMARY $(N)$, IERROR \}

IF (IERROR -EO. 14) 100050

52 IMF IRST $=0$

INFIRST $=$ INFIRST $\bullet 1$

ATODIPI = ALASTM

DN F ATOPIPI - ALASTN

IFIINFTRST EO I) 55, 56

DEGA

DEGA

01367

01368

DEGA

01369

01370

DEGA

DEGA

01371

01372

01373

DEGA

01374

01375

DEGA

01376

DEGA

01377

02378

DEGA

01379

DEGA. OI3BO

DEGA OI381

DEGA

01382

DEGA 01383

DEGA Ö1324

DEGA OIJES

DEgA $013 B 6$

DEGA OI3B7

DEGA

01388

DEGA

01389

DEGA

01390

01391

DEGA

01392

DEGA

DEGA

01393

01394

CALL FINOAIŻ (IN, INMAX, XLAMARYQN): ALFAARYPNI.

DEGA

DEGA

01395

$X_{L L P I}(N), A L A S T N, A I N, A Z N, J M A X N, A N T, J N T$

IF (IERROR.EQ. 12) GO TO 100

IERROR $=0$

CALL TAYLORS (ANT, JNTMAX. ALAST̈N. ON, XLAMARY(N).

$1 X L L P I(N), 0,0,-1.0,0.0$, EMIS, IERROR)

IFIIERROR IEQ. 10$) 100.56$

56 CALL POL YOP (ANT: JNTMAX. ON. ANSIII\}

CALL POLYIP(ANT, JNTMAX, DN, ANS(Z)

JNSMAX $=0$

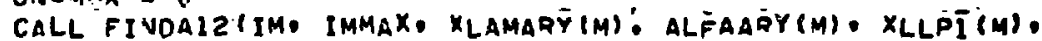

1 ATOPIPI, AIM, AZM, JMAXM, AMS, JMSMAX, IERROR,

IF (IERROR EEQ. I2) GO TO 100

DEGA

DEGA

DEGA

DEGA

DEGA

DEGA

OEGA

DEGA

DEGA

DEGA

OEGA

DEGA

DEGA

$I M=I M+1$

CALL FINDATP IM, IMMAX, XLLPI (M), ALASTM.

1 ATOPPIM, XLAMARY (M): IERROR)

DEGA

DEGA

DEGA

IF (IERROR OEQ. 14). 100, 50

$50 D=A T O P I-A T O P I P_{1}$

IERROR =

DEGA

DEGA

DEGA

CALL TAYLORS (AMS, JMSMAX, ATOPIPI, D. XLAMARY (M):

DEGA

DEGA

IF IIERROR EE. 10$)$ GO TO 100

CALL TAYLORSIANS. JNSMAX, ATOPIPI, D. XLAMARY (N),

DEGA

DEGA

DE.GA

DEGA

IF IIERROR EQ. IOI GO TO 100

CALL DVODIATODIPI, 0. $-1,0,0.0$, DVPOLY TOVDD. EMDV̈DDI

DEGA

CALL POLYMUL (AMS, JMSMAX, DVPOLY, IDVDD, SI. ISI)

CALL POLYMUL (ANS: JNSMAX, $S_{1}, I_{1}, S_{2}$, IS2)

CALL POLYINT (SZ, ISZ, D, P)

DEGA

OEGA

OEGA

DEGA

IF (ABS (D) IT. ABS (CAPO (MN) *EMATELE) 58.57

DEGA

01397

01398

01399

01400

01401

01402

01403

01404

0 i40s

01406

01407

01408

01409

01430

01411

01412

01413

01414

01415

01416

01417

01418

01419

01420

01421

01422

01423

01424

01425

01426

01427

PRIN! 7. ISSMAX

ucum

vouas 


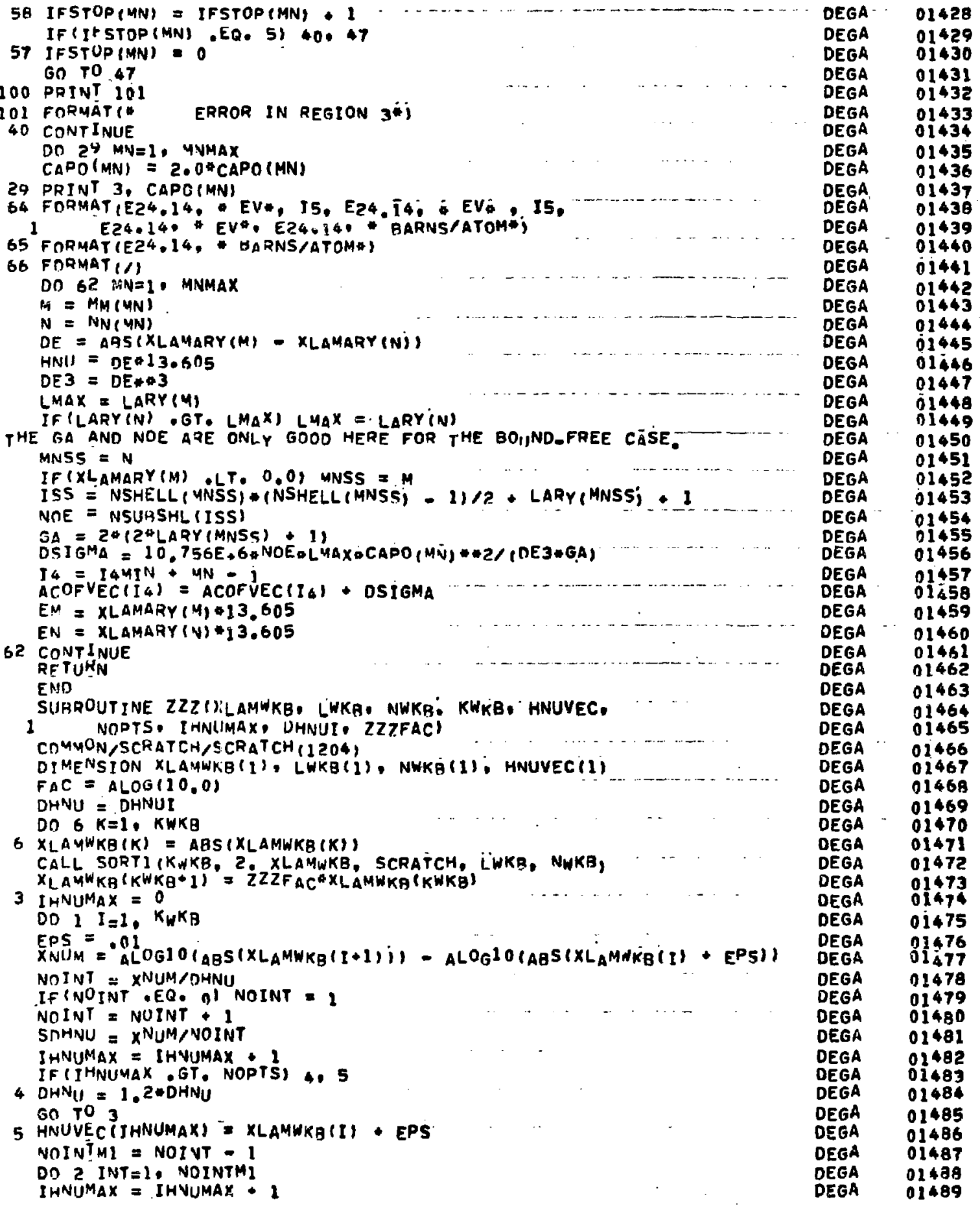


IF I I NIJMAX OT. NOPTS, 60 TO 4

XNUM = FAC (ALOGIO (ABS (XLAMHKBII) - EPSI) INT-SDHNÜ)

01494

2 HAUVEC (IHNUMAX) $=$ EXP(XNUM)

IHNUMAX $=$ IHNUMAX +1

IF I IHNUMAX - GT. NOPTS' GO TO

1 HNUVEC (IHNUHAX) $=$ XLAMWKB $(I+1)$

DO $7 \mathrm{~K}=1$, KWKB

$7 X L A M W K B(K)=-X L A M W K B(K)$

RETUKN

END

SUBROUTINE CARSON(XLAMBDA. CZ, MFAC̈ CAPR; XLLPI:

1 CAPF, CAPFP. THETA. THETAP, IERROR)

COMMON/PI/PI: TWOSPI

IERROP $=0$

SWALLC = ABS(CZ)

SMALLK = SORT (XLAMBDA)

CAPM = SQRT (TWOSPI/SMALLK)

$C A P H=M F A C * C A P M$

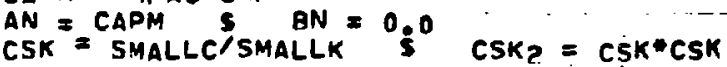

$A C O N=X L L P 1+$ CSK2 5 BCON $=-$ - (CSK2 $\cdot$ XLLP1)

$D E O M=1.0$ S T.OK $=2.00$ SMALLK

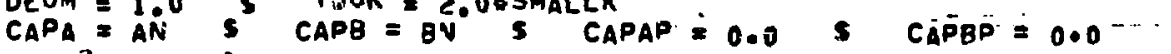

DO 63 NPI $=1,15$

DEOM = DEOMACAPR

$N=N P_{1}=1$

XNP1 $=$ NPI

XNNP1 $=$ NOXNP1

TWONPI $=12.0 * N \cdot 1.01 * C S K$

XOEOM $=$ TWOK $\times$ XNPI

ANPI $=($ (ACON - XNNP 1$) \angle B V-$ TWONP $\{$ SAN $), X O E O M$

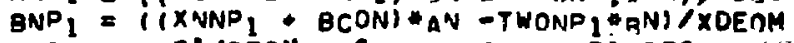

$\triangle \triangle D O=\triangle N P 1 / D E O M$ S BADD $=$ BNPI/DEOM

APADU $=X^{N P I} \triangle A A D D$ s APADO $=x^{N P I * B A D O}$

$C_{A P A}=C A P A+\triangle A D D$ S CAPA $=C_{A} P B \cdot B A D D$

CAPAP = CAPAP $\triangle A P A D D * C A P A P=C A P B D * B P A D D$

CAFAY = ABS (CAPA) - $\triangle B S$ (CAPB)

CAPABP = $\triangle B S(C A P A P)$ ABS (CAPBP)

IF $($ ABS (AADD) LT. CAPABA1,0E-4 - AND.

1 ABS (HADD) LT. CAPABA1.OE-4 AND.

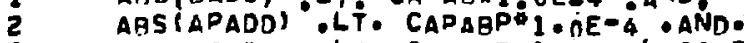

3 ABS(BPADD) LT. CAPABD-1.OE-4; GO TO 62

$A N=A N P_{2}$

$63 B N=B N P_{1}$

PRINT 64

64 FORMATT CAPA, CAPB, CAPAP, AND CAPBP DO NOT CONVERGE,

IERAOR $=12$

RFTURN

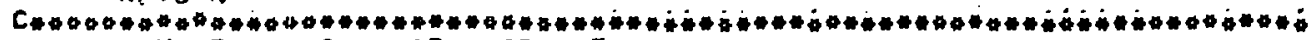

$C$ RUN THIS CODE FOR CAPR . GT. I.0

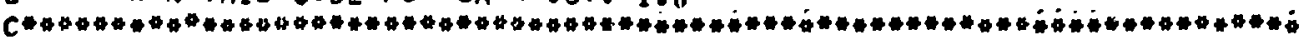

$62 C_{A P A P}=-C A P A P / C A P R$

$C \triangle P_{B}=-C A P B D / C A P Q$

CAPF2 = CAPA"CAPA * CAPB CAPB

CAPF = SQRT (CAPFZ)

CAPFP = CAPAACAPAP . CAPBACAPAPI /CAPF

THETA = SMALLK*CAPR - CSK*ALOG(CADR) - ATAN2 (CAPA. CAPB)

THETAP = SMALLK $*$ CSK/CAPR - CCAPAPOCAPB - CAPBP\#CAPAI/CAPFE

RF TURN

END

SUBROUTINE TAYLORI (A, JHAX, D. XLAMBDA, $X_{L}, C_{1}, C_{2}$, EM$_{1}$, IERROR) DIMENSION A(I).

DEGA

DEGA

DEGA

DEGA

DEGA

DEGA

DEGA

OEGA

DEGA

DEGA

DEGA

DEGA

DEGA

DEGA

DEGA

DEGA

DEGA

DEGA

OEGA

DEGA

DEGA

DEGA

DEGA

DEGA

DEGA

DEGA

DEGA

DEGA

DEGA

DEGA

DEGA

GEGA

DEGA

DEGA

DEGA

DEGA

DEGA

DEGA

DEGA

DEGA

DEGA

DEGA

DEGA

DEGA

DEGA

DEGA

DEGA

DEGA

DEGA

DEGA

DEGA

DEGA

DEGA

DEGA

DEGA

DEGA

DEGA

DEGA

DEGA

DEGA

DEGA

DEGA

nRUM
01491

01492

01493

01494

01495

01496

01497

01498

01499

01500

01501

01502

01503

01504

01505

01506

01507

01508

01509

01510

01511

01512

01513

01514

01515

01516

01517

01518

01519

01520

01521

01523

01524

01526

01527

01528

01529

$01530^{\circ}$

01531

01532

01533

01534

01535

01536

01537

01538

01539

01540

01541

01542

01543

01544

01545

01546

01547

01548

01549

01550

01551

PRIN! 7. ISSMAX

טuu 


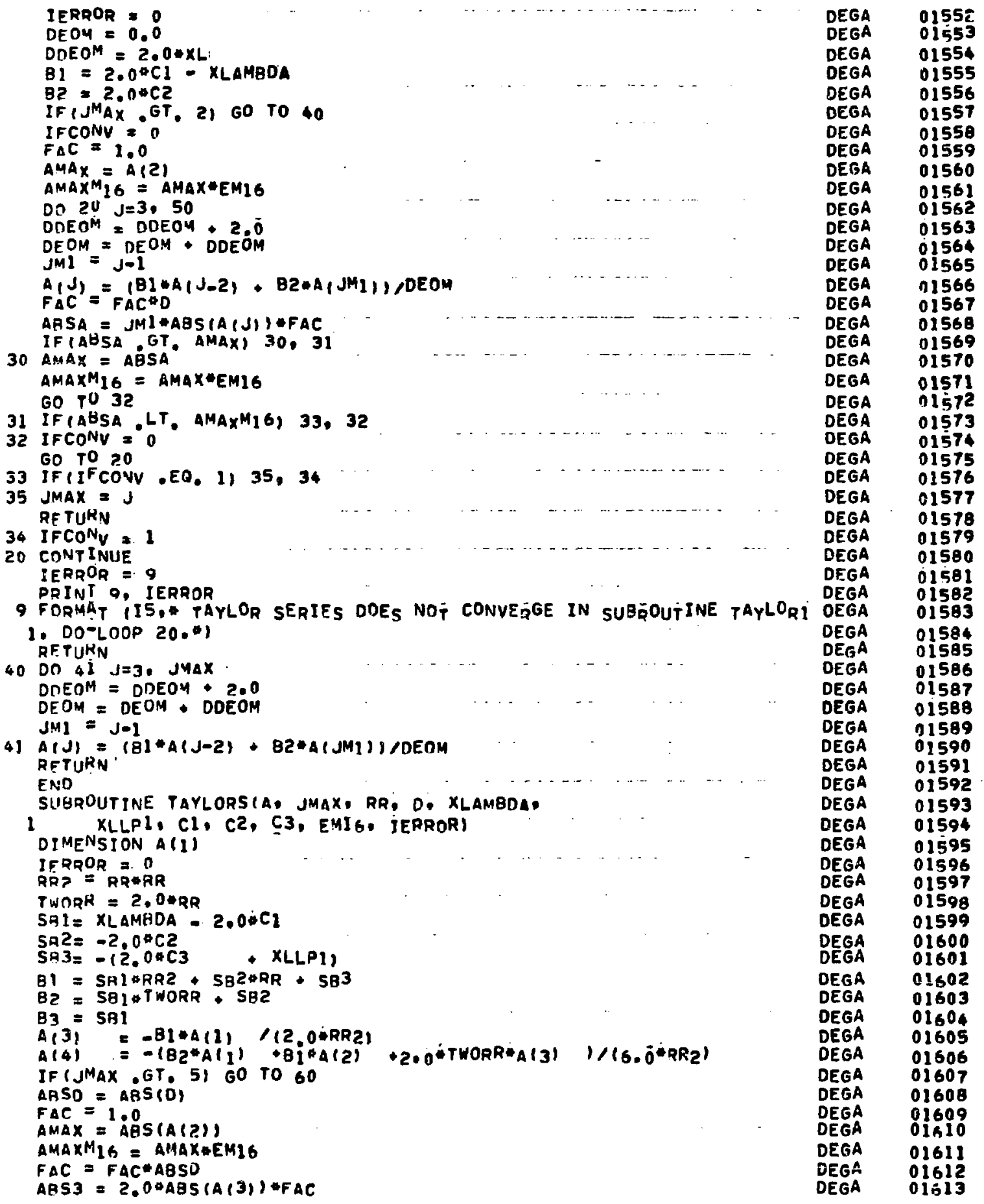

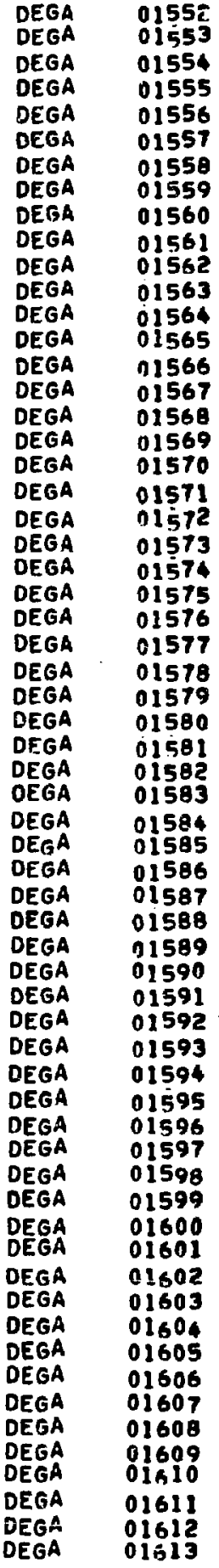




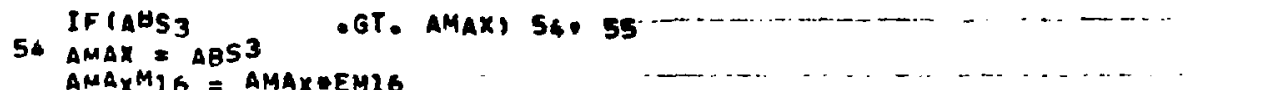

55 FAC $=$ FAC $\triangle A B S D$

AASS $=3.0$ ABS(A (4)) OFAC

IF (ABSA ¿GT. AMAX) S6. 57

$56 A M A X=A B S 4$

$A M A \times M 16=A M A X=E M I S$

57 Do $26, J=6,50,2$

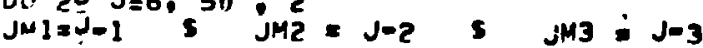

JH4 $=J-4 \quad 5 \quad J M 5=J-5$

OFOM = JM3 JM2 TRR2

DEA

DEGA

DEGA

DEGA

DEGA

DEGA

DEGA

DEGA

DEGA

DEGA

DEGA

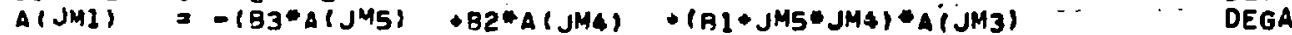

- JM4 JM3*THORR A J JMES J /DFOM

DEGA

DEOM = JH2*JM1 ARR2

$A(J)=-\left(A 3^{\circ} A\left(J M_{4}\right)+B 2^{\circ A}\left(J M_{3}\right)+\left(B_{1}+J 4^{\circ} J M 3\right) \cdot A(J M 2)\right.$

$\mathbf{l}$ -JM3*.JM2*TWORR*A (JMI) I/DEOH

DEGA

DEGA

$F A C=F A C A B S D$

$\triangle A S A L=J M 2$ JAS(ATJMI)) WFAC

$F \Delta C=F A C A B S D$

$\triangle F S_{A}=J M 2$ ABS(AIJ) OFAC

DEGA

DEGA

DEGA

DEGA

IF (ABSA,GT. AMAX) 45, 4

$45 \triangle N A X=\triangle B S A$

$A M A X M 16=A M A X * E M 16$

IF (AHSA) G GT. $\triangle M A X) 46,26$

$46 A M A X=A B S A I$ S AMAXM16

44 IF(ABSAI GT. AMAX) 46.47

47 IF (ABSA.LT. AMAXMIO) 48.26

48 IF (ALSA) LLT. AMAXMI6) 49,26

69 JMAX $=J$

RFTURN

26 CONTINUE

IEAROR $=20$

PRINT 10 . IERPOR Í SERTS DOES NOT CONVERGE IN SUAROUTINE TAYLOR

10 FARMAT. DOLLOOP 26 IN LOOP $25 . \% 1$

JMAX $=50$

IERROR = 0

1 FOAMAT (OE24,16)

PRINT 1, AMAX. AMAXM1G, A8SA. ABSAL̄ RETUKN

60 DO $2^{T} J=6 \cdot \operatorname{JMAX} \cdot 2$

$J M I=J-1 \quad S \quad J M C=J-2 \quad S \quad J M 3: J 03$

JM4 $=\operatorname{Jos}_{0} S \mathrm{JMS}=J-5$

OFOM $=J M 3 \cdot J M 2 * R A 2$

$A(J M 1)=-\left(B 3 * A\left(J^{45}\right), B 2 * A(J M 4)+(\dot{A} 1+J M 5 * J M 4) * A j J H 3\right)$

DEGA

DEGA

DEGA

DEGA

DEGA

DEGA

DEGA

DEGA

DEGA

DEGA

DEGA

DEGA

DEGA

DEGA

DEGA

DEGA

DEGA

DEGA

DEGA

DEGA

DEGA

DEGA

DEGA

DEGA

DEGA

DEGA

1 - JM4*JM3*THCER*A (JMZ) I/OEOM

DEGA

DEOM $=J M 2 * J M I$ JR2

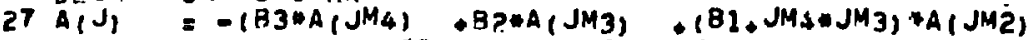

- JM3 JMZ TWORA*A (JMi) I/OEOM

DEGA

DEGA

DEGA

RETURN

DEGA

DEGA

DEGA

SUBROUTINE POLYOP( AP JMAX, D. PI

DEGA

OIMENSION A (1)

$M=$ JMAX

$P=A(M)$

$J U P=M-1$

IF (JUP LT. I) RETUAN

$001 \mathrm{~J}=1$, JUP

$M=M_{0}-1$

$I P=P O D+A(M)$

RETURN

DEGA

DEGA

DEGA

DEGA

DEGA

DEGA

DEGA

DEGA

01614

01615

01616

01617

01618

01619

01620

01621

01622

01623

01624

01625

01626

01627

01628

01629

01630

01631

01632

01633

01634

01635

01636

01637

01638

01639

01640

01641

01642

01643

01644

01645

$0: 646$

01647

01648

01649

01650

01651

01652

01653

01654

01655

09656

01657

01658

01659

01660

01661

01662

01663

01664

01665

01666

01667

01688

01669

01670

01671

01672

01673

01674

01675

PRIN! 7. ISSMAX

UEGA

00003 


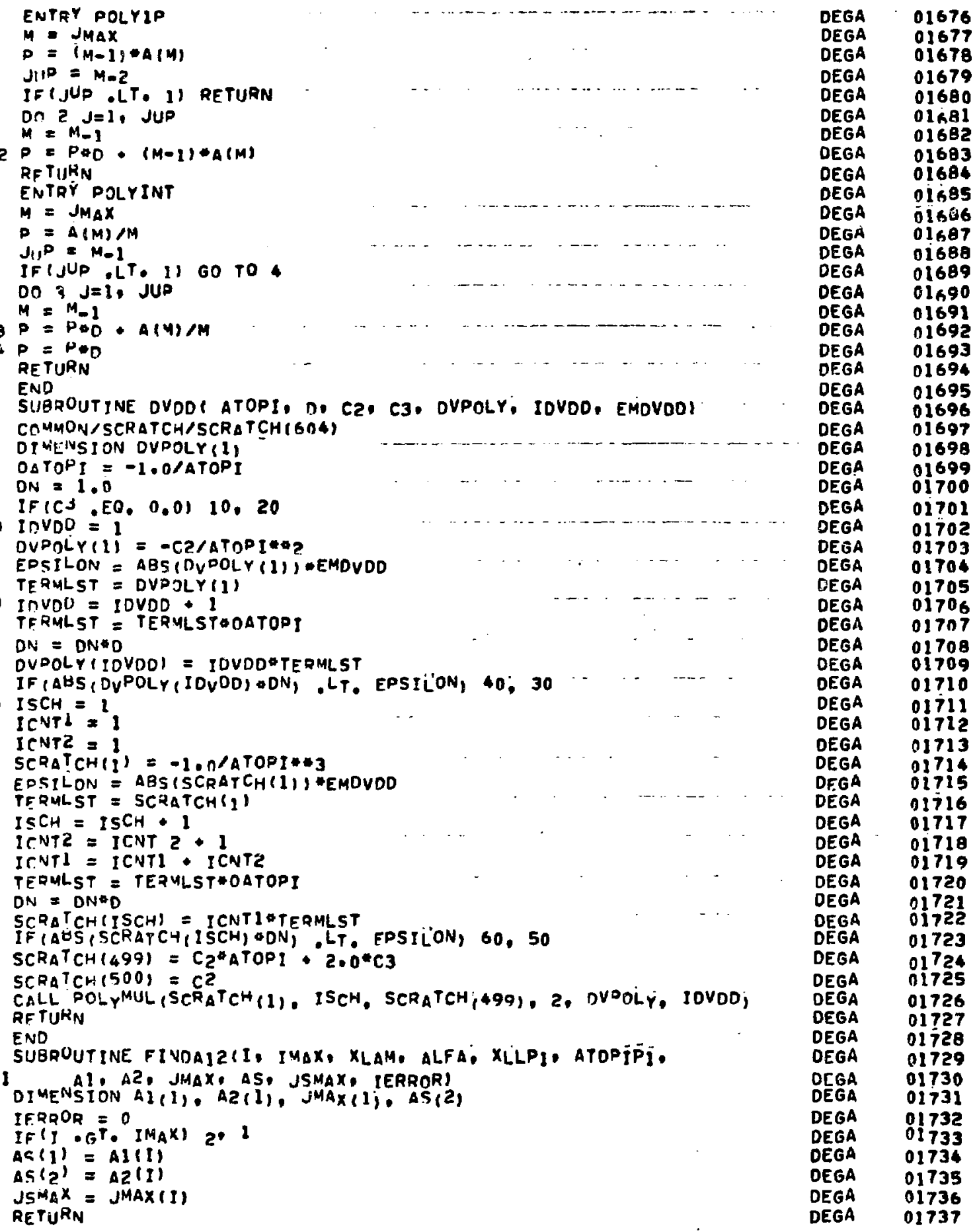


CALL CARSONIXLAM, -1.0. 1. ATOPIPI: XLLPI.
CADF. CAOFP, THETA, THETAP. IERRORI

1 ALAST $=$ ATOPPI IIMT RE TUAN

2 IF $(X L A M B, G T \cdot 0.0)$ \&. 3

DEGA

DEGA

DEGA

DEGA

DEGA

DEGA

DEGA

DEGA

DEGA

OEGA

DEGA

DEGA

DEGA

DEGA

DEGA RETURN

- OR = -2"ALAST

$R 1=1.05 \% A L A S T$

CALL ORMAXSBiORMAX, ALAST, R1, XLAMB, XLLP̈I, 1 ;

DEGA

DEGA

DEGA

IF (DR .GT. DRYAX) DR = DRMAX

DEGA

ALAST = ALAST - DR

RETUAN

DEGA

DEGA

END 


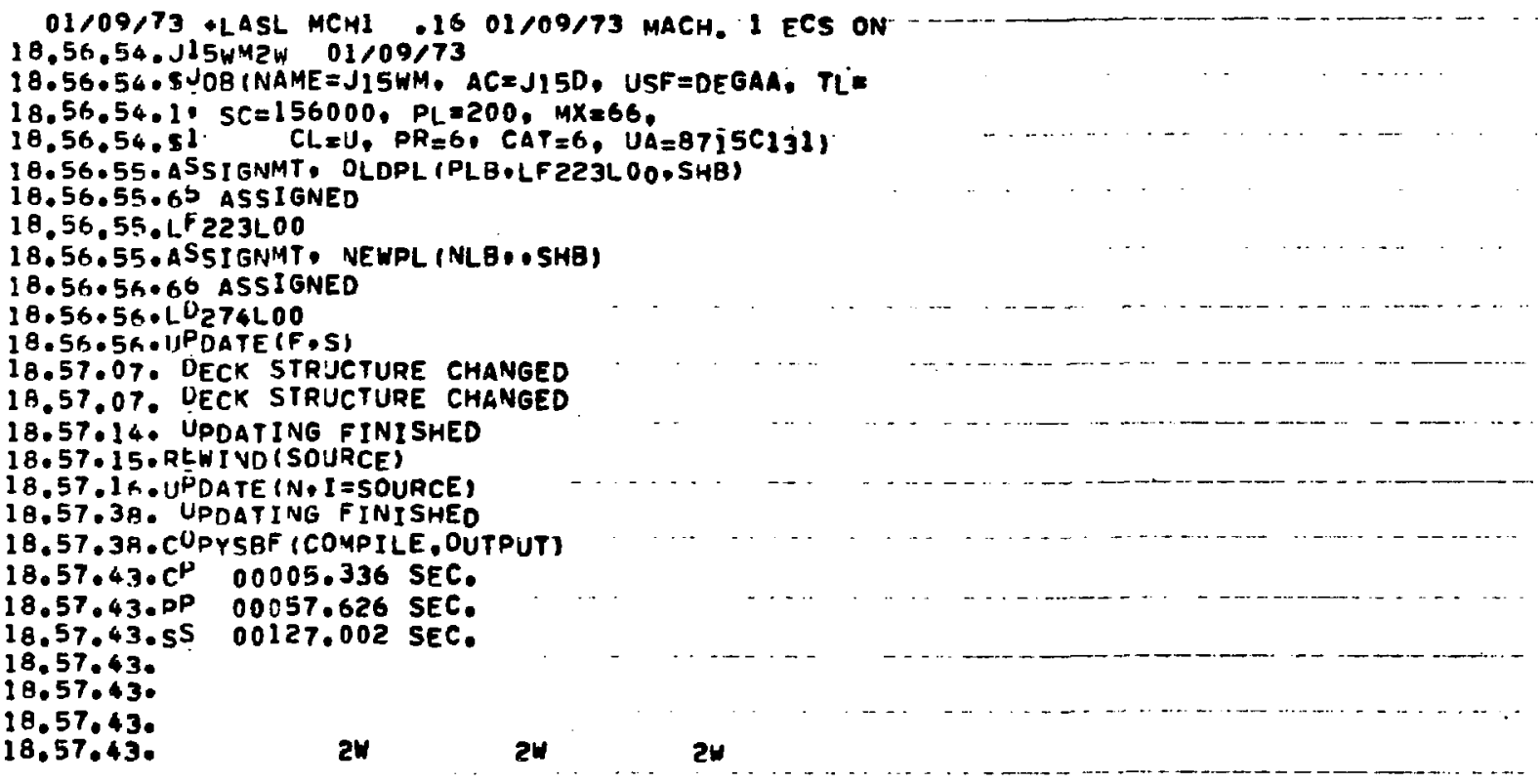

